\title{
1 Criteria and Tools for Determining Drainage Divide Stability
}

3 Adam M. Forte ${ }^{1 *}$ \& Kelin X. Whipple ${ }^{2}$

4

$5 \quad{ }^{1}$ Department of Geology and Geophysics, Louisiana State University, Baton Rouge, LA

$6{ }^{2}$ School of Earth and Space Exploration, Arizona State University, Tempe AZ 7

*Corresponding author email: aforte8@Isu.edu

\section{Abstract}

12 Watersheds are the fundamental organizing units in landscapes and thus the controls on 13 drainage divide location and mobility are an essential facet of landscape evolution. Additionally, 14 many common topographic analyses fundamentally assume that river network topology and 15 divide locations are largely static, allowing channel profile form to be interpreted in terms of 16 spatio-temporal patterns of rock uplift rate relative to base level, climate, or rock properties.

17 Recently however, it has been suggested that drainage divides are more mobile than previously

18 thought and that divide mobility, and resulting changes in drainage area, could potentially 19 confound interpretations of river profiles. Ultimately, reliable metrics are needed to diagnose 20 the mobility of divides as part of routine landscape analyses. One such recently proposed 21 metric is cross-divide contrasts in $\chi$, a proxy for steady-state channel elevation, but cross-divide 22 contrasts in a number of topographic metrics show promise. Here we use a series of landscape 23 evolution simulations in which we induce divide mobility under different conditions to test the 24 utility of a suite of topographic metrics of divide mobility and for comparison with natural 25 examples in the eastern Greater Caucasus Mountains, the Kars Volcanic Plateau, and the 26 western San Bernadino Mountains. Specifically, we test cross-divide contrasts in mean gradient, 27 mean local relief, channel bed elevation, and $\chi$ all measured at, or averaged upstream of, a 28 reference drainage area. Our results highlight that cross-divide contrasts in $\chi$ only faithfully 29 reflect current divide mobility when uplift, rock erodibility, climate, and catchment outlet 
elevation are uniform across both river networks on either side of the divide, otherwise a $\chi$ anomaly only indicates a possible future divide instability. The other metrics appear to be more

32 reliable representations of current divide motion, but in natural landscapes, only cross-divide contrasts in mean gradient and local relief appear to consistently provide useful information. Multiple divide metrics should be considered simultaneously and across-divide values of all metrics examined quantitatively as visual assessment is not sufficiently reliable in many cases. We provide a series of Matlab tools built using TopoToolbox to facilitate routine analysis.

\section{Introduction}

Drainage divides are fundamental organizing boundaries within landscapes. The extent to which the topologic form of divides, and thus river networks as a whole, are largely static

41 (e.g., Bishop, 1995; Oberlander, 1985) or are dynamic features, changing rapidly through

42 progressive divide migration and/or discrete capture events has recently become a topic of

43 considerable interest and some debate (e.g. Whipple et al., 2017c; Willett et al., 2014).

44 Assessing whether a drainage divide is potentially mobile is important, not only for quantifying

45 how landscape evolution is affected by the resulting changes in drainage area, but also because 46 many of the topographic metrics we use to interpret climatic or tectonic change (e.g., Wobus et 47 al., 2006) assume that drainage area has not changed significantly over the response timescale 48 of a catchment (e.g., Howard, 1988; Kooi and Beaumont, 1996; Whipple, 2001). Violation of this 49 static drainage area assumption at best complicates the interpretation of topographic metrics 50 and at worst invalidates the inferences drawn from them (e.g. Whipple et al., 2017a, 2017b;

51 Willett, 2017; Yang et al., 2015). While recent work suggests that under normal circumstances

52 the rate of divide motion is slow compared to the rate of channel adjustment to drainage area 53 change (Whipple et al., 2017c), the potential importance of drainage divide mobility suggests

54 that assessments of divide stability should be a routine part of topographic analyses.

$55 \quad$ Metrics of the relative stability of drainage divides are not new, indeed Gilbert (1877)

56 first proposed a means of assessing divide stability with his 'law of unequal declivities', positing 57 that if a divide was asymmetrical, this would imply different erosion rates on either side of the 58 divide. The resulting across-divide erosion rate contrast would force the divide to move toward 
59 the side with lower slopes and erosion rates (Figure 1A). Recently, Willett et al (2014) proposed 60 a new method of assessing divide stability through the use of $\chi$-maps. $\chi$, discussed in more 61 detail in the following section, can be used as a proxy for steady-state channel elevation and 62 thus this quantity should be nearly equal on either side of a stable divide. Maps of drainage 63 networks colored by $\chi$ can reveal $\chi$-anomalies across divides, where the $\chi$ value at channel 64 heads are higher on one side of a divide, suggesting that this divide is unstable and should 65 move from lower to higher $\chi$. Barring complicating factors, divide migration would continue 66 until the topology of the drainage network and drainage area distribution has changed such 67 that the $\chi$-anomaly is removed. In a limited number of locations, $\chi$-anomalies appear 68 coincident with an across-divide difference in average erosion rate, the underlying driver of divide motion (e.g., Beeson et al., 2017; Willett et al., 2014). $\chi$-maps are appealing as they are 1) relatively easy to calculate and 2) allow for a quick

71 visual assessment of the stability of divides across a large area. There are, however, some

72 challenges with their use and interpretation. Most significantly, the interpretation of $\chi$ 73 anomalies typically assumes uniform uplift, rock erodibility, and climate (Willett et al., 2014) 74 and thus in situations where any of those parameters vary, as is often the case in natural 75 systems, $\chi$-anomalies can occur even when divides are stable (e.g. Whipple et al., 2017c). This 76 led Whipple et al. (2017c) to propose a suite of alternative metrics of divide stability, largely an 77 expansion of the ideas originally put forward by Gilbert (1877), including cross divide differences in channel elevation at a reference drainage area, mean headwater hillslope 79 gradient, and mean headwater local relief. Whipple et al. (2017c) showed that for a simple synthetic landscape experiencing a non-uniform uplift rate, these alternative metrics were

81 more consistent indicators of the current rate and direction of divide motion than across-divide

82 differences in $\chi$. Here we expand upon that work by 1) developing a set of user friendly Matlab 83 based tools to produce maps of these alternative metrics along with $\chi$-maps and to perform 84 detailed analysis of multiple divide stability criteria, 2) applying these tools to two synthetic 85 landscapes with non-uniform uplift and non-uniform lithology, 3) applying these metrics to 86 three natural examples, and 4) comparing and contrasting the relative utility of these four 87 different divide stability metrics. 


\subsection{Theory and Limitations of Metrics}

Active motion of a drainage divide implies across-divide differences in erosion rates,

93 thus many potential metrics of divide stability will essentially be topographic proxies for erosion

94 rate. This was the basis for Gilbert's (1877) law of unequal declivities, which assumed that

95 divides bounded by distinctly different gradients were unstable, with faster erosion on the

96 steeper side progressively moving the divide towards the side with a gentler slope (Figure 1A).

97 Since the time of Gilbert, empirical measures of erosion rate and comparison to various

98 topographic metrics have suggested monotonic relationships at the catchment scale between

99 erosion rates and normalized channel steepness (river slope normalized for drainage area) or

100 local topographic relief (e.g., Harel et al., 2016; Kirby and Whipple, 2012; Lague, 2014) and at

101 the hillslope scale between erosion rates and mean hillslope gradient, hillslope relief, and

102 hilltop curvature (e.g., Hurst et al., 2013; Roering et al., 2007, 1999). Ultimately, divide motion

103 is driven by differences in erosion rate at or in close proximity to the divide itself, so a metric

104 like normalized channel steepness, which is only measurable away from the divide, may not be

105 a viable proxy. Therefore, we choose to focus on gradient and relief. We do not consider

106 hillslope curvature as accurate measurement of this quantity requires high resolution

107 topographic data (e.g., Roering et al., 1999) and thus is not widely applicable to areas for which

108 such data does not exist. Because mean gradients reach threshold values in steep landscapes

109 and become insensitive to increases in erosion rate (e.g., Burbank et al., 1996), if gradients on

110 both side of a divide are above $~ 0.7$, then it is expected that the slope metric will no longer be

111 sensitive to divide mobility. We also consider a third proxy, across-divide differences in channel

112 elevation at a reference drainage area. Together we refer to these three metrics as the 'Gilbert

113 metrics'. In detail, all three Gilbert metrics are intimately related because for a given divide, if a

114 channel on one side has a steeper hillslope gradient, this generally implies both greater local

115 relief and lower elevation of the channel at a reference drainage area as a simple geometrical

116 consequence (Figure 1B). 
We compare the Gilbert metrics to differences in the quantity ' $\chi$ ' across a divide,

118 (Willett et al., 2014). The derivation of and underlying rationale for the calculation of $\chi$ is 119 discussed in detail in several recent publications (e.g., Harkins et al., 2007; Mudd et al., 2014;

120 Perron and Royden, 2013; Royden and Perron, 2013) so we provide only a brief treatment here.

121 In practice, $\chi$ is an integral quantity evaluated along a channel from the outlet $\left(x_{b}\right)$ to the

122 position of interest $(x)$ with

123

$$
\chi=\int_{x_{b}}^{x}\left(\frac{A_{0}}{A\left(x^{\prime}\right)}\right)^{\theta_{\text {ref }}} d x^{\prime}
$$

125

126 where $A$ is upstream drainage area, $A_{0}$ is a reference scaling area, $\theta_{\text {ref }}$ is a reference concavity

127 (Wobus et al., 2006), and $x^{\prime}$ is a dummy variable. A plot of channel elevation vs $\chi$ for a stream 128 that is equilibrated to a spatially constant uplift rate and erosional efficiency should be a 129 straight line and under these circumstances $\chi$ can be considered a proxy for steady-state 130 channel elevation. If $A_{0}$ is set to unity then the slope of the chi-z plot will equal the normalized 131 channel steepness (Wobus et al., 2006) but is dimensionless. As described by Willett et al. 132 (2014), differences in $\chi$ at a reference drainage area across a drainage divide imply different 133 steady-state channel elevations if uplift, climate, and rock properties are spatially uniform. 134 Thus, the divide and drainage network topology are unstable if uplift, climate and rock 135 properties are indeed uniform or will become unstable if current spatial differences in these 136 properties are eliminated in future. This led to the proposition that maps of stream networks colored by $\chi$ and the identification of $\chi$-anomalies across drainage divides could provide proxies 138 for the stability of a drainage network.

In practice, interpretation of $\chi$-maps and $\chi$-anomalies has some challenges. When the 140 assumption of spatially uniform rate of uplift (or base level fall) and erosional efficiency (set 141 primarily by climate and rock properties) is violated, $\chi$-anomalies can develop and persist at 142 stable divides (e.g., Whipple et al., 2017c). In addition $\chi$-values are sensitive to the choice of $x_{b}$ 143 and thus the elevation of the catchment outlet defined for computation of $\chi$. Because $\chi$ is an 144 integrated quantity and calculated from the outlet to the headwaters of a stream network, a $\chi$ 145 anomaly can result because of the choice of different outlet elevations for streams on either 
146 side of the divide. Many potential problems with this can be avoided with careful analysis and

147 treatment of data (e.g., Willett et al., 2014), such as ensuring that stream networks are

148 complete and all drain to the desired outlet elevation, but in some instances the choice of the

149 'correct' outlet elevation is non-trivial. As an example, we consider the case of the Greater

150 Caucasus Mountains and two principle drainage divides within this range, one between rivers

151 draining to the Black Sea or Caspian Sea and one between rivers draining into the northern or

152 southern forelands of this range (Figure 2). We consider three options for selecting outlet

153 elevations and calculate $\chi$ using (1) true base level, which varies between $0 \mathrm{~m}$ for rivers draining

154 to the Black Sea and -27 m for rivers draining into the internally drained Caspian Sea, (2) a

155 constant elevation of $550 \mathrm{~m}$ that roughly approximates the range-front of the Greater Caucasus

156 in both the northern and southern forelands, or (3) a variable outlet elevation based on manual

157 mapping of the apparent bedrock-alluvial transition at the range-front (Figure 2). If we choose

158 to use true base level, this suggests the presence of a stark $\chi$-anomaly around all streams

159 draining into the Black Sea and through the southern foreland (Figure 2A). This $\chi$-anomaly

160 persists (but is more subtle) if we use the constant elevation of $550 \mathrm{~m}$, but the anomaly

161 disappears when using the bedrock-alluvial transition as the outlet elevation (Figure 2B \& C).

162 Similarly, in the eastern Greater Caucasus, $\chi$-anomalies suggest that the main divide between

163 northern and southern drainages is unstable, but is predicted to move either south using true

164 base-level (Figure 2A) or north using constant elevation or the bedrock-alluvial transition

165 (Figure 2B \& C). This highlights that care must be exercised when choosing outlet elevations for

$166 \chi$ analysis, but also that there may be non-unique answers depending on different, but still

167 reasonable, choices of outlet elevation.

168

169

2.2. Proposed Methodology for Use of Divide Metrics

170 While there are some potential problems with the use of $\chi$-maps, they are appealing as

171 a data exploration tool as they allow for quick assessment of the relative stability of a drainage

172 divide and associated drainage network. Here we develop similar maps using the three

173 "Gilbert" metrics described above. Mapping the elevation metric only requires coloring a

174 drainage network by channel elevation. The elevation metric is interpreted the same as $\chi$ in $\chi$ - 
175 maps: divides are expected to move from low to high values in the presence of an anomaly in 176 channel elevations (Figure 1C \& D).

177 For the local relief and gradient metrics, we are primarily concerned with average values 178 of these properties near the divide, so a simple strategy of coloring stream networks by 179 upstream running averages of either local relief or gradient is sufficient. These two metrics are 180 more direct proxies for erosion and as such, divides are expected to move from high to low 181 values (Figure 1C \& D). For all four metrics, we are only concerned with the values at the 182 channel heads, which are approximated by choosing a reference drainage area at which to 183 evaluate the values, which we refer to as 'stream endpoints', so for all metrics (including $\chi$ ) a 184 full map of values along streams are not necessary, but provide for useful visuals.

185 Visual comparisons of contrasts in colors across a divide are useful for identifying 186 potentially interesting patterns. However, the perception that a particular divide is unstable can 187 be influenced by visual bias or choices of color scales. To interrogate this further one must 188 assess the actual across-divide differences in the quantities of interest. Additionally, sometimes 189 a single drainage divide may be heterogeneous so it is useful to segment a divide and analyze 190 the stability of these sections individually. We visualize individual divide sections as histograms 191 of values at all of the stream endpoints on either side of a divide (Figure 1D). In practice, this is 192 useful to assess the degree of overlap or separation between values on either side of a divide. 193 Along with the histograms, we calculate a mean, standard error of the mean, 95\% bootstrap 194 confidence interval, and standard deviation for the population of values on either side of a 195 divide. In this study, we primarily use the conservative criteria that a divide is potentially stable 196 according to a given metric if the mean of one side of the divide is within one standard 197 deviation of the mean of the other side. These 'delta' values and their associated uncertainties 198 can then be standardized so that positive and negative delta values of the different metrics 199 indicate similar divide migration direction, providing an easy visual assessment of divide 200 stability for individual divide segments (Figure 1E). The specific stability criteria we use is 201 arbitrary, but it serves well to illustrate our main points. Ultimately determining the most 202 suitable criteria requires comparisons of these types of data with empirical observations of 
divide motion. More generally, we emphasize the importance of looking at the populations of values across a divide and choosing some consistent criteria for stability or instability.

\subsection{Tools for Evaluating Divide Stability}

To ease assessing divide stability, we developed a series of Matlab functions based upon TopoToolbox (Schwanghart and Scherler, 2014). These functions are designed to produce visually appealing and readily assessed maps of the metrics described in the previous section (Figure 1). Beyond facilitating rapid qualitative assessment, a primary goal was also to allow users to interrogate individual sections of divides more deeply as will be illustrated in the

213 (http://github.com/amforte/DivideTools) and all of the base plots and data for the subsequent

214 figures and maps were generated with these codes. In the supplement, we provide a brief 215 summary of the primary functions included in this repository and where appropriate, the 216 rationale behind the workings of these functions.

\section{Principles of Metric Interpretation from Simulations}

We present two landscape evolution models as simple examples of the expected

220 behavior of the different divide metrics and to form a basic set of rules for interpreting these 221 metrics in concert. These simulations are explicitly designed to explore cases that violate the 222 underlying assumptions of $\chi$-map analysis, specifically landscapes experiencing non-uniform 223 uplift rate and/or spatially/temporally variable erosional efficiency. Both models were run in

224 Fastscape (Braun and Willett, 2013) and were $10 \mathrm{~km}$ wide by $5 \mathrm{~km}$ long with a grid spacing of 25

225 meters. For both models, we track the average rate of divide motion at each time-step and 226 compare that to across-divide differences in erosion rate, which is driving the divide motion, 227 and the four proposed metrics, channel head elevation, mean upstream local relief, mean 228 upstream gradient, and $\chi$ (computed using equation 1 ).

\subsection{Asymmetric Uplift Simulation}


The first simulation matches the scenario previously presented in Whipple et al. (2017c).

232 In this simulation, we induce divide motion by first imposing an asymmetric uplift rate that

233 increases toward the top of the model on an initially steady-state landscape, thus driving the

234 divide towards the north (top) side of the model. This uplift-rate gradient is imposed for $20 \mathrm{Myr}$

235 after which we force the model to return to a spatially uniform uplift rate for another 20 Myr to

236 allow the divide to return to its original position at the center of the model. As expected,

237 across-divide differences in erosion rate are linearly correlated with divide migration rates

238 (Figure 3A). Across divide differences in all of the Gilbert metrics show similar linear

239 correlations with divide migration rate (Figure 3B-D). In contrast, during the asymmetric uplift

240 phase, $\chi$ is inversely correlated with divide migration rate, with the magnitude of the $\chi$ -

241 anomaly increasing as the divide approaches a stable position. Conversely, when the uniform

242 uplift phase begins, $\chi$-anomalies correctly track divide migration rate (Figure 3E). Visualizing

243 these across-divide differences as histograms of the values of the metrics at the reference

244 drainage area provides an assessment of the variability even in this simple synthetic landscape

245 and also highlights when the different metrics disagree (Figure 4).

\subsection{Dipping Hard Layer Simulation}

The second simulation has uniform uplift throughout the model run, but has a $500 \mathrm{~m}$ thick layer, dipping at $35^{\circ}$ to toward the top of the model that is more resistant to erosion than

250 the rest of the landscape. The model is first run for a sufficient time to develop a steady state 251 landscape with a single erosional efficiency. When the hard layer is first exposed, the divide

252 begins to move south (e.g. 3.5 Myr in Figure 5). Once the hard layer reaches the divide, the 253 divide begins to move north (e.g 6.0 \& 8.0 Myr in Figure 5), until the hard layer is completely 254 eroded at which time the divide again moves south toward the center of the model (e.g. 10.0 255 Myr in Figure 5). Like the asymmetric uplift model, divide migration rate is roughly linearly 256 correlated with across-divide differences in erosion rate and all three Gilbert metrics (Figure $2575 \mathrm{~A}-\mathrm{D}$ ), whereas $\chi$ has a more complicated relationship to divide migration rate (Figure 5E). Also, 258 like the asymmetric uplift model, this complicated relationship between across-divide 
differences in $\chi$ and divide migration rate results in times when $\chi$-anomalies incorrectly predict the current direction of divide motion (Figure 6).

\subsection{Proposed Usage of Metrics}

Both simulations indicate that the Gilbert metrics are well correlated to both the current rate and direction of divide migration rate, and by extension the magnitude and sign of acrossdivide differences in erosion rates. However, it is important to note that the relationship between values of across-divide differences in any of these metrics and either the exact divide migration rate or across divide difference in erosion rate will depend on various factors including erosional efficiency, uplift rates, and the form of the erosion law (e.g. Whipple et al., 2017c). Thus, outside of application to models, the magnitudes of across divide differences in any of these metrics can only be reliably interpreted in terms of the direction of divide motion.

271 With respect to $\chi$, the model results highlight the expected outcome that $\chi$ only correctly

272 predicts the current direction of divide motion when the uniform condition assumptions

273 inherent in the interpretation of $\chi$-maps are met. What the models also highlight is that $\chi$ -

274 anomalies, and the divide motion implied by them, that exist or develop during non-uniform

275 portions of the model runs indicate the predicted motion of the divide when and if the

276 landscape returns to uniform conditions in the future. For example, at 2.0 Myr in the

277 asymmetric uplift model, when the divide is moving north because of the gradient in uplift rate,

278 the $\chi$-anomaly that progressively develops indicates that the divide will eventually move south

279 when (or if) that uplift gradient is relaxed (Figure $3 \& 4$ ).

Generally, the results of these two simulations suggests that using $\chi$-maps in concert with one (or all) of the Gilbert metrics is ideal and further that if $\chi$-maps are used exclusively,

282 the current stability of a drainage divide may be interpreted incorrectly. If the different metrics 283 agree, this should indicate both the direction of current divide motion and that the uniformity 284 assumption within $\chi$ is met, or alternatively that the differences in uplift rate and erosional 285 efficiency in the landscape either are small or counterbalance each other. If $\chi$ disagrees with 286 the other metrics, this likely suggests that the Gilbert metrics are indicative of current divide 287 behavior and that $\chi$ is (1) indicating potential future divide behavior should differences in uplift 
rate and/or erosional efficiency be eliminated, and (2) may suggest there is sufficient variability in uplift rate and/or erosional efficiency to cause divergence in the metrics. With this as a rubric

290 for interpreting across divide differences in these metrics, we now apply them to three field 291 examples.

\section{Field Examples}

\subsection{Eastern Greater Caucasus Mountains}

The Greater Caucasus Mountains are the main loci of active shortening within the 297 central Arabia-Eurasia collision zone (e.g., Reilinger et al., 2006) and in the eastern Greater 298 Caucasus (west of $45^{\circ} \mathrm{E}$ ) are characterized by active thrust systems along both its northern and southern margins (Forte et al., 2014). This segment of the Greater Caucasus divide is notable as

300 its location is consistently offset southward, sometimes by up to $40 \mathrm{~km}$, with respect to the 301 highest peaks of the range. Based on spatial patterns in normalized channel steepness and 302 results of landscape evolution models, Forte et al., (2015) hypothesized that (1) the drainage 303 divide location predates development of the topographic crest of the range, (2) the divide 304 location is at least partially controlled by spatial gradients in uplift rate that reach a maximum 305 near the divide, and (3) eventually the divide should move north as channels are generally 306 steeper south of the divide.

For analysis purposes, we segment this drainage divide into 8 sections based on visual inspection of the four metrics and choose break points between portions of the divide that appear to display transitions in at least one of the criteria. Results for all metrics and associated river profiles for the eight divide segments are available in the supplement (Supplemental

311 Figures 1-16). In practice, while the elevation metric was useful in the model results (e.g. Figure 3124 \& 6), the results of the elevation metric are typically equivocal in natural settings we have 313 examined due to large standard deviations (Figure 7). The elevation metric, and indeed all of 314 the metrics, tend to indicate more divide mobility if the standard error of the mean is used to 315 estimate uncertainty. Unsurprisingly, the mean upstream slope and mean upstream relief metrics are very similar, though the similarity of these metrics will depend on the chosen relief 
317 radius (e.g., DiBiase et al., 2010). Thus, in comparing divide metrics along the length of the

318 divide for this and subsequent examples, we focus our discussion on $\chi$ and relief.

319 With the exception of two segments (GC7 \& GC8, Figure 7C), $\chi$ always predicts

320 northward movement of the divide (using the $550 \mathrm{~m}$ outlet elevation) whereas the relief metric

321 suggests the divide is stable within uncertainty (using the standard deviation) except for two

322 segments (GC3 and GC5, Figure 7C). The means of all metrics (except for GC7) agree in the

323 direction of divide motion and applying a less restrictive uncertainty (e.g. standard error) shows

324 more agreement between all metrics. As discussed earlier, the choice of outlet elevation for $\chi$

325 in the eastern Greater Caucasus (e.g. Figure 2) significantly influences predicted divide

326 behavior, with $\chi$ suggesting southward motion of the divide if 'true base level' is used for the

327 outlet elevation (Figure 7D). There are no quantitative estimates of erosion rates on either side

328 of the divide so we do not have a way to evaluate the 'right' answer in this setting, but

329 depending on the uncertainty criteria used, this result is consistent with previous suggestions

330 by Forte et al. (2015) that the divide is currently fixed but may eventually move northward

331 depending on future circumstances or may already be moving northward. There are isolated

332 south flowing drainages showing characteristic 'area-gain' signatures in $\chi$-normalized profiles

333 (Willett et al., 2014) indicating past divide motion to the north (Figure 8), though these

334 signatures are rare (Supplemental Figures 2, 4, 6, 8, 10, 12, 14, \& 16).

335 In terms of diagnosing contributions to divide stability, there are no significant

336 differences in either rock type (Forte et al., 2014) or mean annual precipitation (Forte et al.,

337 2016) directly across the divide, suggesting that a change in erosional efficiency is unlikely as a

338 driver. Thus, the simplest interpretation of these results is similar to that posited by Forte et al.

$339(2015,2014)$, that this indicates the presence of an uplift rate gradient that is 'holding' the

340 divide in place and that the $\chi$ metric is sensitive to this and indicating the expected reaction of

341 the divide if or when this uplift rate gradient dissipates.

\section{4.2. Kars Volcanic Plateau}

344 The Kars Volcanic Plateau is also part of the Arabia-Eurasia collision zone, but the

345 tectonics and local geology are decidedly different than that of the Greater Caucasus to the 
north. This portion of the collision zone has relatively low rates of active internal deformation

347 (Reilinger et al., 2006), which occur primarily on normal and strike slip faults with some

348 portions of the deformation related to local volcanic features (e.g., Dhont and Chorowicz, 2006;

349 Koçyiğit et al., 2001). The Kars Plateau is part of the broader East Anatolian Plateau which lacks

350 mantle lithosphere (Zor, 2008) after a slab detachment or delamination event at 7-8 Ma

351 (Keskin, 2003; Şengör et al., 2003). The average 2 km high, roughly dome shaped plateau (e.g.,

352 Şengör et al., 2003) Is thought to have been produced by this delamination event through

353 mantle upwelling (e.g., Göğüş and Pysklywec, 2008). The delamination is also thought to have

354 driven extensive melting and the eruption of a package of nearly horizontal volcanic rocks

355 ranging in composition from basalts to rhyolites with thicknesses of 100-1000 m that blanket

356 much of the plateau region (Keskin et al., 1998; Pearce et al., 1990, Figure 8B).

357 We selected two distinct drainage divides within the Kars Volcanic Plateau, both of

358 which lie near the edges of the volcanic deposits (Figure 9B). We segment the western drainage

359 divide into 4 sections based again on visual inspection of divide metrics, but also to separate

360 areas where there are major differences in the outlet locations on at least one side of the

361 divide. Streams west of the KV1 \& KV2 divides are part of the Choruh watershed and flow into

362 the Black Sea and streams east of the KV1 \& KV2 divides form the headwaters of the Kura river,

363 the main axial drainage within the Kura Basin and which flows eastward between the Greater

364 and Lesser Caucasus and eventually into the Caspian Sea. Streams east of KV3 are also part of

365 the Choruh watershed, but streams west of KV3 flow southeast into the Ararat Basin and are

366 tributaries of the Arax River that merges with the Kura River shortly before it empties into the

367 Caspian. KV4 divides two different tributaries of the Arax river and KV5, on the eastern edge of

368 the Kars Plateau, separates branches and tributaries of the Kura river (Figure 9).

$369 \quad$ For all the analyzed divides, the relief metric suggests they are stable using the standard

370 deviation criterion and close to stable using the standard error whereas $\chi$ consistently suggests

371 that divides should move toward the center of the Kars Plateau (Figure 9D). Using the model

372 results as a basis for interpretation suggests this is likely a case in which a contrast in either

373 erosional efficiency or rock uplift perturbs the $\chi$ metric (e.g., Figure 5 \& 6). Specifically, in all

374 cases, rivers within the plateau flow through significant portions of volcanic rocks, whereas 
375 rivers more external to the plateau flow through less of the young volcanic sequence (Figure

376 9B). This interpretation depends on the hypothesis that key volcanic units are more resistant to

377 erosion, which has not been quantified in this region, but is consistent with the form of the

378 topography (e.g. river profiles in Supplemental Figures $18,20,22,24, \& 26$ ). It is also possible

379 that differential uplift, specifically from dynamic topography, influences this pattern. For the

380 case of the western divide separating the Kars Plateau from the Choruh watershed (KV1, KV2, \&

$381 \mathrm{KV} 3$ ), Forte et al. (2016) suggested that the topography of this region was primarily controlled

382 by response to mantle upwelling (Zor, 2008) producing a gradient in uplift rate between the

383 outlet and headwaters of the Choruh watershed. Ultimately, because we do not have

384 quantitative estimates of divide mobility from catchment averaged or in-situ erosion rates, it is

385 difficult to (1) independently know the stability of these divides or (2) link the stability of these

386 divides to a particular cause, but it does suggest that environments such as this where the

387 Gilbert and $\chi$ metrics are in consistent disagreement represent important opportunities for

388 empirically testing these metrics.

\subsection{San Bernadino Mountains}

The San Bernadino Mountains are part of the Transverse Ranges in southern California

392 and are bounded to the south by several strands of the San Andreas Fault (e.g., Spotila et al.,

393 1998). The western portion of the range primarily consists of the Big Bear Plateau which is a

394 high-elevation, low-relief region interpreted as a relict landscape developed in deeply

395 weathered granite that is surrounded by steep escarpments on nearly every side (e.g., Blythe et

396 al., 2000; Spotila et al., 2002, 1998). Thermochronologic data indicate that the Big Bear Plateau

397 has been uplifted with respect to both the Mojave Desert to the north and Los Angeles Basin to

398 the south. Prior work suggests that the escarpments surrounding the Big Bear Plateau are

399 retreating inwards, gradually consuming the plateau (e.g., Binnie et al., 2008; Spotila et al.,

400 2002).

401 We investigate a portion of the drainage divide that roughly defines much of the Big

402 Bear Plateau and includes portions of both the southern and northern Big Bear escarpments as 403 defined by Binnie et al. (2008) and segment this divide into 10 sections (Figure 10). We use 
404 available cosmogenic erosion rates for this region (Binnie et al., 2008, 2007) and a relation

405 between mean local relief within a $2.5 \mathrm{~km}$ radius and these catchment averaged erosion rates

406 (Supplemental Figure 27) to produce a continuous map of erosion rate to compare to the 407 various divide metrics (Figure 10). This result is broadly consistent with a similar map produced

408 by Spotila et al (2002) based on low-temperature thermochronology and geologic constraints.

409 In this region, we use a constant outlet elevation of $1100 \mathrm{~m}$ to calculate $\chi$. We choose this

410 outlet elevation as this is approximately the effective base level to which drainages on the

411 northern side of the San Bernadino Mountains grade, though this means a portion of drainages

412 on the southern flank are excluded as the effective base level for these southern drainages is

413 significantly lower in elevation.

414 Across all 10 divide segments, $\chi$ and Gilbert metrics are both largely consistent with

415 each other and what is predicted from the erosion rate map (Figure 10D). If we accept the

416 erosion rate map as accurate and that contrasts in erosion rate across a divide from this map

417 are unequivocal evidence of current or future divide motion, then despite agreement overall,

418 there are examples of both $\chi$ and relief failing to correctly identify divide instability given

419 uncertainty in cross-divide differences (Figure 10D). In detail, SB2 and SB8 are cases where $\chi$

420 agrees with erosion rates (but not relief) and SB6 is a case where relief agrees with erosion

421 rates (but not $\chi$ ). There are possible interpretations of these deviations, but importantly, these

422 are all cases where (1) a relatively small number of values are used to determine potential

423 divide motion and (2) the determination of divide stability or mobility is dictated by how much

424 overlap or separation in means and standard deviations are required to deem a divide stable or

425 mobile, respectively. This highlights the utility of viewing divide metrics in forms like the

426 histograms used here for evaluating confidence in a given determination and also suggests that

427 there is likely a minimum segmentation length of divides below which the data is simply too

428 noisy to make a clear determination (Figure 10D). In this case all of the divide metrics are

429 broadly consistent with prior interpretations (e.g., Binnie et al., 2008; Spotila et al., 2002) of this

430 region suggesting that portions of the divide along the southern and northern Big Bear

431 escarpments are mobile and actively consuming the Big Bear Plateau (Figure 10). The only 
432 stable portion of the divide appears to be between internal plateau streams and streams 433 draining into Big Bear Lake (SB5 \& SB6, Figure 10).

$434 \quad$ Using the model results as a means to interpret the divide metrics would suggest that all 435 other divides are currently moving and that any spatial differences in erosional efficiency or

436 uplift rate are absent or sufficiently small such that $\chi$ is still a viable metric in this setting. This is 437 consistent with known constraints from this region, specifically uniform uplift, simple bedrock 438 geology, and unique relationships between erosion rate and mean channel steepness and 439 erosion rate and mean hillslope gradient (e.g., Binnie et al., 2007; DiBiase et al., 2010).

\section{Discussion and Conclusions}

The results of both the simulations and field examples highlight differences in the utility 443 of the considered metrics for assessing drainage network stability and further demonstrate that 444 relying on any one metric is limiting. The Gilbert metrics are the best choice to assess the 445 current status of the drainage network (i.e. are divides currently moving), whereas $\chi$-maps may 446 be the best choice to assess whether a drainage network may reorganize in the future, though

447 (1) the lack of a clear timescale that emerges from these measurements and (2) the reliance on 448 a future and uncertain change in uplift and/or erosional efficiency gradients complicates this 449 assessment. Among the Gilbert metrics, relief is likely the most reliable. Gradient also works 450 well in the natural examples, but there are challenges related to the development of threshold 451 slopes (e.g., Burbank et al., 1996) so care must be exercised when using mean gradients, and by 452 extension local relief with small radii which mirror gradients (e.g., DiBiase et al., 2010), 453 especially in high-relief landscapes. The elevation metric works well in model results, but in 454 most natural cases always suggests stable divides within uncertainty using the standard 455 deviation. We believe that there is value in considering all of the Gilbert metrics, but emphasize 456 the importance of interrogating the results of the divide stability analysis.

$457 \quad$ Ultimately, using the Gilbert and $\chi$ metrics in concert maximizes the information one 458 can extract from the landscape with regard to drainage network stability. The strengths of the 459 two classes of metric are not necessarily surprising. The top-down method of calculation for the 460 Gilbert metrics means that they are largely only sensitive to changes in the hillslopes directly 
461 near divides and thus represent a more 'instantaneous' view of the behavior of the divides. In

462 contrast, the bottom-up method of calculation of $\chi$-values at divides means that they are

463 sensitive to spatial variability in rock strength, climate, and tectonics throughout a catchment

464 and thus represent a more integrated, 'long-term' view of possible influences on divide

465 stability. These differences in scale also present different challenges in calculation. The Gilbert

466 metrics, at least the mean upstream gradient and to a lesser extent, mean upstream local relief,

467 have the potential to be sensitive to data resolution (e.g., Finlayson and Montgomery, 2003),

468 where as because $\chi$-values only require drainage area measurements, these should be

469 relatively insensitive to data resolution as long as flow routing algorithms are reasonably

470 accurate. In contrast, the divide-scale of the Gilbert metrics make them entirely insensitive to

471 any of the choice of outlet elevation issues that can potentially plague $\chi$-maps (e.g. Figure 2 ). It

472 is also worth noting that none of the metrics are useful for explicitly illuminating past divide

473 motion. All metrics in certain scenarios may be useful in this regard to the extent that current

474 divide motion implies some prior history of divide motion, but because none of these metrics

475 contain any time information, this assumption is hard to validate without independent

476 evidence of past divide motion.

477 In addition to considering multiple metrics, more detailed analyses of differences in

478 values across divides are necessary to fully assess divide stability. In many cases, visual

479 differences in maps of either $\chi$ or the Gilbert metrics seem to suggest a robust 'anomaly' across

480 a divide, but the histogram of values or the uncertainty on delta values actually show significant

481 amounts of overlap in values, e.g. divide GC2 which in map view seems to highlight an across

482 divide difference in local relief (Figure 7A), but in detail has relatively similar values in local

483 relief near channel heads (Figure 7D). A lingering issue is what constitutes suitable amounts of

484 overlap in values across a divide to suggest that said divide is stable or unstable. We do not

485 have any basis for suggesting that the criteria we primarily use (i.e. neither mean value is within

486 one standard deviation of the other for a stable divide) is correct. Comparing predictions using

487 the standard deviation and standard error highlights the importance of the stability criteria, as

488 for example in the Greater Caucasus examples, using the standard deviation with the Gilbert

489 metrics suggested mostly stable divides where as using the standard error suggests more 
490 mobile divides. Generally, because standard deviations are larger than bootstrap confidence 491 intervals which are in turn larger than standard errors, using standard deviations bias results 492 towards stable divides (more possibility of overlap) and standard errors bias results towards 493 mobile divides (less possibility of overlap) with bootstrap confidence intervals representing a 494 middle ground. Choosing any estimation of uncertainty is reasonable, but we emphasize that at 495 minimum workers should specify what criteria they are using to judge relative stability or 496 mobility.

497 The software tools provided along with this work allow for relatively easy analysis of 498 drainage divide stability and hopefully will aid the addition of this analysis to routine 499 characterization of landscapes. However, this should always be done in concert with traditional 500 landscape analyses. As described above, the presence of a $\chi$-anomaly along with absence of a 501 Gilbert-anomaly at a divide indicates a spatial gradient in uplift rate, erosional efficiency, or 502 both may exist in one or both sets of the catchments that define the divide, but it doesn't 503 provide any information as to the nature of these gradients or their location. For this, maps of 504 streams colored by normalized channel steepness or examining traditional longitudinal or $\chi$ 505 transformed river profiles would provide more information. Thus, we primarily view these types 506 of metrics as cursory data analysis tools to illuminate areas that necessitate deeper 507 investigation.

508 Finally, fully testing the accuracy of different metrics of divide stability fundamentally 509 requires comparing them to areas for which we have some constraints on erosion rates on 510 either side of divides and thus direct information on the degree of divide mobility. Special 511 attention should be paid to areas where the Gilbert and $\chi$ metrics disagree, as understanding 512 erosion rate contrasts (or the lack of contrasts) in these settings have the greatest potential to 513 provide more general information on the utility of these metrics in different situations and thus 514 contribute to determining the most reliable topographic expression of divide mobility.

\section{Acknowledgments}


518 The most up to date version of the tools described in this paper are available on github

519 (http://github.com/amforte/DivideTools). This work and development of these tools was

520 supported by EAR-1450970 awarded to AMF and KXW. The implementation of the method to

521 control outlet elevation and check of stream completeness was adapted from methods

522 suggested by Wolfgang Schwanghart via his blog (https://topotoolbox.wordpress.com/). We

523 thank Nicole Gasparini for helpful discussions regarding implementation of the tools.

\section{Figure Captions}

527 Figure 1 - A) Schematic of Gilbert's (1877) 'Law of Unequal Declivities', predicated on the idea 528 that divides will move when erosion rates are not equal on either side of the divide and that 529 this difference in erosion rate will likely be driven by differences in topographic gradient on 530 either side of the divide. B) Reference drainage area used in all metrics for calculating across 531 divide differences. C) Idealized form of maps of the four different divide metrics discussed in 532 the main text in the case that they are all consistent and all indicative of divide motion to the 533 left (Side 2). D) Corresponding plots of the distributions of values at minimum reference 534 drainage areas. All metrics are predicated on the idea that the stable condition is nearly equal 535 quantities on either side of the divide, however the prediction of motion direction based on 536 across divide differences is different for the different metrics. For $\chi$ and elevation metrics, the 537 divide should move towards the side with higher values, whereas for relief and gradient, the 538 divide should move towards the side with lower values. E) Comparison of delta values for all 539 four metrics with propagated uncertainties normalized such that positive and negative delta 540 values indicate the same direction of divide motion across all metrics. If any portion of the 541 mean or its uncertainty overlaps with the stable divide line, then we assume the divide is 542 stable. Bars are considering standard deviation as the uncertainty, shaded boxes the standard 543 error. Though not shown, bootstrap confidence intervals would be intermediate.

545 Figure 2 - Example from the Greater Caucasus Mountains of the complications of the sensitivity 546 of $\chi$ values to the choice of outlet elevation. Extent of maps are all the same, heavy black line is 
547 divide between rivers flowing to the Caspian (base level $-27 \mathrm{~m} \mathrm{ASL}$ ) and Black (base level 0m

548 ASL) Seas, thin black line is divide between rivers flowing north and south. Solid black arrows

549 indicate general flow direction for streams on either side of divides, hollow arrows indicate

550 interpreted direction of divide motion from $\chi$-anomalies. Maps show $\chi$ calculated as a

551 continuous grid with base level defined as A) true base level, i.e. calculated from river mouths

552 at either the Black or Caspian Seas, B) a constant elevation of 550m ASL, which approximates

553 the range-front for most of the Greater Caucasus, and C) an estimate of the bedrock-alluvial

554 transition based on manual clipping of the DEM. All three outlet elevations are equally valid,

555 but suggest markedly different stability for the main divides.

557 Figure 3 - Selected results from the asymmetric uplift model. Left side are plots of average

558 delta values of divide migration rate compared to A) erosion rate, B) channel head elevation, C)

559 local $250 \mathrm{~m}$ relief, D) gradient and E) $\chi$. Points are colored by the model time step with open

560 circles during the asymmetric uplift phase and filled circles during the uniform uplift phase.

561 Right side are maps of selected portions of the landscape during 5 key time frames and from

562 top to bottom, colored by A) erosion rate, B) channel elevation, C) upstream mean relief, D)

563 upstream mean gradient, and E) $\chi$. In top erosion rate panels, the rate and direction of divide

564 motion is displayed as a vector, with divide motion towards the top of the page defined as

565 positive.

566

567 Figure 4 - Divide metric histograms for three key timesteps during the asymmetric uplift model:

568 A) near peak divide migration rate during the tilt phase (2.0 Myr); B) stable divide near the end

569 of the tilt phase (19.8 Myr); and C) near peak divide migration rate during the return phase

570 (21.4 Myr).

571

572 Figure 5 - Selected results from the dipping hard layer model, plot setup is nearly identical to

573 Figure 3, except the top map panel is split between erosion rate on the left and rock strength

574 on the right. The erosional efficiency, $\mathrm{K}$, of the hard layer is 0.25 times the rest of the landscape. 
576 Figure 6 - Divide metric histograms for two key timesteps during the dipping hard layer model:

577 A) near peak divide migration rate before the hard layer reaches the divide (3.5 Myr) and B)

578 when the divide and the hard - soft contact are coincident (6.0 Myr).

Figure 7 - Divide stability analysis of the southeastern Greater Caucasus drainage divide. For 581 this analysis, we use a constant outlet elevation of $550 \mathrm{~m}$ for calculating $\chi$ (e.g. Figure 2B). A)

582 Stream network colored by mean upstream relief superimposed on a continuous $\chi$ grid draped

583 over a hillshade. White line is the divide, black squares mark boundaries between divide

584 segments and small inset shows nomenclature for the divide segments. Black box shows outline 585 of Figure 8A. B) Hillshade colored by elevation of the same area for context. C) Standardized 586 delta plot for the 8 segments along the divide. Bars are considering standard deviation as the 587 uncertainty, shaded boxes the standard error.

Figure 8 - Evidence of northward divide motion in the eastern Greater Caucasus. A)

590 Topography near the divide with a possible capture highlighted, see Figure 7 for location within

591 context. When identifying potential former captures from 'area-gain' signatures in $\chi$ -

592 normalized profiles, a viable former connection such as this is an essential observation given

593 the extremely short time-scale of preservation for such signatures within topography (Whipple

594 et al., 2017c). B) $\chi$-transformed profiles of the two drainages highlighted in 8A. Section of the

595 south flowing drainage shows characteristic 'area-gain' signature below a possible captured

596 reach. C) Longitudinal profile of the two drainages highlighted in 8A.

598 Figure 9- Kars volcanic plateau. For this analysis, we use a constant outlet elevation of 550m 599 for calculating $\chi$. A) Stream network colored by mean upstream relief on top of continuous $\chi$ 600 grid and hillshade. While lines indicate divides, black squares are boundaries between divide 601 segments. Inset in top left shows labels for the divide segments. B) Simplified geologic map 602 from Forte et al. (2016), area is same as in A, divides shown for reference. C) Hillshade colored 603 by elevation for the Kars area with labels of features discussed in the main text. D) Standardized 
604

605

606

607

608

609

610

611

612

613

614

615

616

617

618

619

620

621

622

623

624

625

626

627

628

629

630

631

632

delta plot for the 5 segments along the divide. Bars are considering standard deviation as the uncertainty, shaded boxes the standard error.

Figure 10 - Western San Bernadino Mountains. A) Streams colored by mean upstream relief on top of a continuous $\chi$ grid draped over a hillshade. White lines mark divides of interest, black squares show boundaries between divide segments. Inset in top left show names for divide segments. B) Interpolated erosion rate map based on cosmogenic erosion rate data from Binnie et al. $(2008,2007)$, see text and supplement for additional discussion. C) Hillshade colored by elevation of the western San Bernadino Mountains with labels for important features discussed in text. D) Standardized delta plot for the 10 segments along the divide. Bars are considering standard deviation as the uncertainty, shaded boxes the standard error.

\section{References}

Beeson, H.W., McCoy, S.W., Keen-Zebert, A., 2017. Geometric disequilibrium of river basins produces long-lived transient landscapes. Earth Planet. Sci. Lett. 475, 34-43. doi:10.1016/j.epsl.2017.07.010

Binnie, S.A., Phillips, W.M., Summerfield, M.A., Fifield, L.K., 2007. Tectonic uplift, theshold hillslopes, and denudation rates in a developing mountain range. Geology 35, 743-746. doi:10.1130/G23641A.1

Binnie, S.A., Phillips, W.M., Summerfield, M.A., Fifield, L.K., Spotila, J.A., 2008. Patterns of denudation through time in the San Bernardino Mountains, California : Implications for early-stage orogenesis. Earth Planet. Sci. Lett. 276, 62-72. doi:10.1016/j.epsl.2008.09.008

Bishop, P., 1995. Drainage rearrangement by river catpure, beheading and diversion. Prog. Phys. Geogr. 19, 449-473. doi:10.1177/030913339501900402

Blythe, A.E., Burbank, D., Farley, K.A., Fielding, E.J., 2000. Structural and topographic evolution of the central Transverse Ranges, California, from apatite fission-track, (U-Th/He) and digital elevation model analyses. Basin Res. 12, 97-114.

Braun, J., Willett, S.D., 2013. A very efficient O(n), implicit and parallel method to solve the 
stream power equation governing fluvial incision and landscape evolution. Geomorphology 180-181, 170-179. doi:10.1016/j.geomorph.2012.10.008

Burbank, D., Leland, J., Fielding, E., Anderson, R.S., Brozovic, N., Reid, M.R., Duncan, C., 1996. Bedrock incision, rock uplift and threshold hillslopes in the northwestern Himalaya. Nature $379,505-510$.

Dhont, D., Chorowicz, J., 2006. Review of the neotectonics of the Eastern Turkish-Armenian Plateau by geomorphic analysis of digital elevation model imagery. Int. J. Earth Sci. 95, 3449.

DiBiase, R.A., Whipple, K.X., Heimsath, A.M., Ouimet, W.B., 2010. Landscape form and millenial erosion rates in the San Gabriel Mountains, CA. Earth Planet. Sci. Lett. 289, 134-144.

Finlayson, D.P., Montgomery, D.R., 2003. Modeling large-scale fluvial erosion in geographic information systems. Geomorphology 53, 147-164. doi:10.1016/S0169-555X(02)00351-3

Forte, A.M., Cowgill, E., Whipple, K.X., 2014. Transition from a singly vergent to doubly vergent wedge in a young orogen: The Greater Caucasus. Tectonics 33, 2077-2101. doi:10.1002/2014TC003651

Forte, A.M., Whipple, K.X., Bookhagen, B., Rossi, M.W., 2016. Decoupling of modern shortening rates, climate, and topography in the Caucasus. Earth Planet. Sci. Lett. 449, 282-294. doi:10.1016/j.epsl.2016.06.013

Forte, A.M., Whipple, K.X., Cowgill, E., 2015. Drainage network reveals patterns and history of active deformation in the eastern Greater Caucasus. Geosphere 11. doi:10.1130/GES01121.1

Gilbert, G.K., 1877. Geology of the Henry Mountains, USGS Report. Government Printing Office, Washington, D.C.

Göğüş, O.H., Pysklywec, R.N., 2008. Mantle lithopshere delamination driving plateau uplift and synconvergent extension in eastern Anatolia. Geology 36, 723-726.

Harel, M.A., Mudd, S.M., Attal, M., 2016. Global analysis of the stream power law parameters based on worldwide 10Be denudation rates. Geomorphology 268, 184-196. doi:10.1016/j.geomorph.2016.05.035

Harkins, N., Kirby, E., Heimsath, A.M., Robinson, R., Reiser, U., 2007. Transient fluvial incision in 
the headwaters of the Yellow River, northeastern Tibet, China. J. Geophys. Res. 112, F03S04.

Howard, A.D., 1988. Equilibrium models in geomorphology, in: Anderson, M.G. (Ed.), Modelling Geomorphological Systems. John Wiley \& Sons, pp. 49-70.

Hurst, M.D., Mudd, S.M., Yoo, K., Attal, M., Walcott, R., 2013. Influence of lithology on hillslope morphology and response to tectonic forcing in the northern Sierra Nevada of California. J. Geophys. Res. 118, 832-851. doi:10.1002/jgrf.20049

Keskin, M., 2003. Magma generation by slab steepening and breakoff beneath a subductionaccretion complex: An alternative model for collision-related volcanism in Eastern Anatolia, Turkey. Geophys. Res. Lett. 30, doi:10.1029/2003GL018019.

Keskin, M., Pearce, J.A., Mitchell, J.G., 1998. Volcano-stratigraphy and geochemistry of collisionrelated volcanism on the Erzurum-Kars Plateau, northeastern Turkey. J. Volcanol. Geotherm. Res. 85, 355-404.

Kirby, E., Whipple, K.X., 2012. Expression of active tectonics in erosional landscapes. J. Struct. Geol. 44, 54-75.

Koçyiğit, A., Yılmaz, A., Adamia, S., Kuloshvili, S., 2001. Neotectonics of East Anatolia Plateau (Turkey) and Lesser Caucasus: implication for transition from thrusting to strike-slip faulting. Geodin. Acta 14, 177-195.

Kooi, H., Beaumont, C., 1996. Large-scale geomorphology: Classical concepts reconciled and integrated with contemporary ideas via a surface processes model. J. Geophys. Res. 101, 3361-3386.

Lague, D., 2014. The stream power river incision model: evidence, theory and beyond. Earth Surf. Process. Landforms 39, 38-61. doi:10.1002/esp.3462

Mudd, S.M., Attal, M., Mildowski, D.T., Grieve, S.W.D., Valters, D.A., 2014. A statistical framework to quantify spatial variation in channel gradients using the integral method of channel profile analysis. J. Geophys. Res. 119, 138-152. doi:10.1002/2013JF002981

Oberlander, T.M., 1985. Origin of drainage transverse to structures in orogens, in: Morisawa, M., Hacker, J.T. (Eds.), 15th Annual Binghamton Geomorphology Symposium. pp. 155-182. 
Moorbath, S., Mitchell, J.G., 1990. Genesis of collision volcanism in eastern Anatolia, Turkey. J. Volcanol. Geotherm. Res. 44, 189-229.

Perron, J.T., Royden, L.H., 2013. An intergral approach to bedrock river profile analysis. Earth Surf. Process. Landforms 38, 570-576. doi:10.1002/esp.3302

Reilinger, R., McClusky, S., Vernant, P., Lawrence, S., Ergintav, S., Cakmak, R., Ozener, H., Kadirov, F., Guliev, I., Stepanyan, R., Nadariya, M., Hahubia, G., Mahmoud, S., Sakr, K., ArRajehi, A., Paradissis, D., Al-Aydrus, A., Prilepin, M., Guseva, T., Evren, E., Dmitrotsa, A., Filikov, S. V, Gomez, F., Al-Ghazzi, R., Karam, G., 2006. GPS constraints on continental deformation in the Africa-Arabia-Eurasia continental collision zone and implications for the dynamics of plate interactions. J. Geophys. Res. 111, doi:10.1029/2005JB004051.

Roering, J.J., Kirchner, J.W., Dietrich, D., 1999. Evidence for nonlinear, diffusive sediment transport on hillslopes and implications for landscape morphology. Water Resour. Res. 35, 853-870.

Roering, J.J., Perron, J.T., Kirchner, J.W., 2007. Functional relatoniships between denudation and hillslope form and relief. Earth Planet. Sci. Lett. 264, 245-258.

Royden, L.H., Perron, J.T., 2013. Solutions of the stream power equation and application to the evolution of river longitudinal profiles. J. Geophys. Res. 118, 497-518. doi:10.1002/jgrf.20031

Schwanghart, W., Scherler, D., 2014. Short Communication: TopoToolbox 2 - MATLAB based software for topographic analysis and modeling in Earth surface sciences. Earth Surf. Dyn. 2, 1-7. doi:10.5194/esurf-2-1-2014

Şengör, A.M.C., Özeren, S., Genç, T., Zor, E., 2003. East Anatolian high plateau as a mantlesupported, north-south shortened domal structure. Geophys. Res. Lett. 30, doi:10.1029/2003GL017858.

Spotila, J.A., Farley, K.A., Sieh, K., 1998. Uplift and erosion of the San Bernardino Mountains associated with transpression along the San Andreas fault , California, as constrained by radiogenic helium thermochronometry. Tectonics $17,360-378$.

Spotila, J., House, M.A., Blythe, A.E., Niemi, N.A., Bank, G.C., 2002. Controls on the erosion and geomorphic evolution of the San Bernardino and San Gabriel Mountains, southern 
California. pp. 205-230.

721 Whipple, K.X., 2001. Fluvial landscape response time: How plausible is steady-state 722 denudation? Am. J. Sci. 301, 313-325.

723 Whipple, K.X., Dibiase, R.A., Ouimet, W.B., Forte, A.M., 2017a. Preservation or piracy:

724 Diagnosing low-relief, high-elevation surface formation mechanisms REPLY. Geology 45. 725 doi:10.1130/G39252Y.1

726 Whipple, K.X., DiBiase, R.A., Ouimet, W.B., Forte, A.M., 2017b. Preservation or piracy:

727 Diagnosing low-relief, high-elevation surface formation mechanisms. Geology 45, 91-94. 728 doi:10.1130/G38490.1

729 Whipple, K.X., Forte, A.M., DiBiase, R.A., Gasparini, N.M., Ouimet, W.B., 2017c. Timescales of 730 landscape response to divide migration and drainage capture: Implications for the role of 731 divide mobility in landscape evolution. J. Geophys. Res. Earth Surf.

732 doi:10.1002/2016JF003973

733 Willett, S., 2017. Preservation or piracy: Diagnosing low-relief, high-elevation surface formation 734 mechanism COMMENT. Geology 45. doi:10.1130/G3829C.1

735 Willett, S.D., McCoy, S.W., Perron, J.T., Goren, L., Chen, C.-Y., 2014. Dynamic reorganization of 736 river basins. Science (80-. ). 343, 1248765. doi:10.1126/science.1248765

737 Wobus, C.W., Whipple, K.X., Kirby, E., Snyder, N.P., Johnson, J., Spyropolou, K., Crosby, B.T., 738 Sheehan, D., 2006. Tectonics from topography: Procedures, promise, and pitfalls, in: 739 Willett, S.D., Hovius, N., Brandon, M.T., Fisher, D. (Eds.), Tectonics, Climate, and Landscape 740 Evolution. The Geological Society of America, Boulder, CO, pp. 55-74.

741 Yang, R., Willett, S.D., Goren, L., 2015. In situ low-relief landscape formation as a result of river 742 network disruption. Nature 520, 526-529.

743 Zor, E., 2008. Tomographic evidence of slab detachment beneath eastern Turkey and the 744 Caucasus. Geophys. J. Int. 175, 1273-1282. 

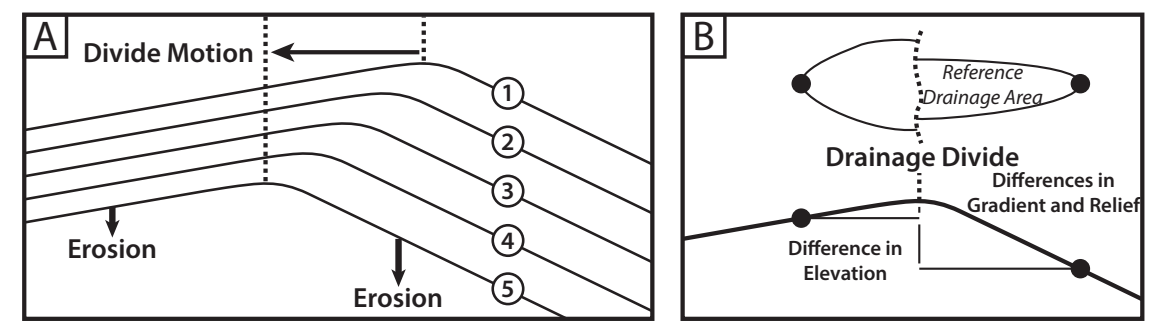

C Elevation or $\chi$
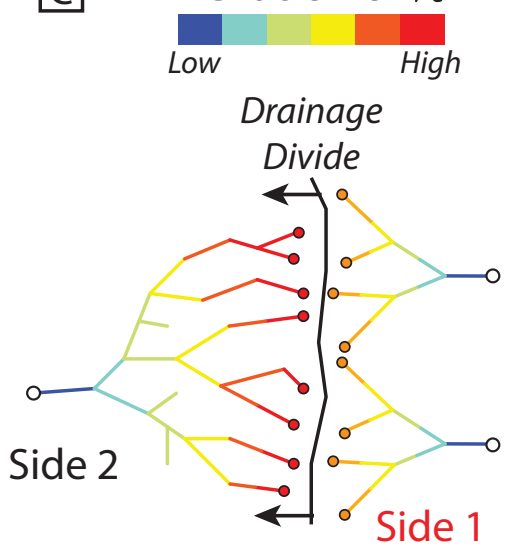

\section{Relief or Gradient}

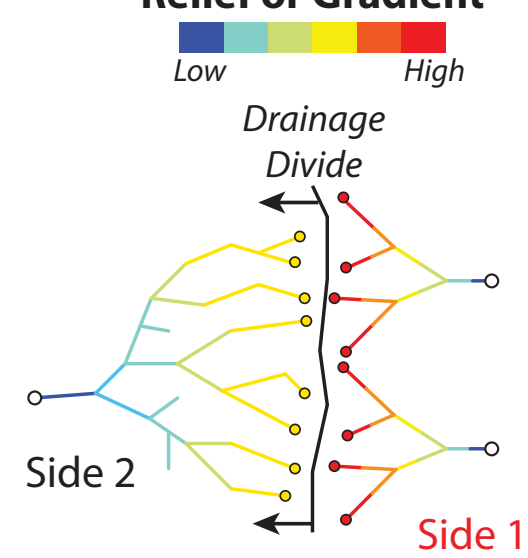

\section{Divide Moves Toward Side 2}

- Mean of Side 1 - Mean of Side 2
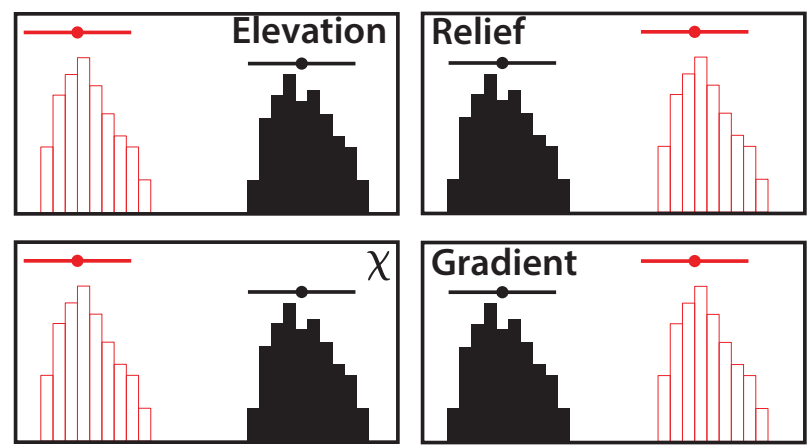

E

Divide Moves

Toward Side 2

Divide is Stable

TrT $\Delta$ Relief

Divide is Stable

कI임 $\Delta$ Elevation

Divide Moves

Toward Side 1 Divide 1

Value at Reference Area Value at Reference Area

Figure 1 


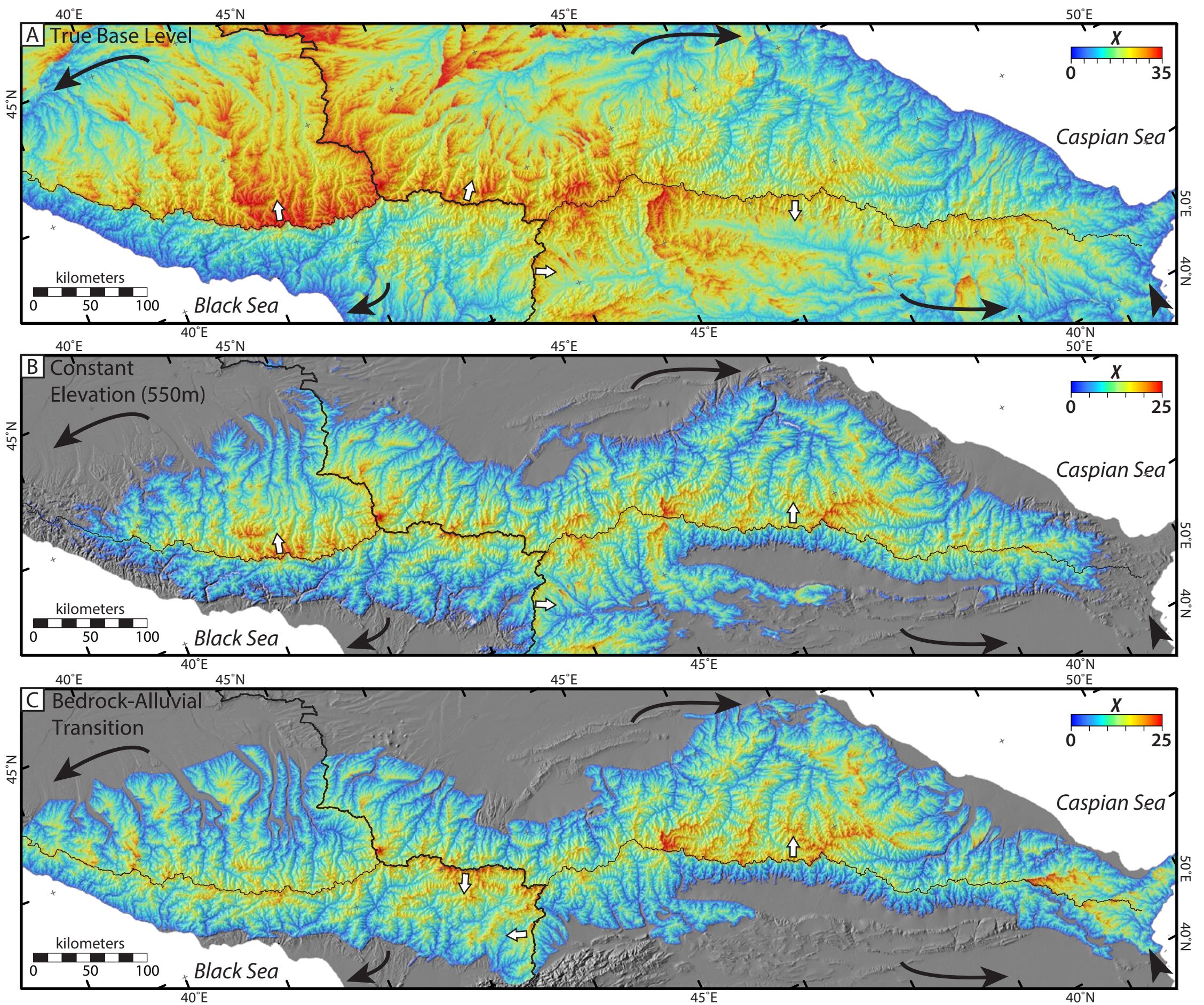

Figure 2 

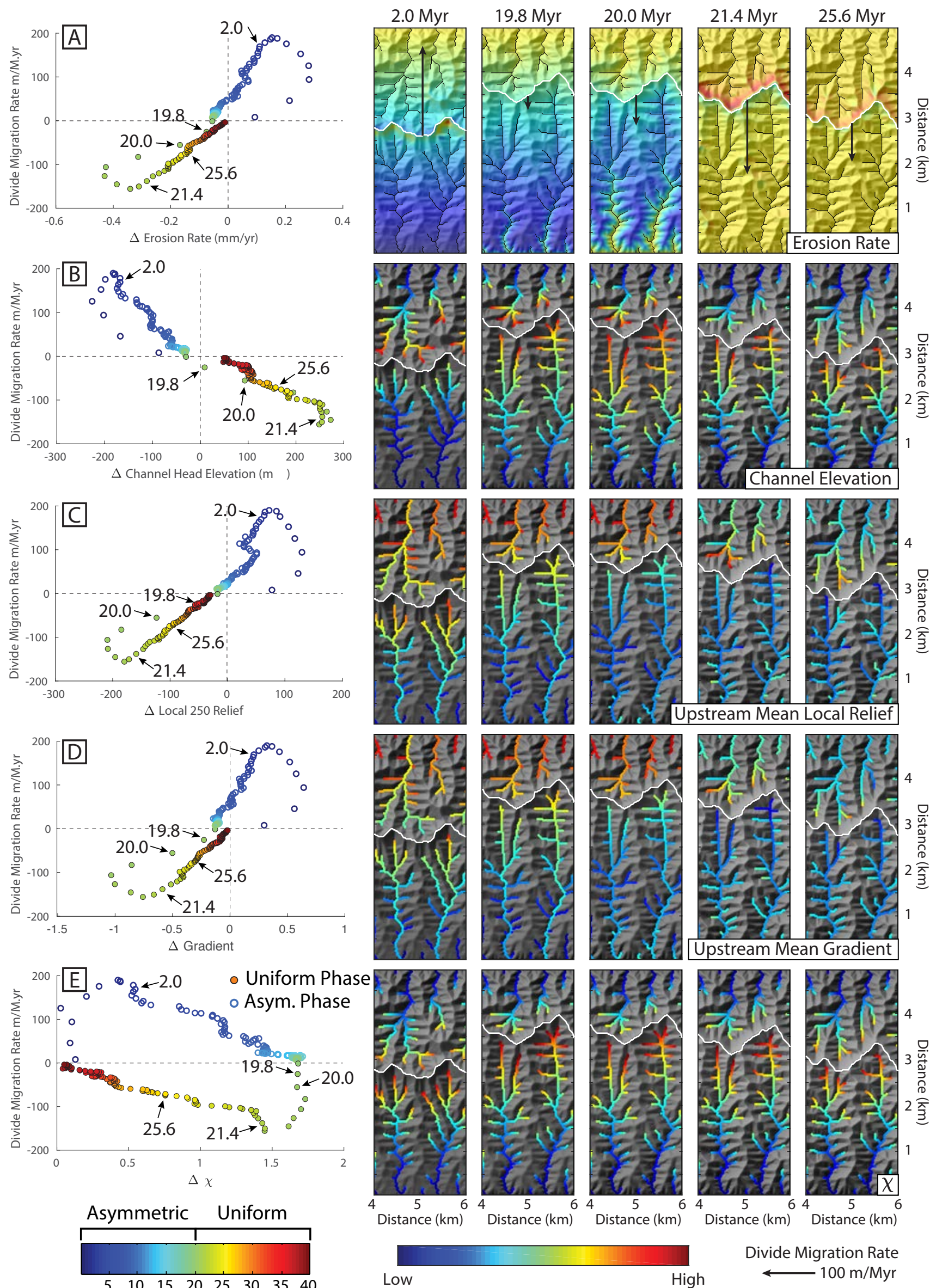

Distance $(\mathrm{km}) \quad$ Distance $(\mathrm{km})$
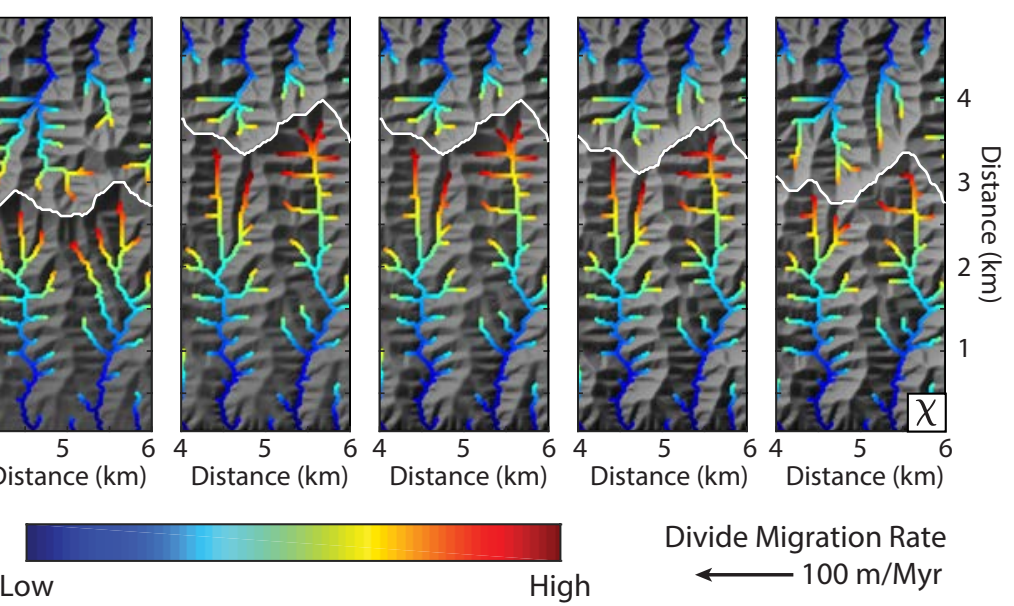

Divide Migration Rate Model Run Time (Myr)

Figure 3 
A Time $=2.0 \mathrm{Myr}$

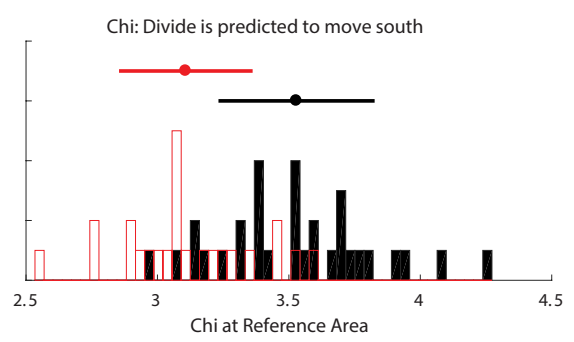

Elevation: Divide is predicted to move north

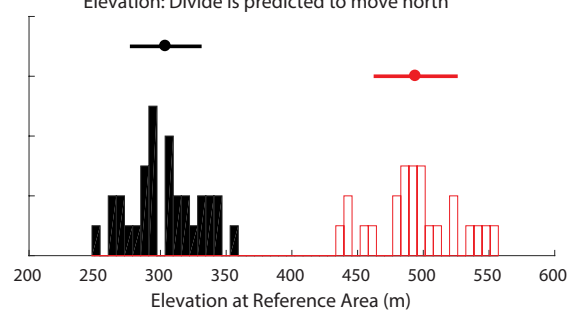

B Time $=19.8 \mathrm{Myr}$

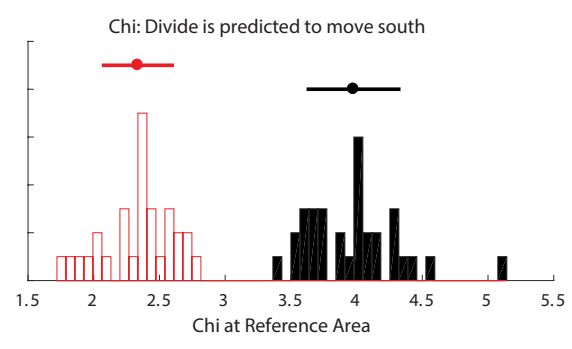

Elevation: Divide is stable

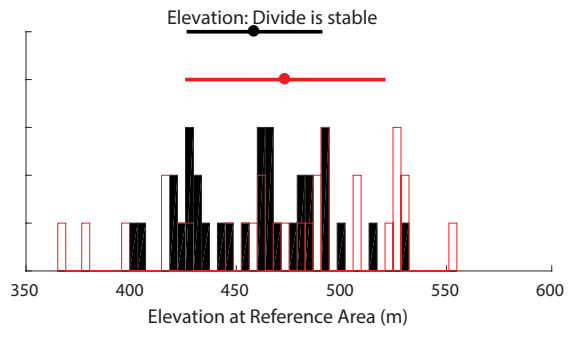

C Time $=21.4 \mathrm{Myr}$

Chi: Divide is predicted to move south

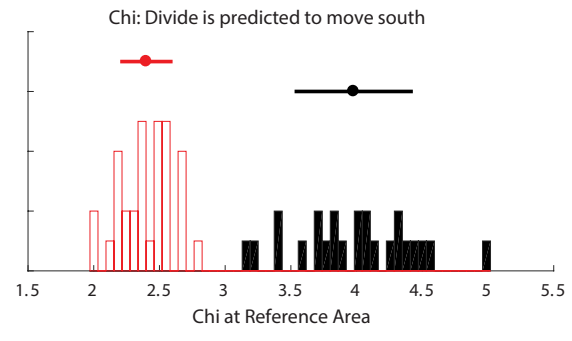

Elevation: Divide is predicted to move south

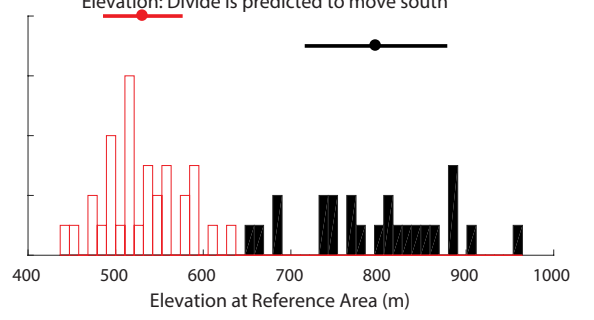

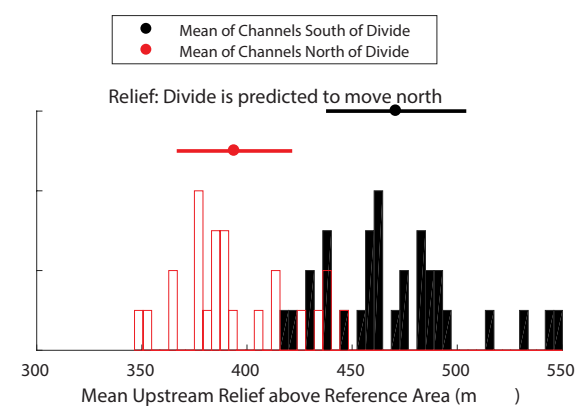

Gradient: Divide is predicted to move north

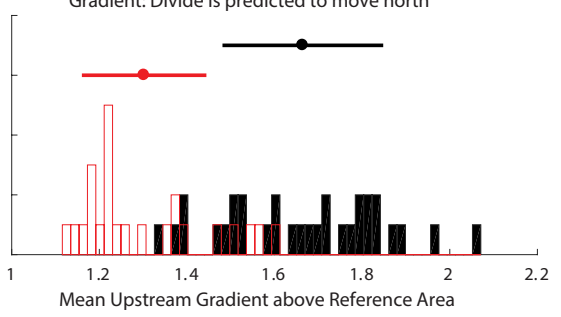

- Mean of Channels South of Divide

Mean of Channels North of Divide

Relief: Divide is stable

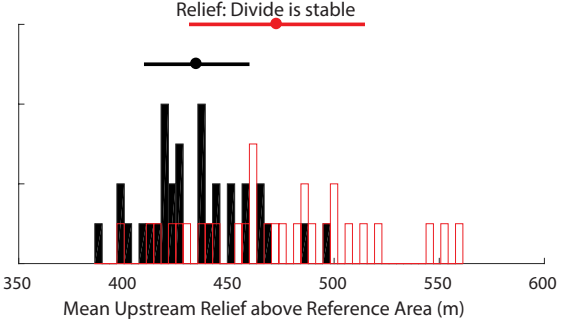

Gradient: Divide is predicted to move south

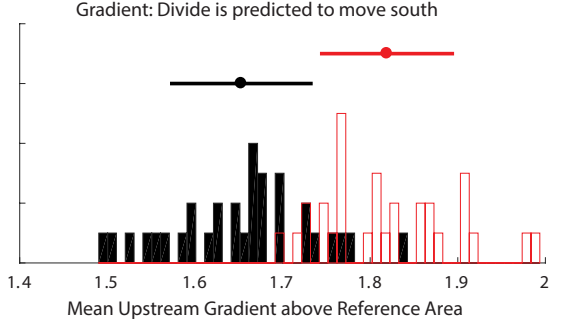

- Mean of Channels South of Divide

Relief: Divide is predicted to move south

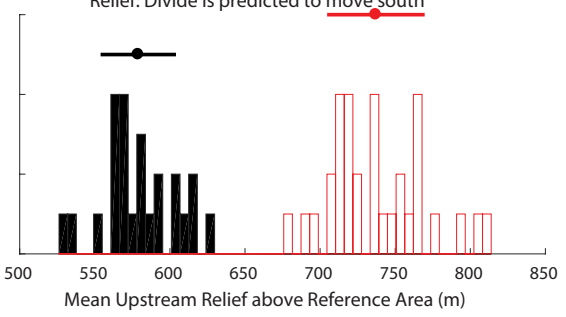

Gradient: Divide is predicted to move south

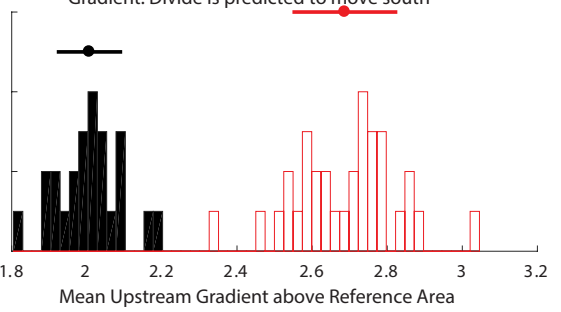

Figure 4 

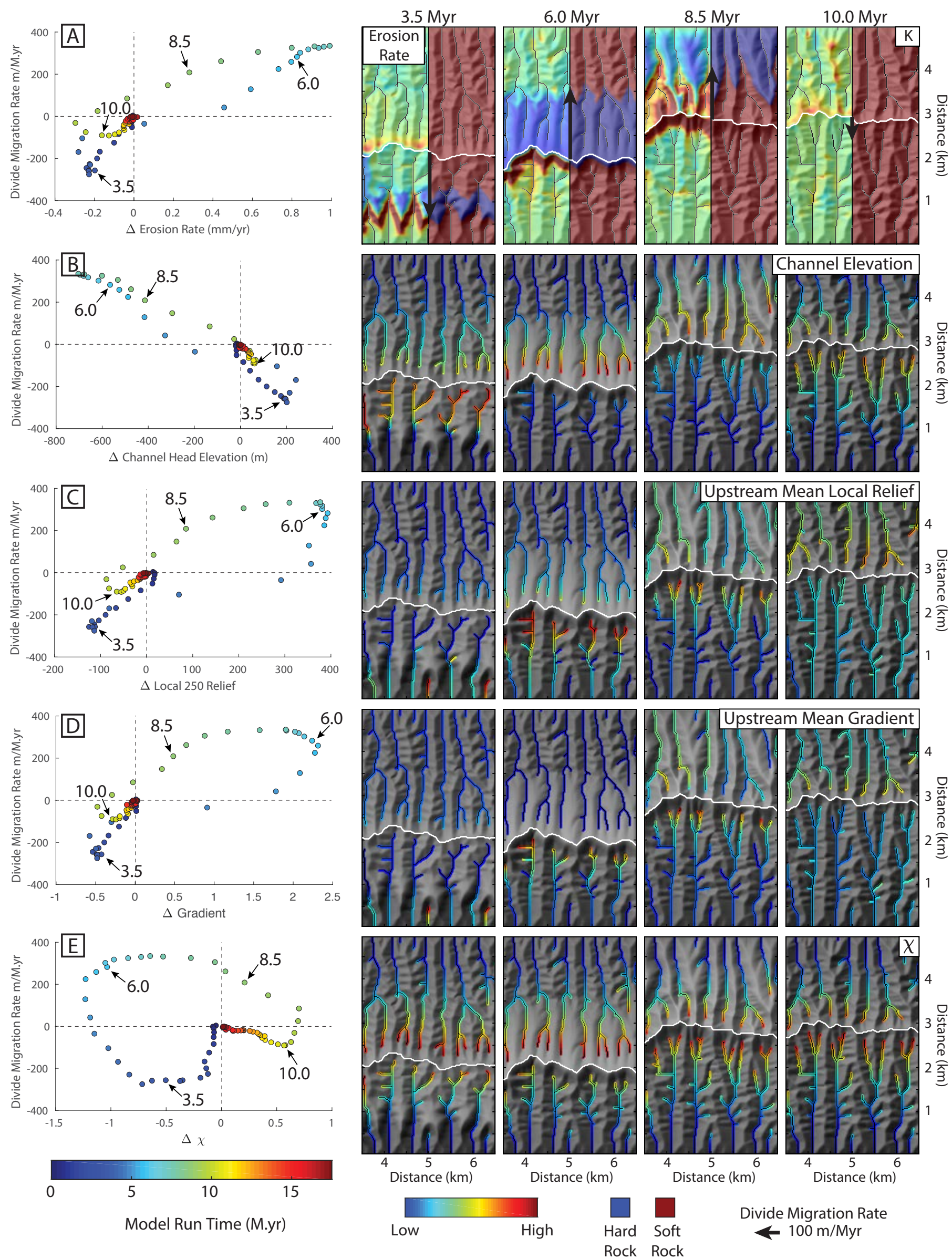

Figure 5 

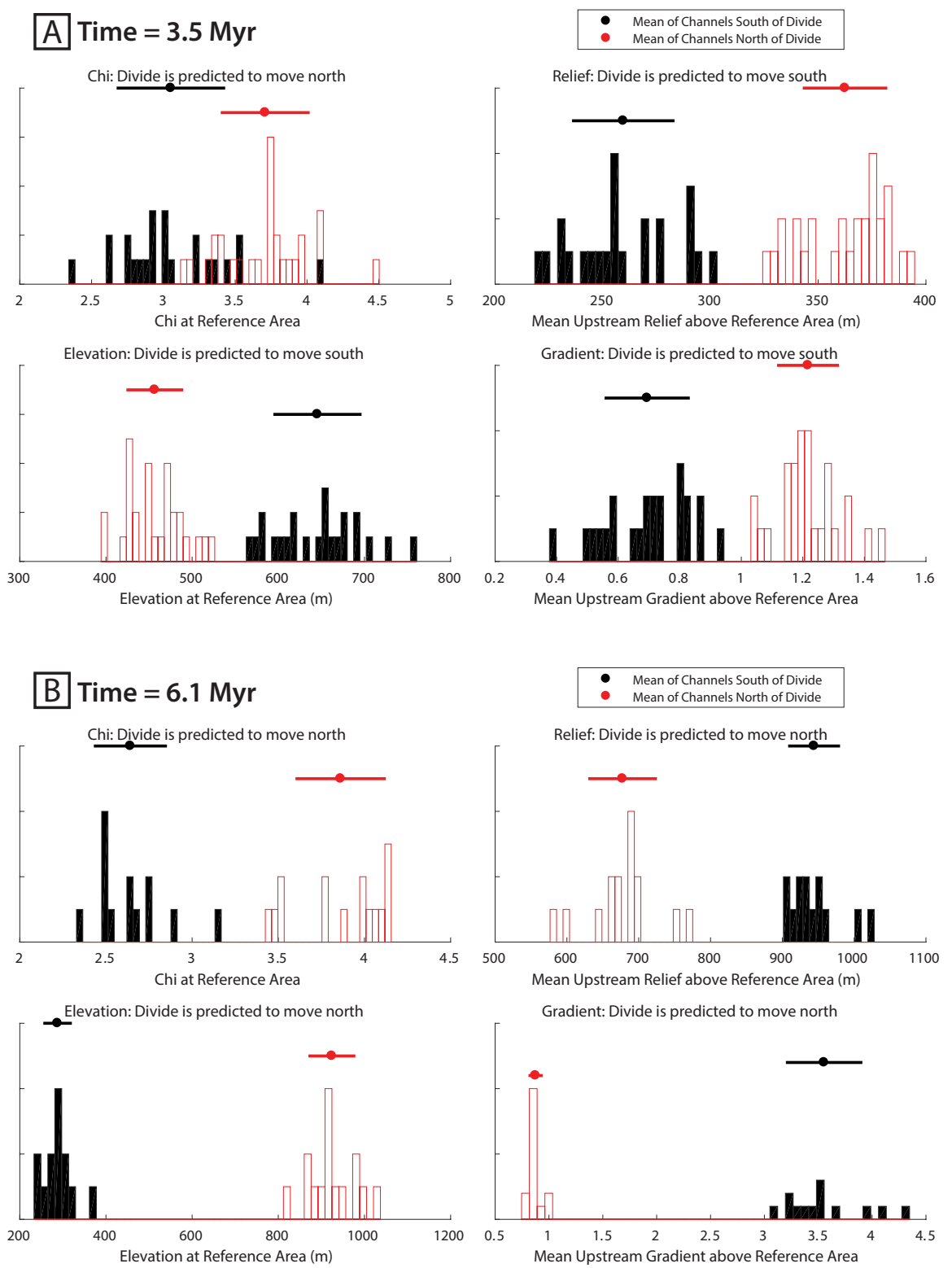

Figure 6 


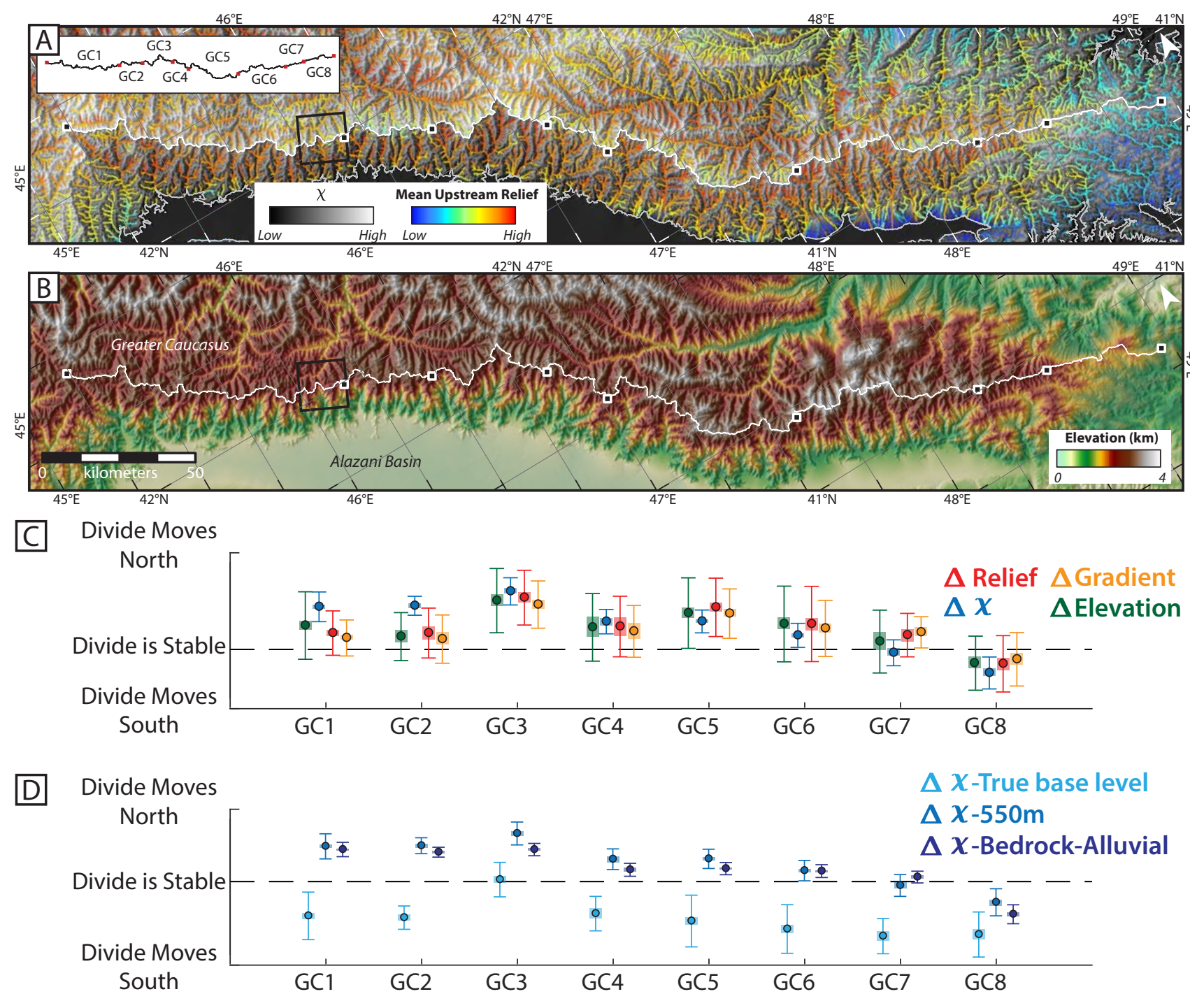

Figure 7 

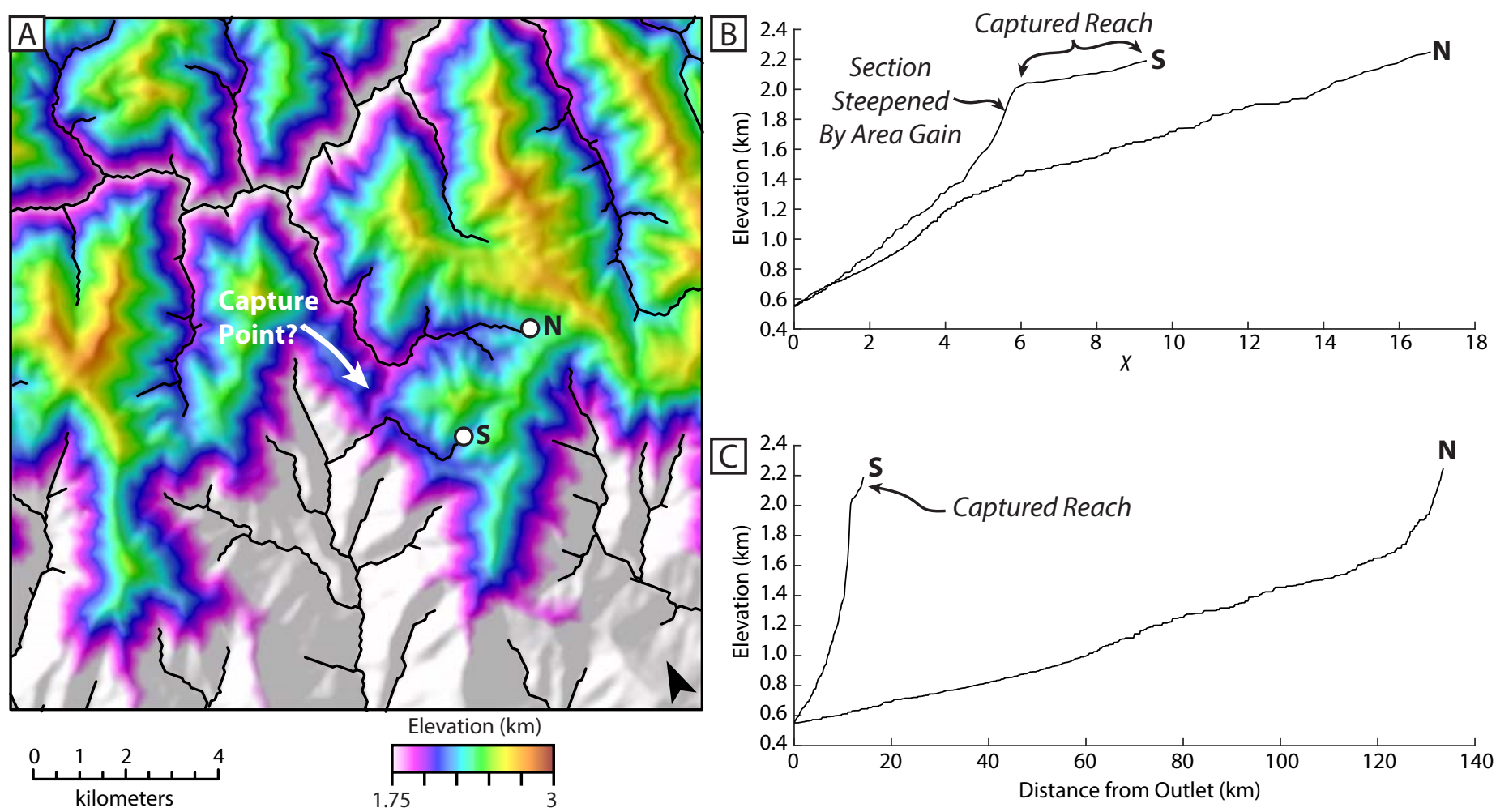

Figure 8

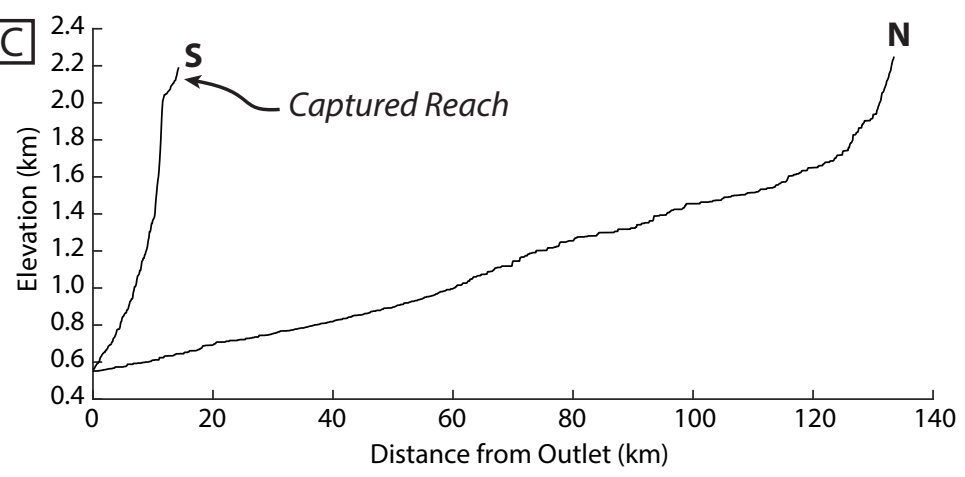




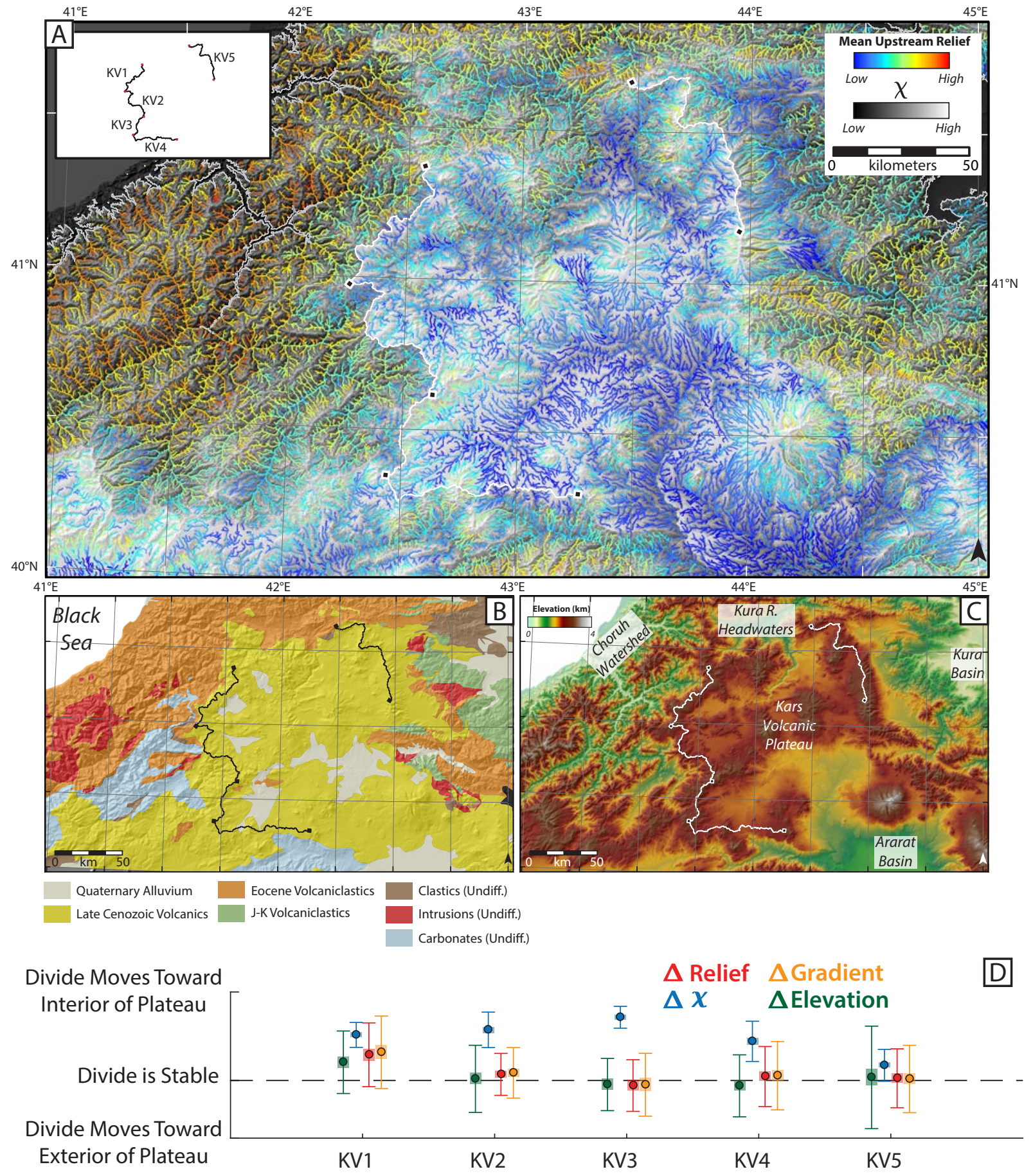

\section{Figure 9}




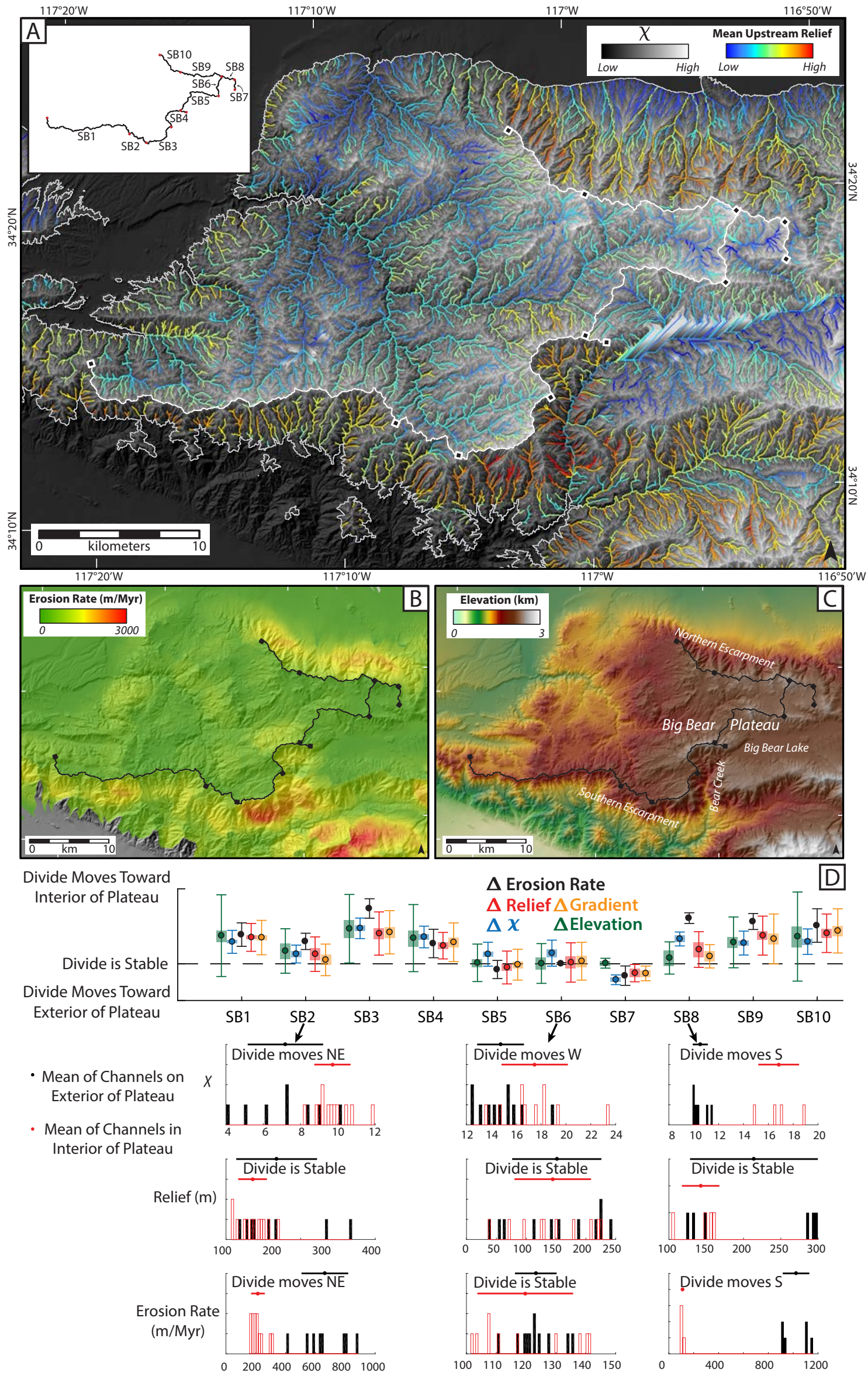

Figure 10 


\section{Supplemental Text for 'Criteria and Tools for Determining Drainage Divide Stability' by Adam M. Forte \& Kelin X. Whipple}

\section{S1. Description of codes included in Github repository}

S1.1. DivideStability - For a given area, this routine produces shapefiles (or alternatively rasters convertible to shapefiles within a GIS program) that includes a stream network with values for all four metrics ( $\chi$, channel elevation, upstream mean relief, and upstream mean gradient) so that the user can produce maps of stream networks colored by these quantities (e.g. Figure 1). To aid in sensible color scaling, values for the 'Gilbert metrics' are normalized to vary between 0 and 1. Because the calculation of $\chi$ is sensitive to the choice of outlet elevation (e.g. Figure 2), careful control of outlet elevation is essential for meaningful interpretations of $\chi$-anomalies. For this reason, this function allows the user to modify a stream network to remove portions of streams below a minimum elevation. This function also checks to make sure that stream outlets along the edge of the DEM meet the criteria defined and that all drainage basins are 'complete', i.e. that the summation of drainage area is accurate and is not influenced by tributaries that are cut off. Either of these cases could result in artificial $\chi$-anomalies, but generally should have no effect on the Gilbert metrics.

S1.2. ChiGrid - The DivideStability code calculates $\chi$ along the stream network, but we find it useful to be able to visualize $\chi$ and an additional metric simultaneously. This code calculates $\chi$ at every pixel in the DEM so that colored stream networks can overlay this $\chi$ raster. Similar to DivideStability, a minimum elevation can be specified for calculating the $\chi$ raster and a check is performed to ensure included drainage basins are complete.

S1.3. AcrossDivide - Tool uses the output of DivideStability and allows users to select sections of a divide of interest to perform detailed analysis of divide sections (e.g. Figure 1D). This function provides users multiple ways of defining a divide of interest, but all of them generally function on the idea that the user (or the function itself in the case of automated detection schemes) defines divides of interest by selecting the drainages that define this divide. End results are plots of the distribution and means of the values at the reference drainage area of all four metrics on either side of the divide of interest (e.g. Figure 1) along with a prediction from each metric independently regarding whether and in which direction the divide should move. The prediction of a divide stability or mobility is made on the basis of a user selected assessment of uncertainty and whether the uncertainty of the distributions overlap with the means of the opposing side of the divide. If there is overlap, the divide is considered stable, and if there is no overlap, the divide is considered mobile. This is not meant as an absolute criteria, simply a quick first order assessment. The user can choose to use the standard deviation of the population (default), the standard error on the mean, or the $95 \%$ bootstrap confidence interval determined from a 1000 iteration resampling scheme. This function also produces a list of channel head coordinates and their respective values for the four metrics that define the divide of interest. 
S1.4. PlotDivideProfiles - To understand the predicted behavior of a divide, it is often necessary to consider the longitudinal profiles of the rivers in question. This functions plots $\chi$-elevation and distance-elevation plots for the streams used to define the divide. Various plotting options exist to allow the user to plot only specific channels and to color drainages by either gradient or relief to compare predictions of individual metrics.

S1.5. AlongDividePlot - If the user has defined multiple divide segments, this allows them to produce a plot similar to what is shown in the text (e.g. Figures 7C, 9D, or 10D). In detail, this function will produce three plots for each divide (made up of multiple segments), (1) a plot of divide segment means with uncertainties, (2) a plot of across-divide delta values with propagated uncertainties with true values (i.e. relief and gradient will have opposite signs from elevation and chi delta values if they are all consistent), and (3) a standardized plot of delta values to that 'positive' values indicate the same direction of divide motion for all metrics. Similar to AcrossDivide, the user can choose to use the standard deviation of the populations, standard error on the mean, or $95 \%$ bootstrap confidence interval as the uncertainty value.

\section{S2. Captions for supplemental figures}

Supplemental Figure 1 - Divide stability histograms for divide GC1.

Supplemental Figure $\mathbf{2}$ - Longitudinal and $\chi$-normalized profiles for rivers that define divide GC1.

Supplemental Figure 3 - Divide stability histograms for divide GC2.

Supplemental Figure 4 - Longitudinal and $\chi$-normalized profiles for rivers that define divide GC2.

Supplemental Figure 5 - Divide stability histograms for divide GC3.

Supplemental Figure 6 - Longitudinal and $\chi$-normalized profiles for rivers that define divide GC3.

Supplemental Figure 7 - Divide stability histograms for divide GC4.

Supplemental Figure 8 - Longitudinal and $\chi$-normalized profiles for rivers that define divide GC4.

Supplemental Figure 9 - Divide stability histograms for divide GC5.

Supplemental Figure 10 - Longitudinal and $\chi$-normalized profiles for rivers that define divide GC5. 
Supplemental Figure 11 - Divide stability histograms for divide GC6.

Supplemental Figure 12 - Longitudinal and $\chi$-normalized profiles for rivers that define divide GC6.

Supplemental Figure 13 - Divide stability histograms for divide GC7.

Supplemental Figure 14 - Longitudinal and $\chi$-normalized profiles for rivers that define divide GC7.

Supplemental Figure 15 - Divide stability histograms for divide GC8.

Supplemental Figure 16 - Longitudinal and $\chi$-normalized profiles for rivers that define divide GC8.

Supplemental Figure 17- Divide stability histograms for divide KV1.

Supplemental Figure 18 - Longitudinal and $\chi$-normalized profiles for rivers that define divide KV1.

Supplemental Figure 19 - Divide stability histograms for divide KV2.

Supplemental Figure 20 - Longitudinal and $\chi$-normalized profiles for rivers that define divide KV2.

Supplemental Figure 21 - Divide stability histograms for divide KV3.

Supplemental Figure 22 - Longitudinal and $\chi$-normalized profiles for rivers that define divide KV3.

Supplemental Figure 23 - Divide stability histograms for divide KV4.

Supplemental Figure 24 - Longitudinal and $\chi$-normalized profiles for rivers that define divide KV4.

Supplemental Figure 25 - Divide stability histograms for divide KV5.

Supplemental Figure 26 - Longitudinal and $\chi$-normalized profiles for rivers that define divide KV5.

Supplemental Figure 27 - Empirical relationship between Be10 erosion rate data and local 2.5 $\mathrm{km}$ relief in the San Bernadino Mountains used to produce the erosion rate map in Figure 10B. 
Supplemental Figure 28 - Divide stability histograms for divide SB1.

Supplemental Figure 29 - Longitudinal and $\chi$-normalized profiles for rivers that define divide SB1.

Supplemental Figure 30 - Divide stability histograms for divide SB2.

Supplemental Figure 31 - Longitudinal and $\chi$-normalized profiles for rivers that define divide SB2.

Supplemental Figure 32 - Divide stability histograms for divide SB3.

Supplemental Figure 33 - Longitudinal and $\chi$-normalized profiles for rivers that define divide SB3.

Supplemental Figure 34 - Divide stability histograms for divide SB4.

Supplemental Figure 35 - Longitudinal and $\chi$-normalized profiles for rivers that define divide SB4.

Supplemental Figure 36 - Divide stability histograms for divide SB5.

Supplemental Figure 37 - Longitudinal and $\chi$-normalized profiles for rivers that define divide SB5.

Supplemental Figure 38 - Divide stability histograms for divide SB6.

Supplemental Figure 39 - Longitudinal and $\chi$-normalized profiles for rivers that define divide SB6.

Supplemental Figure 40 - Divide stability histograms for divide SB7.

Supplemental Figure 41 - Longitudinal and $\chi$-normalized profiles for rivers that define divide SB7.

Supplemental Figure 42 - Divide stability histograms for divide SB8.

Supplemental Figure 43 - Longitudinal and $\chi$-normalized profiles for rivers that define divide SB8.

Supplemental Figure 44 - Divide stability histograms for divide SB9. 
Supplemental Figure 45 - Longitudinal and $\chi$-normalized profiles for rivers that define divide SB9.

Supplemental Figure 46 - Divide stability histograms for divide SB10.

Supplemental Figure 47- Longitudinal and $\chi$-normalized profiles for rivers that define divide SB10. 


\section{Divide GC1}

- Mean of Channels Southwest of Divide

- Mean of Channels Northeast of Divide

Chi: Divide is predicted to move northeast

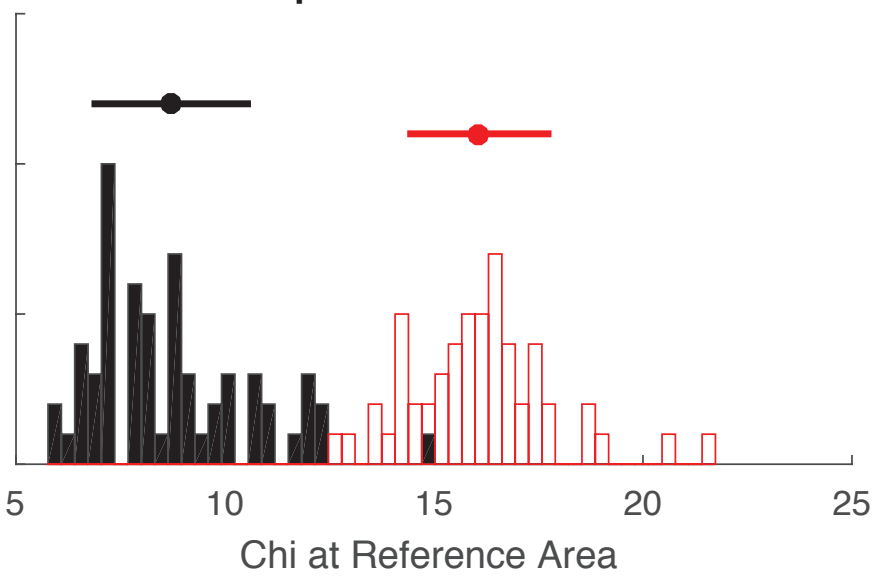

- Mean of Channels Southwest of Divide

- Mean of Channels Northeast of Divide

Elevation: Divide is stable

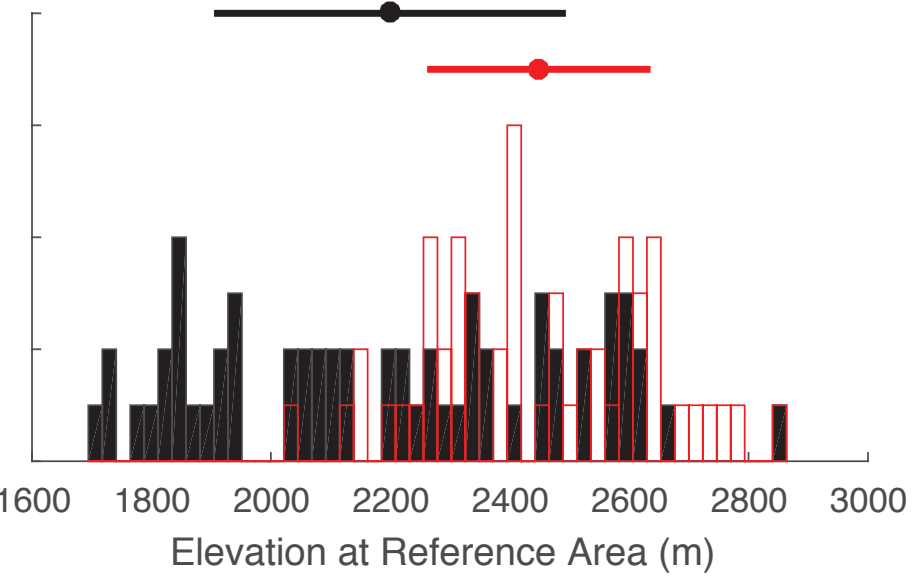

- Mean of Channels Southwest of Divide

- Mean of Channels Northeast of Divide

Relief: Divide is stable

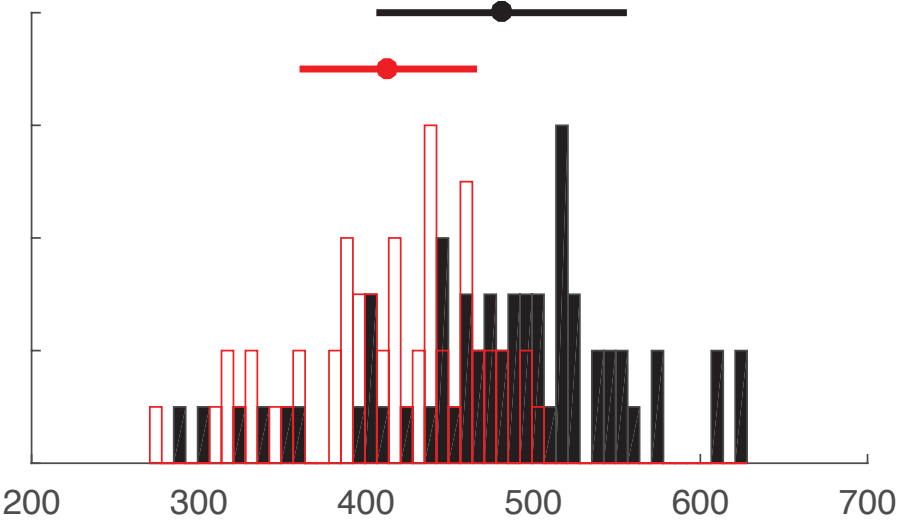

Mean Upstream Relief above Reference Area (m)

- Mean of Channels Southwest of Divide

- Mean of Channels Northeast of Divide

Gradient: Divide is stable

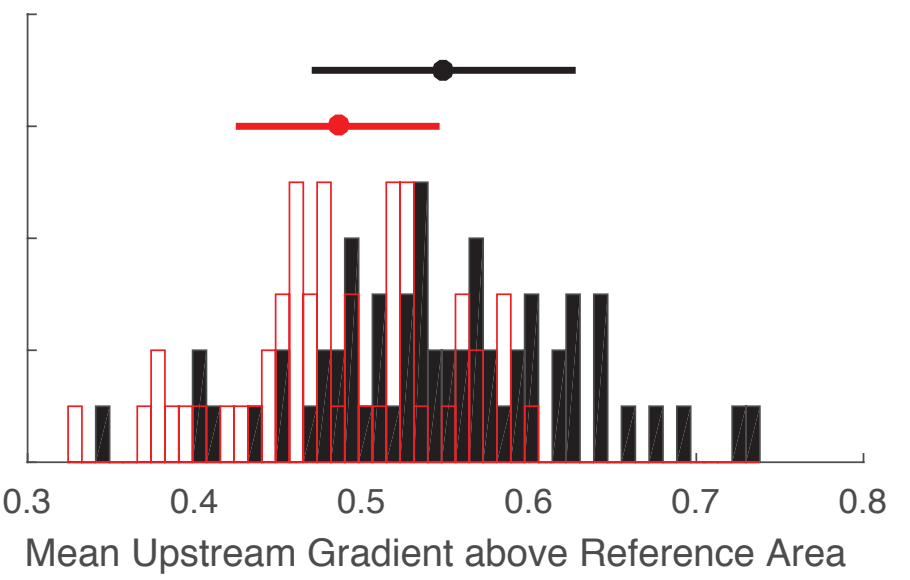

\section{Supplemental Figure 1}




\section{Divide GC1}
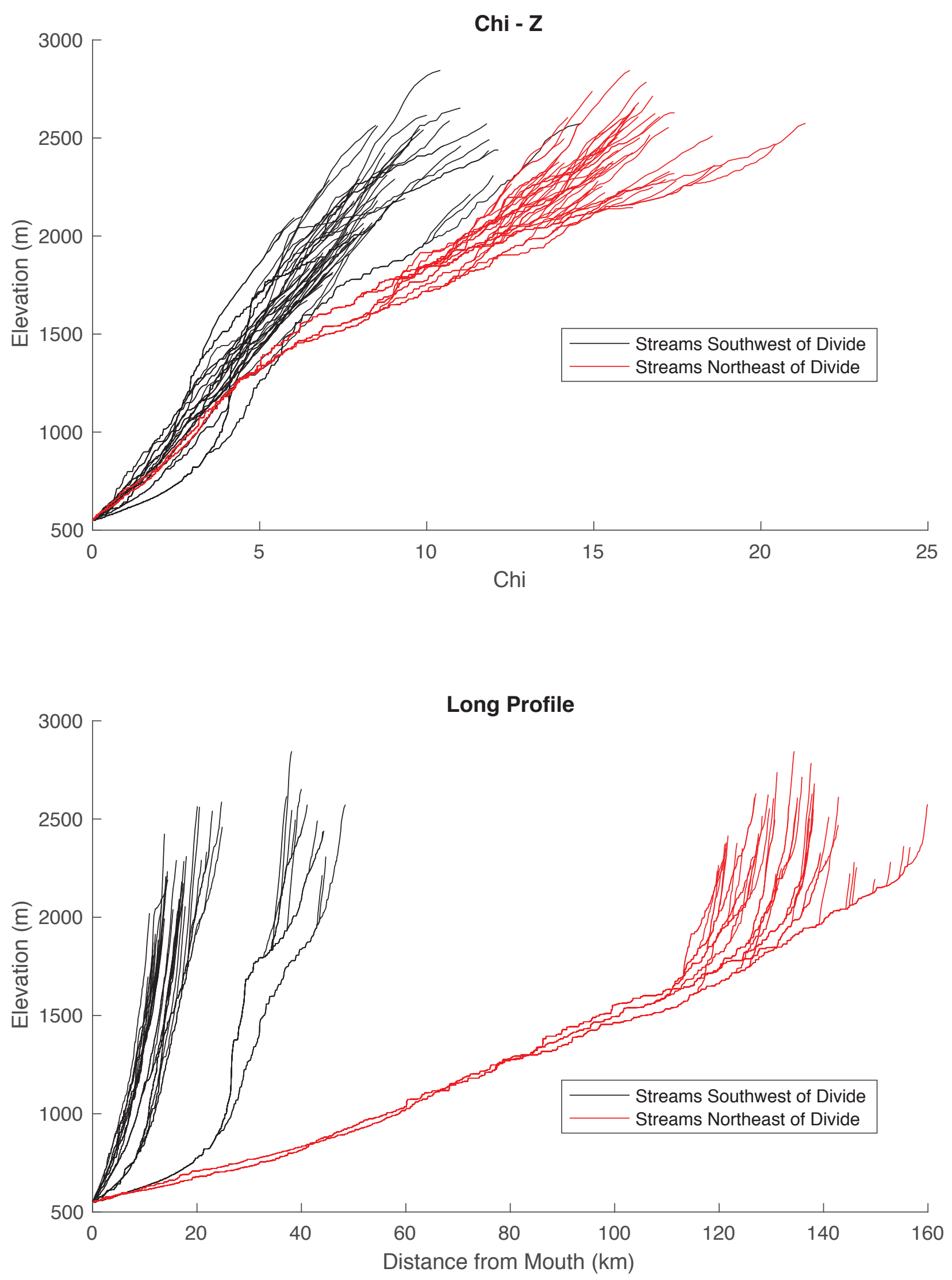

Supplemental Figure 2 


\section{Divide GC2}

- Mean of Channels Southwest of Divide

- Mean of Channels Northeast of Divide

Chi: Divide is predicted to move northeast

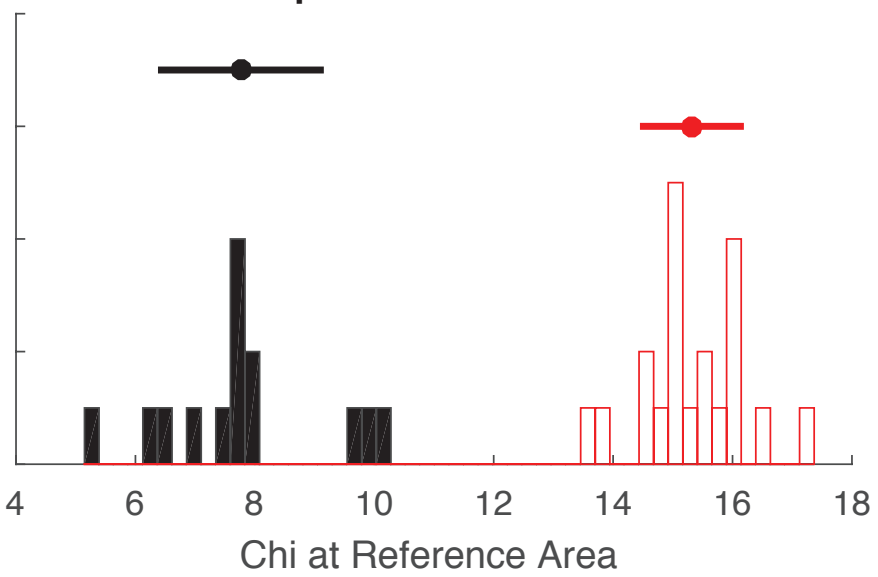

- Mean of Channels Southwest of Divide

- Mean of Channels Northeast of Divide

Elevation: Divide is stable

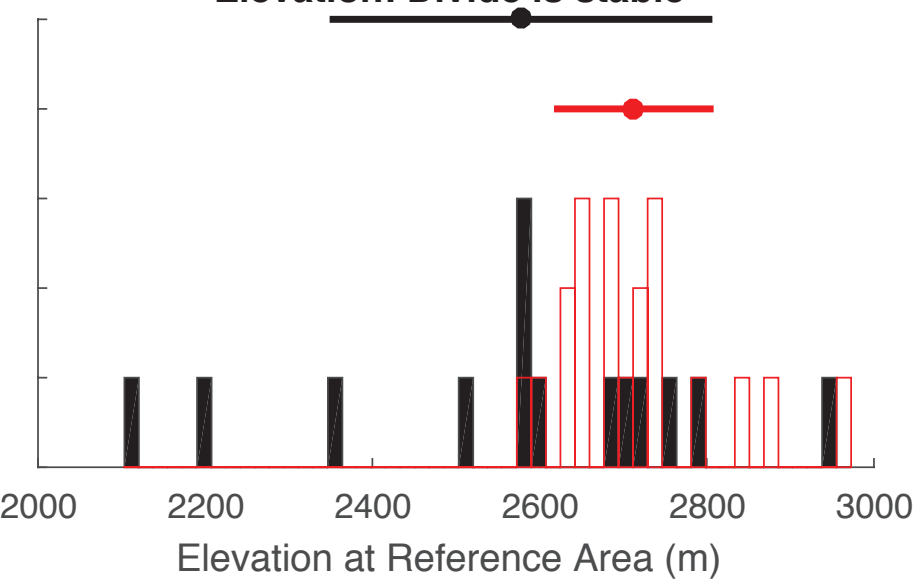

- Mean of Channels Southwest of Divide

- Mean of Channels Northeast of Divide

Relief: Divide is stable

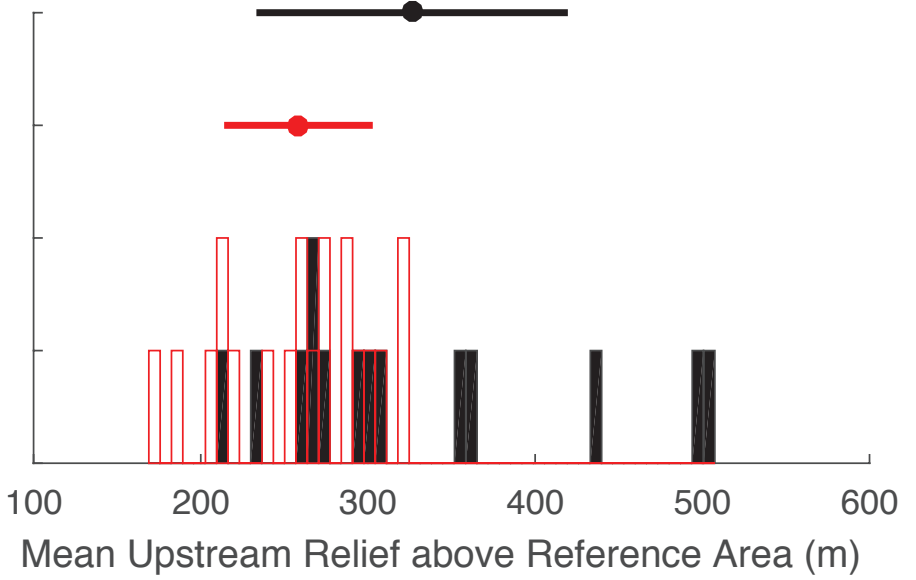

- Mean of Channels Northeast of Divide

\section{Gradient: Divide is stable}

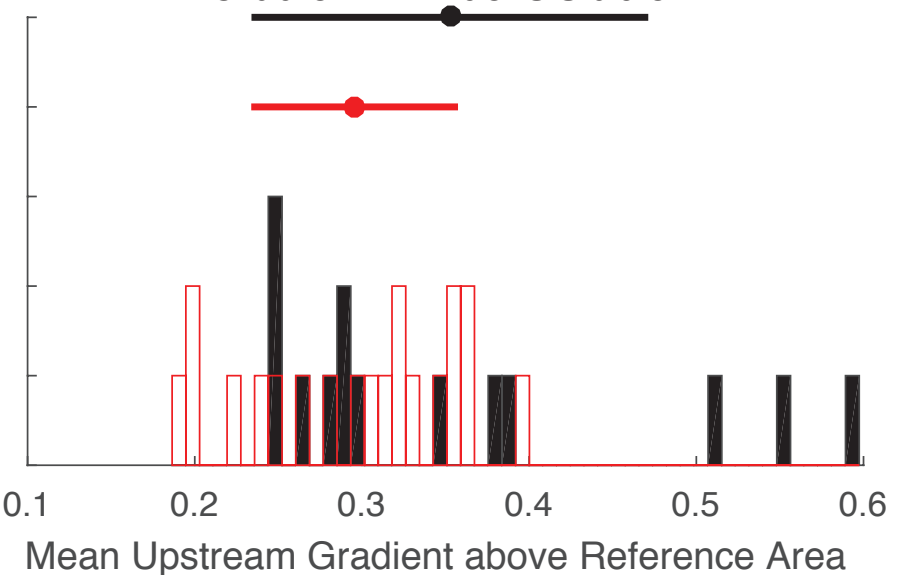

\section{Supplemental Figure 3}


Divide GC2
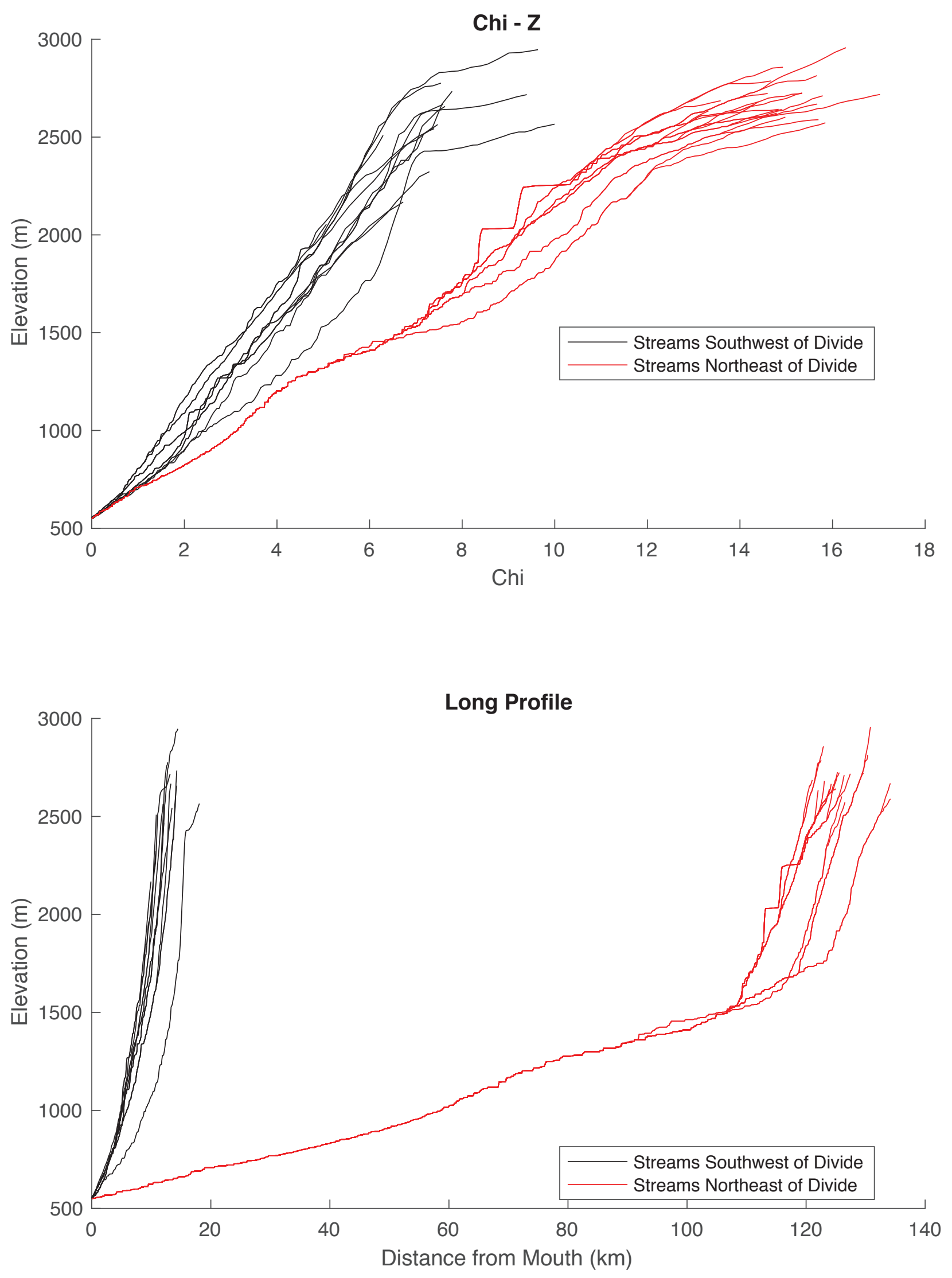

Supplemental Figure 4 


\section{Divide GC3}

- Mean of Channels South of Divide

- Mean of Channels North of Divide

Chi: Divide is predicted to move north

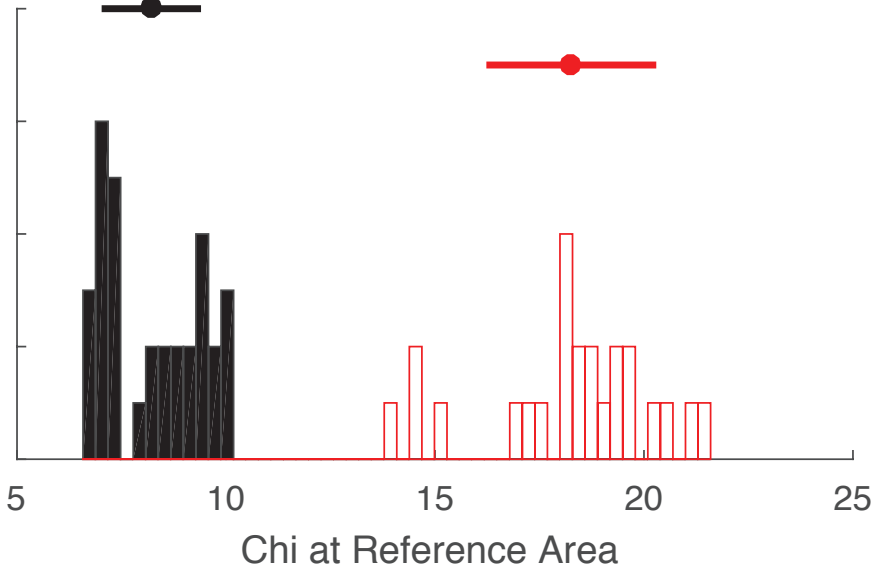

- Mean of Channels South of Divide

- Mean of Channels North of Divide

Elevation: Divide is predicted to move north

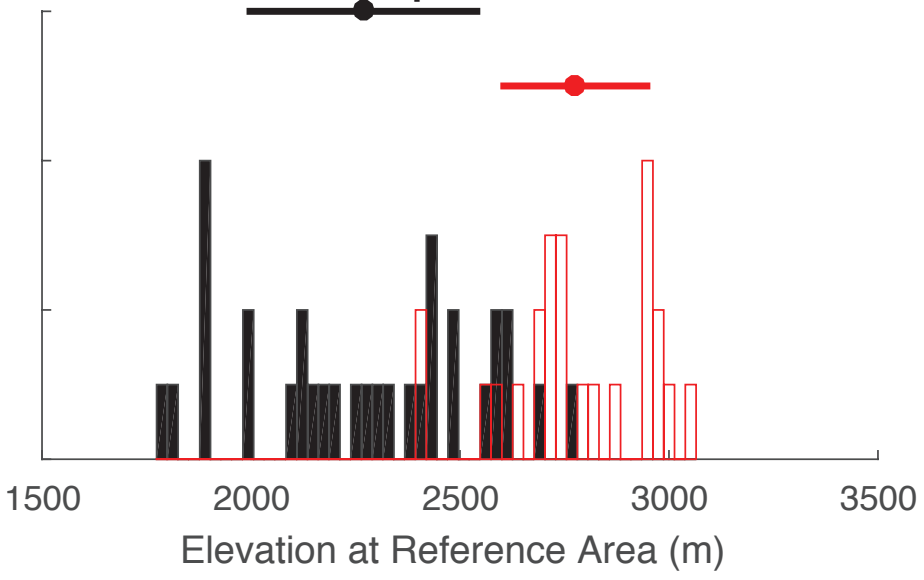

- Mean of Channels South of Divide

- Mean of Channels North of Divide

Relief: Divide is predicted to move north

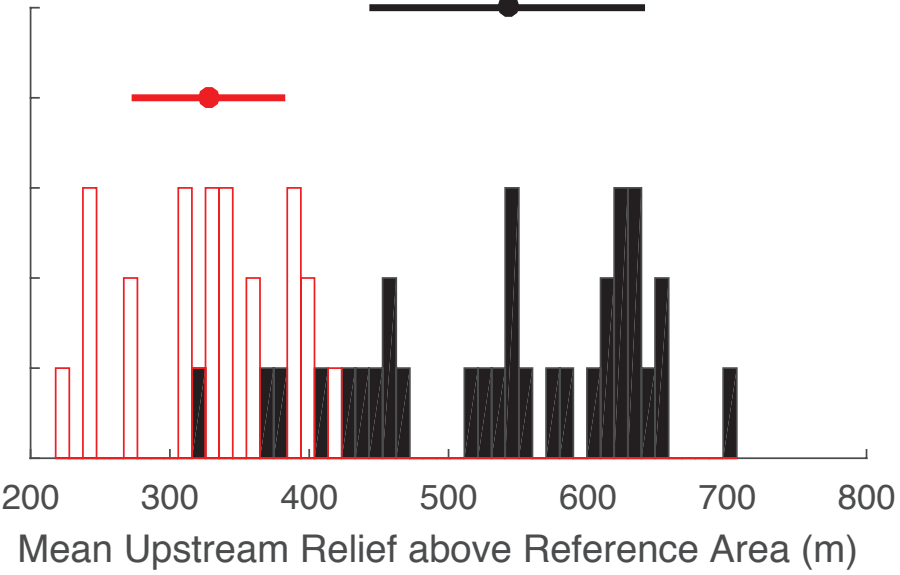

- Mean of Channels South of Divide

- Mean of Channels North of Divide

Gradient: Divide is predicted to move north

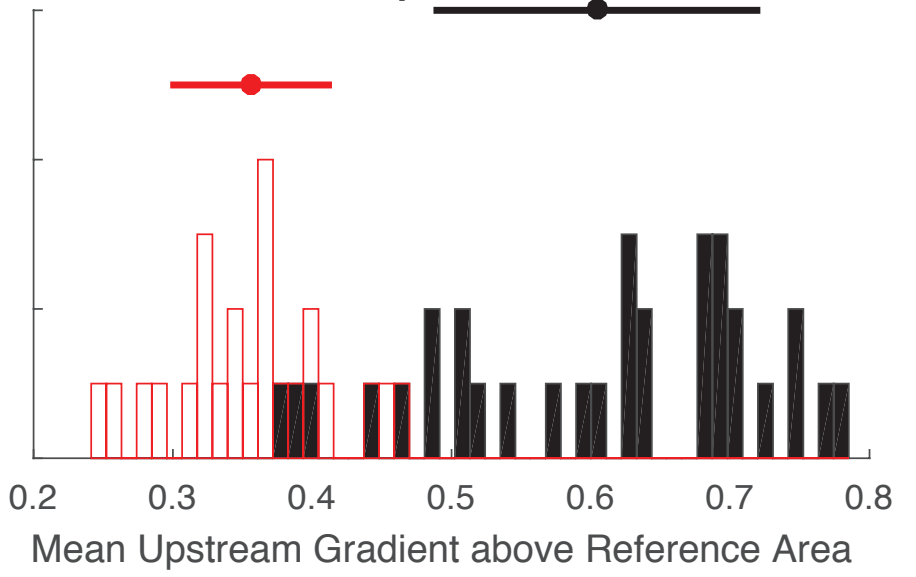

\section{Supplemental Figure 5}




\section{Divide GC3}
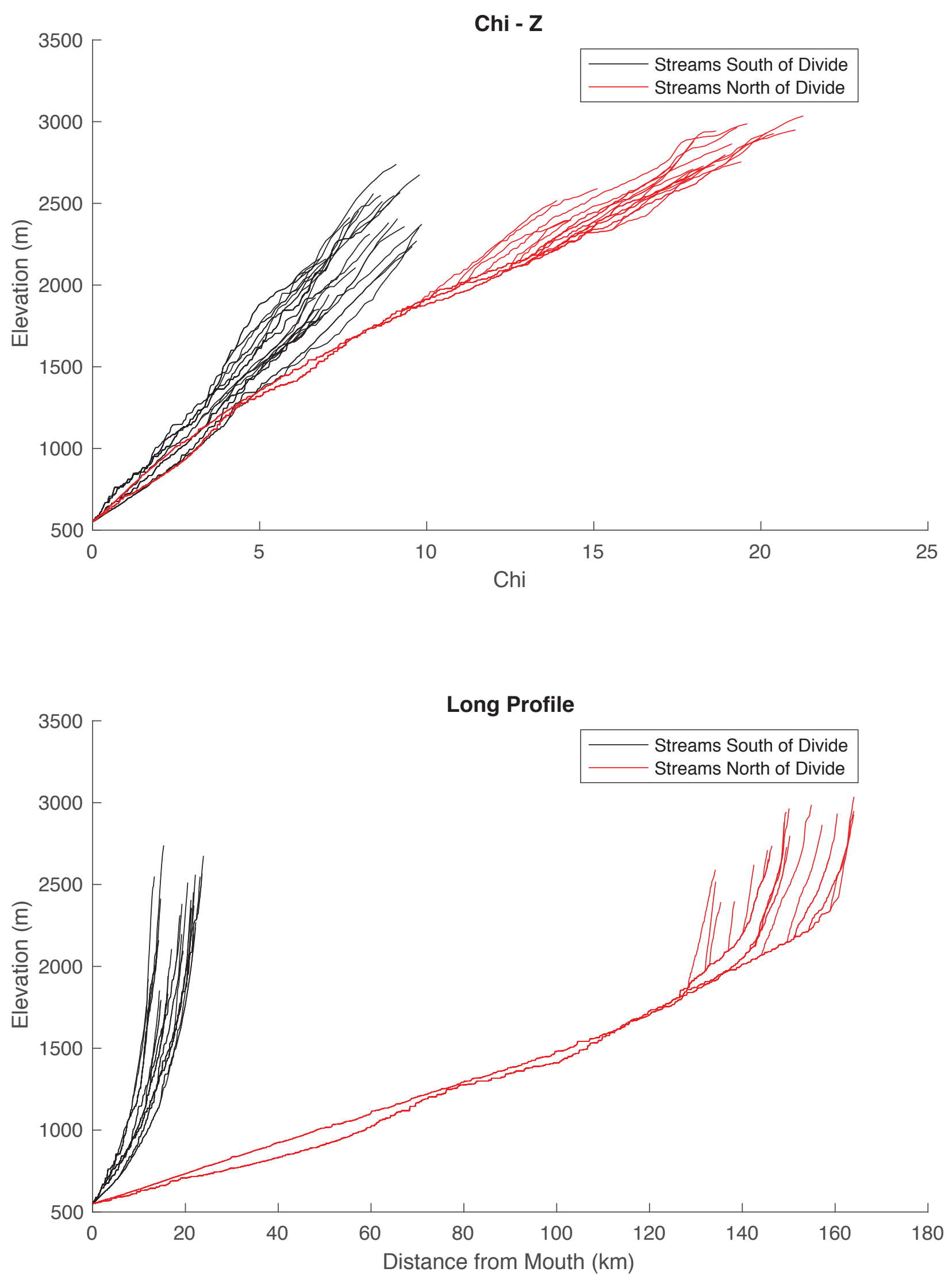

Supplemental Figure 6 


\section{Divide GC4}

- Mean of Channels Southwest of Divide

- Mean of Channels Northeast of Divide

Chi: Divide is predicted to move northeast

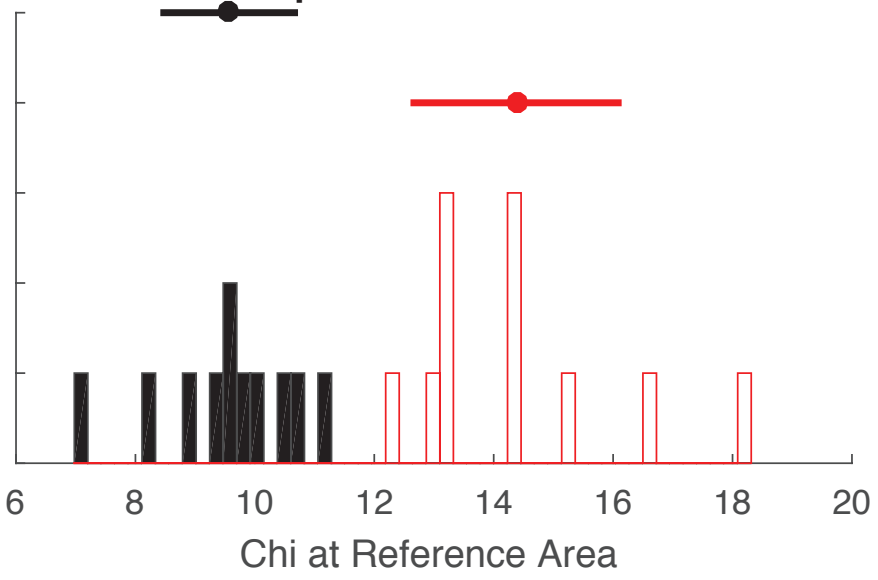

- Mean of Channels Southwest of Divide

- Mean of Channels Northeast of Divide

Elevation: Divide is stable

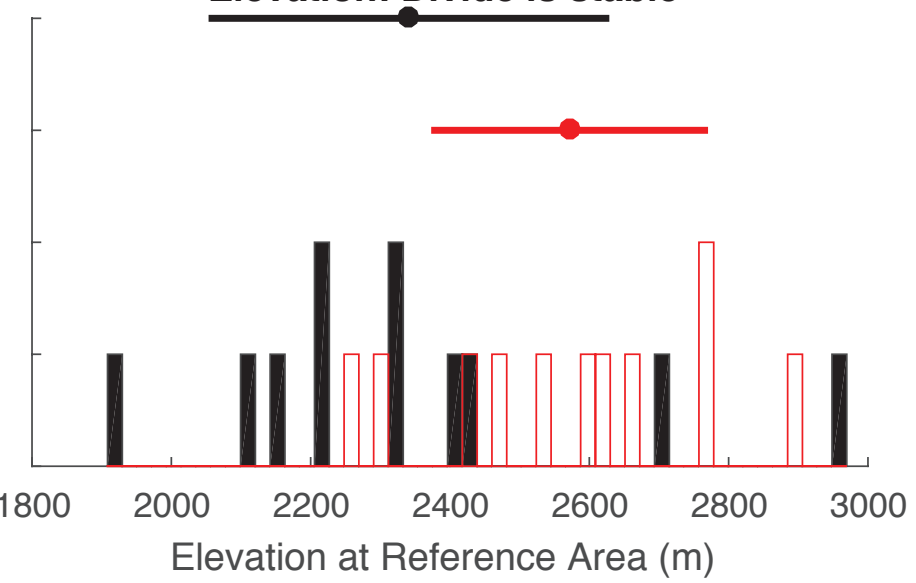

- Mean of Channels Southwest of Divide

- Mean of Channels Northeast of Divide

Relief: Divide is stable

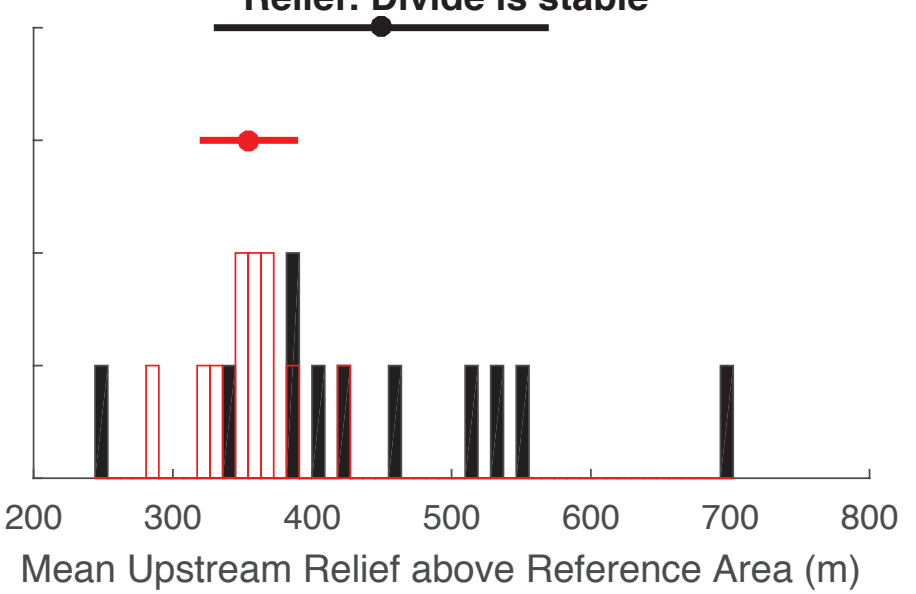

- Mean of Channels Northeast of Divide

Gradient: Divide is stable

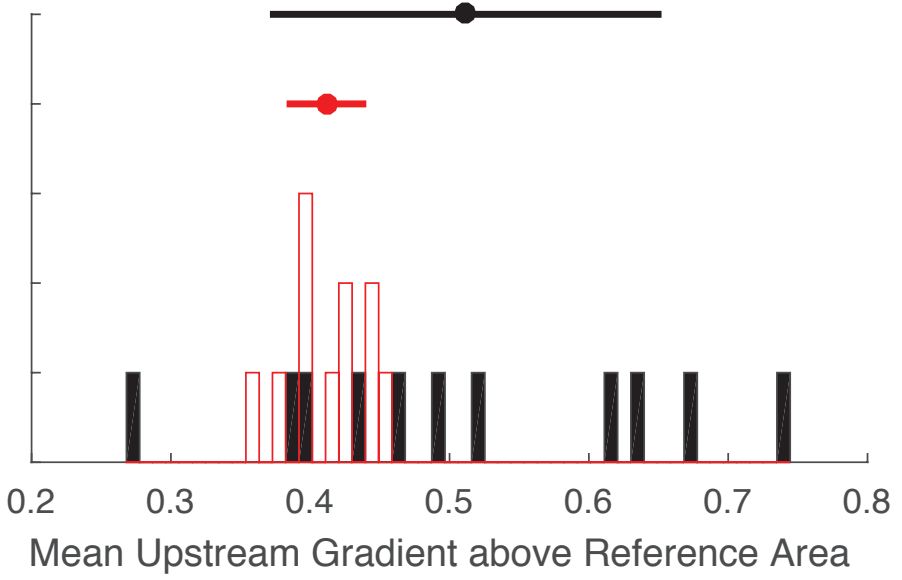

\section{Supplemental Figure 7}




\section{Divide GC4}
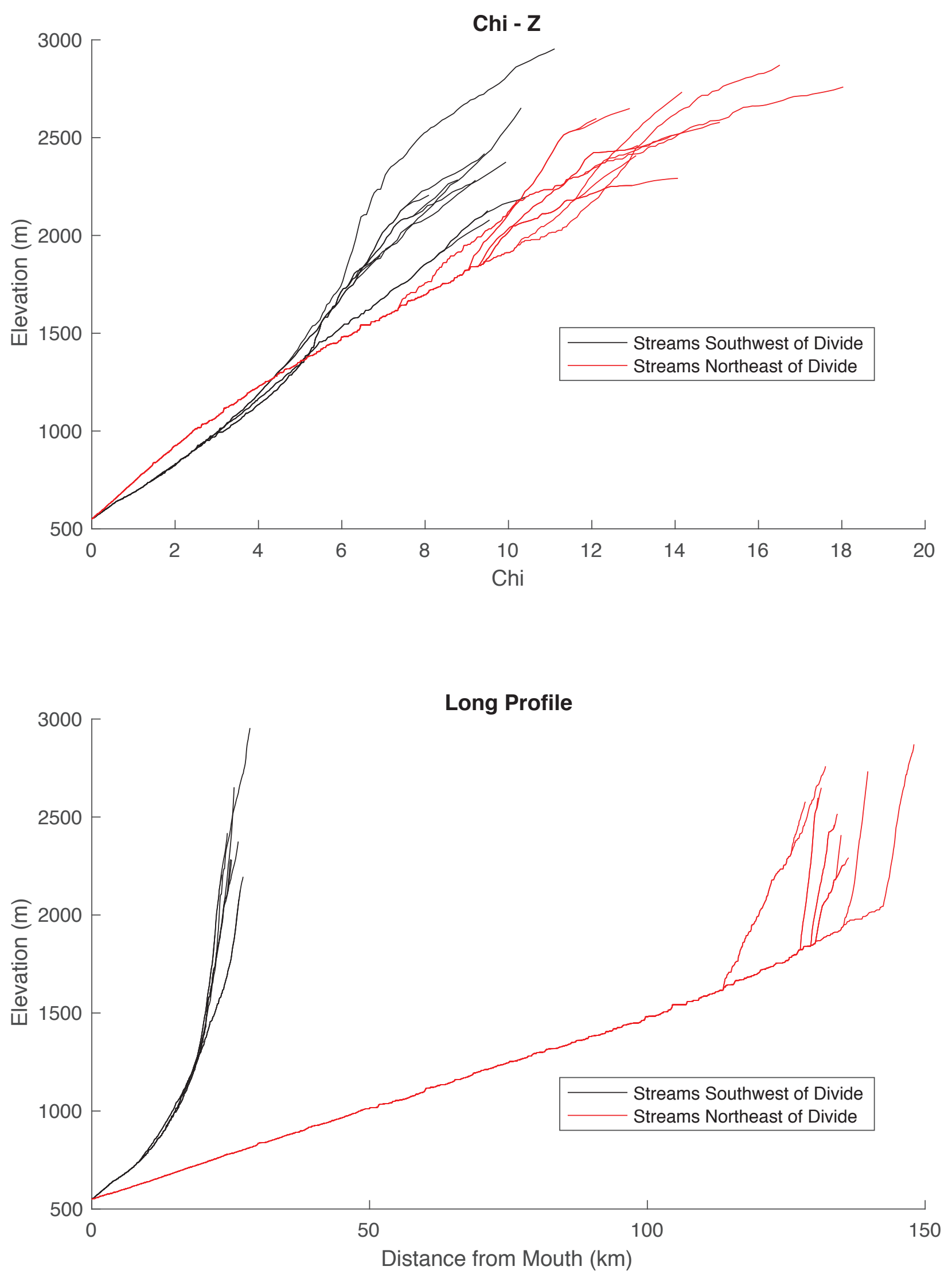

Supplemental Figure 8 


\section{Divide GC5}

- Mean of Channels Southwest of Divide

- Mean of Channels Northeast of Divide

Chi: Divide is predicted to move northeast

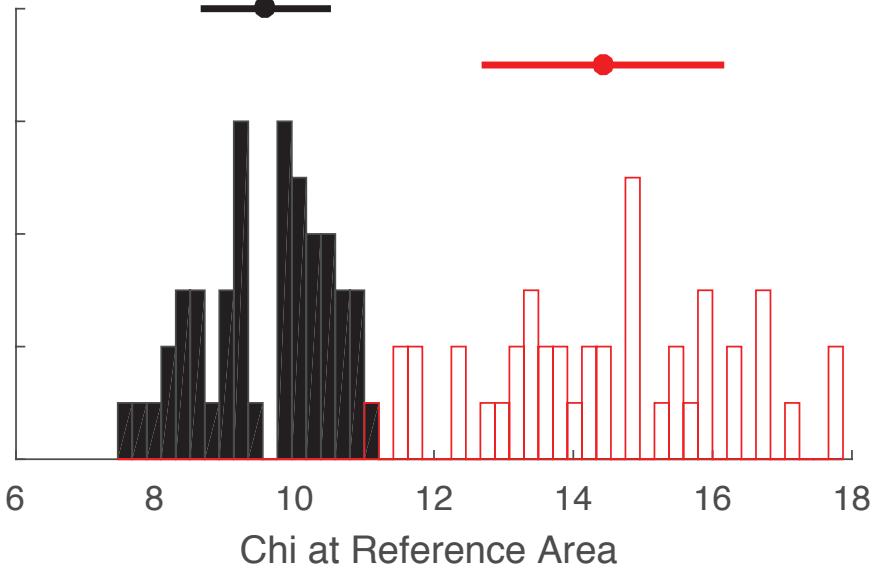

- Mean of Channels Southwest of Divide

- Mean of Channels Northeast of Divide

Elevation: Divide is predicted to move northeast

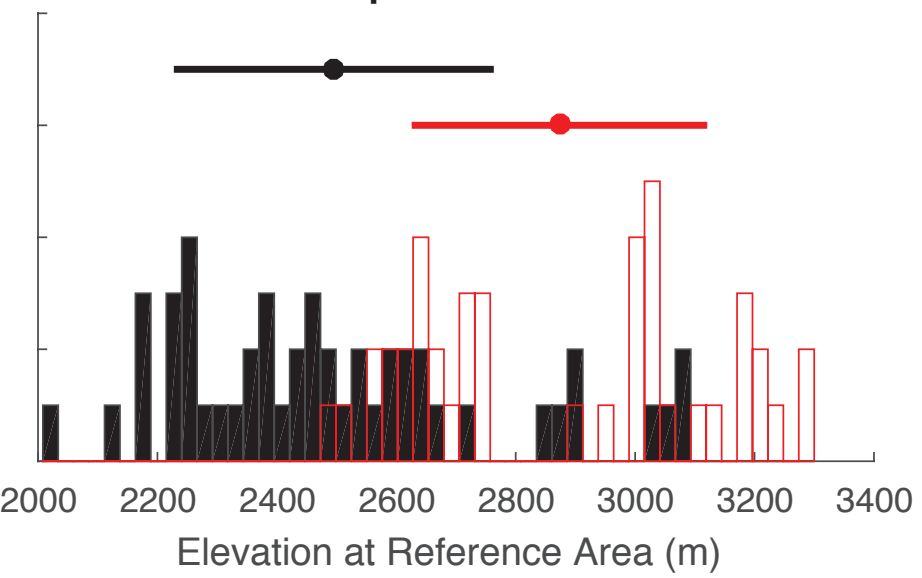

- Mean of Channels Southwest of Divide

- Mean of Channels Northeast of Divide

Relief: Divide is predicted to move northeast

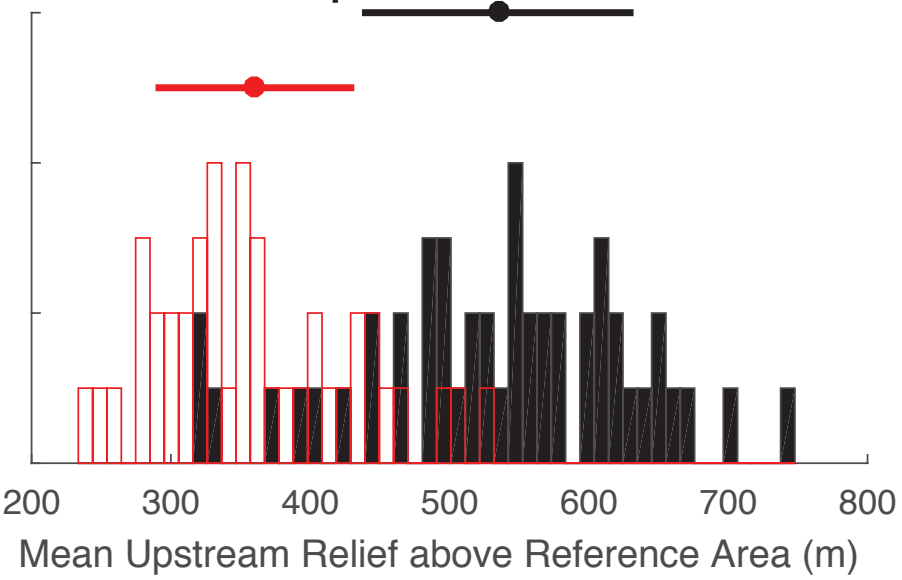

- Mean of Channels Southwest of Divide

- Mean of Channels Northeast of Divide

Gradient: Divide is predicted to move northeast

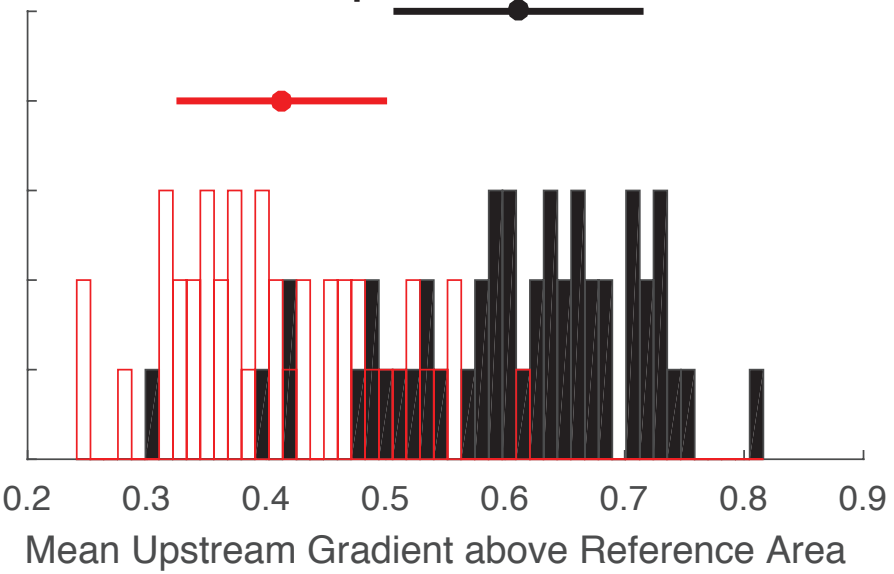

\section{Supplemental Figure 9}




\section{Divide GC5}
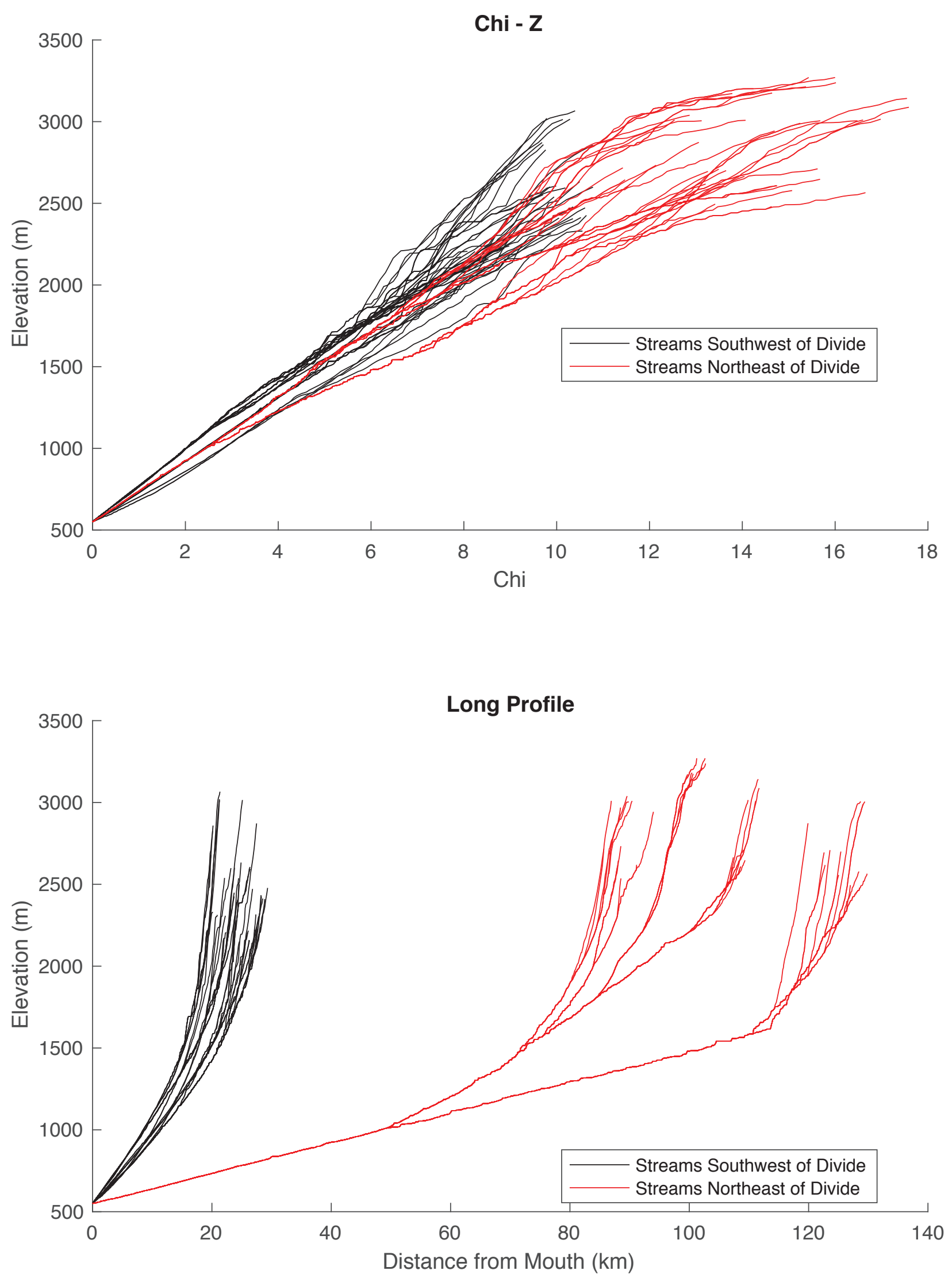


\section{Divide GC6}

- Mean of Channels Southwest of Divide

- Mean of Channels Northeast of Divide

Chi: Divide is predicted to move northeast

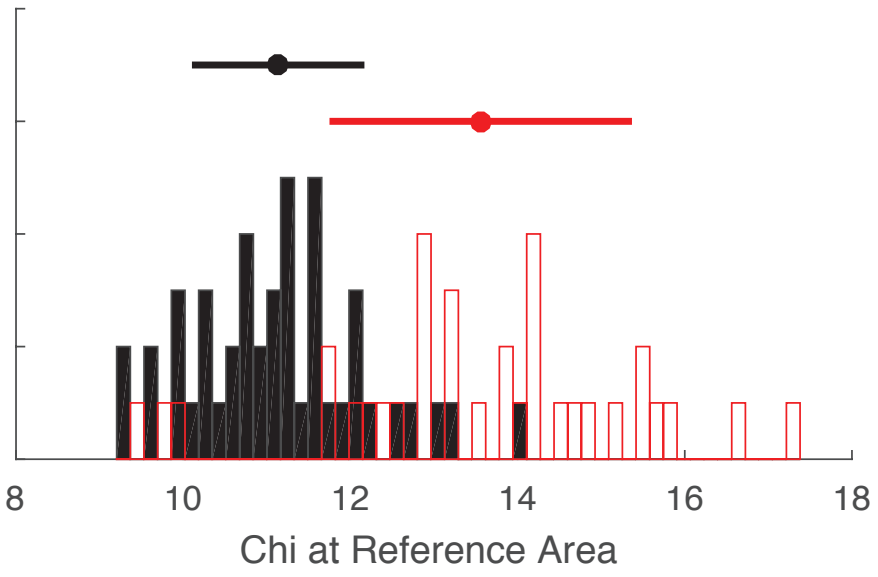

- Mean of Channels Southwest of Divide

- Mean of Channels Northeast of Divide

Elevation: Divide is stable

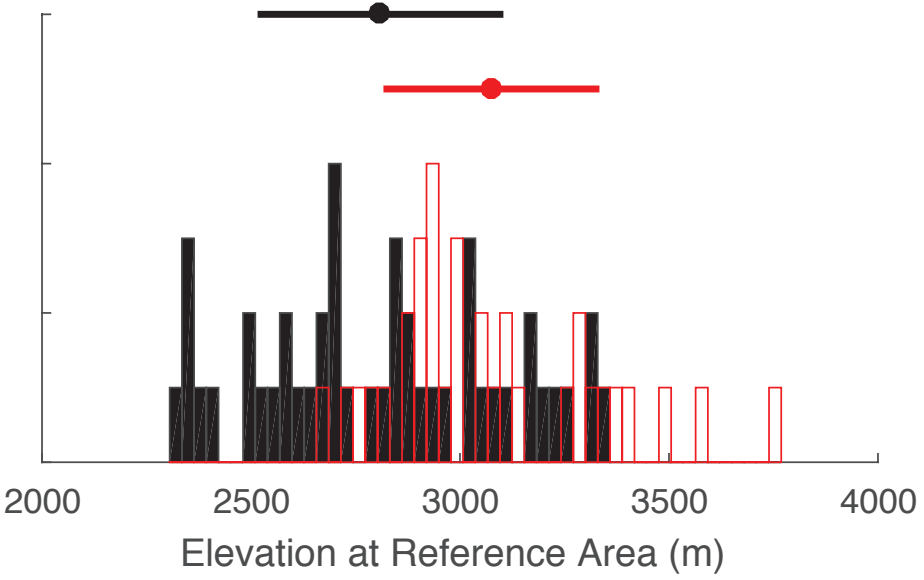

- Mean of Channels Southwest of Divide

- Mean of Channels Northeast of Divide

Relief: Divide is stable

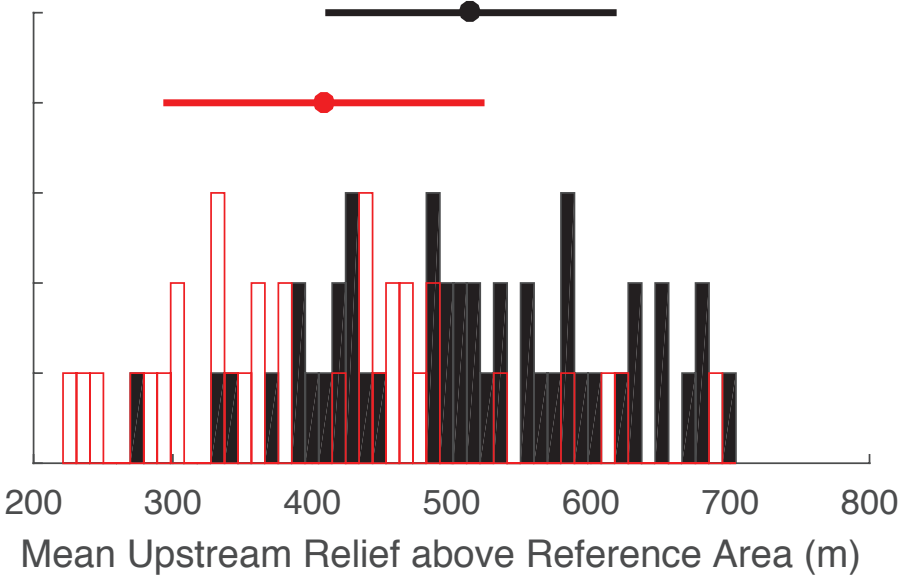

- Mean of Channels Southwest of Divide

- Mean of Channels Northeast of Divide

Gradient: Divide is predicted to move northeast

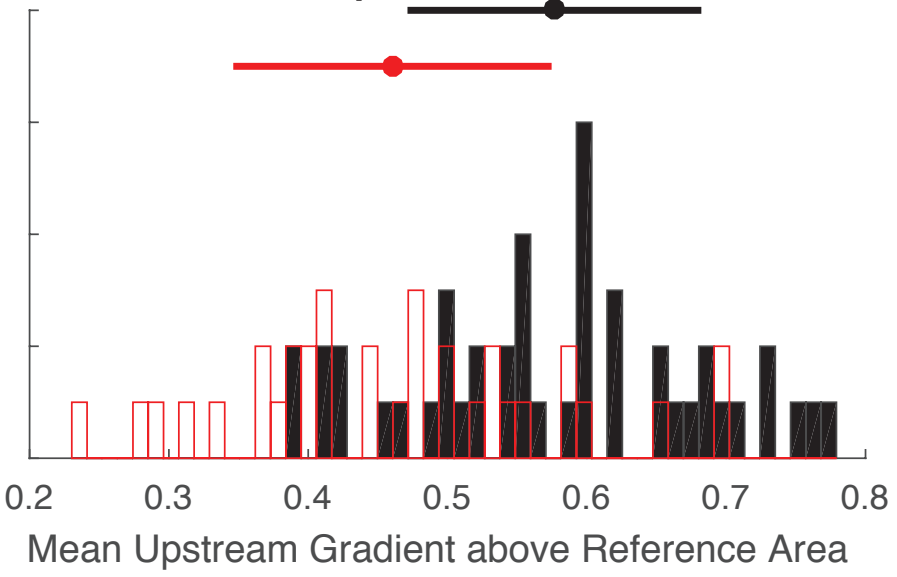

\section{Supplemental Figure 11}


Divide GC6
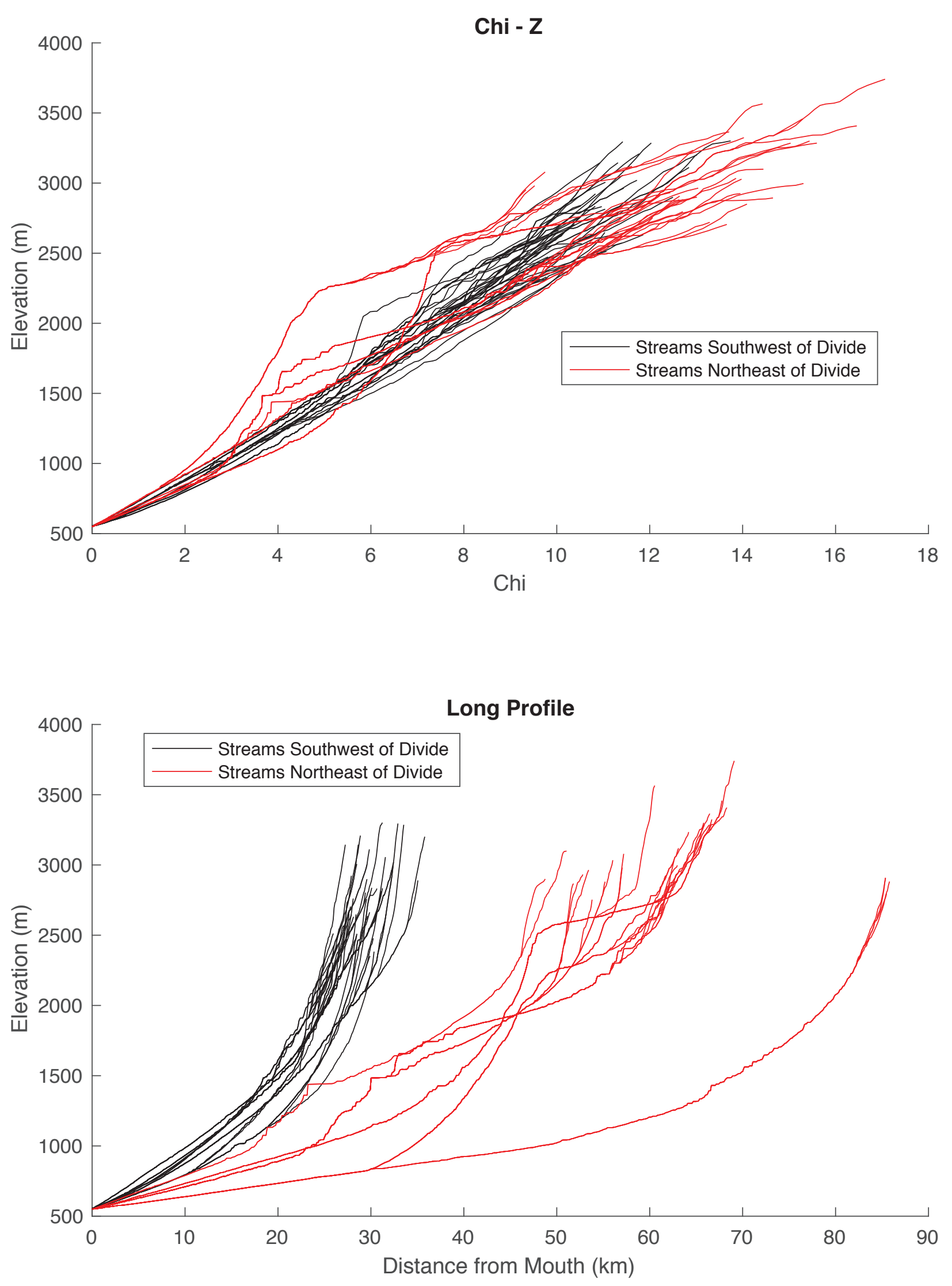

Supplemental Figure 12 


\section{Divide GC7}
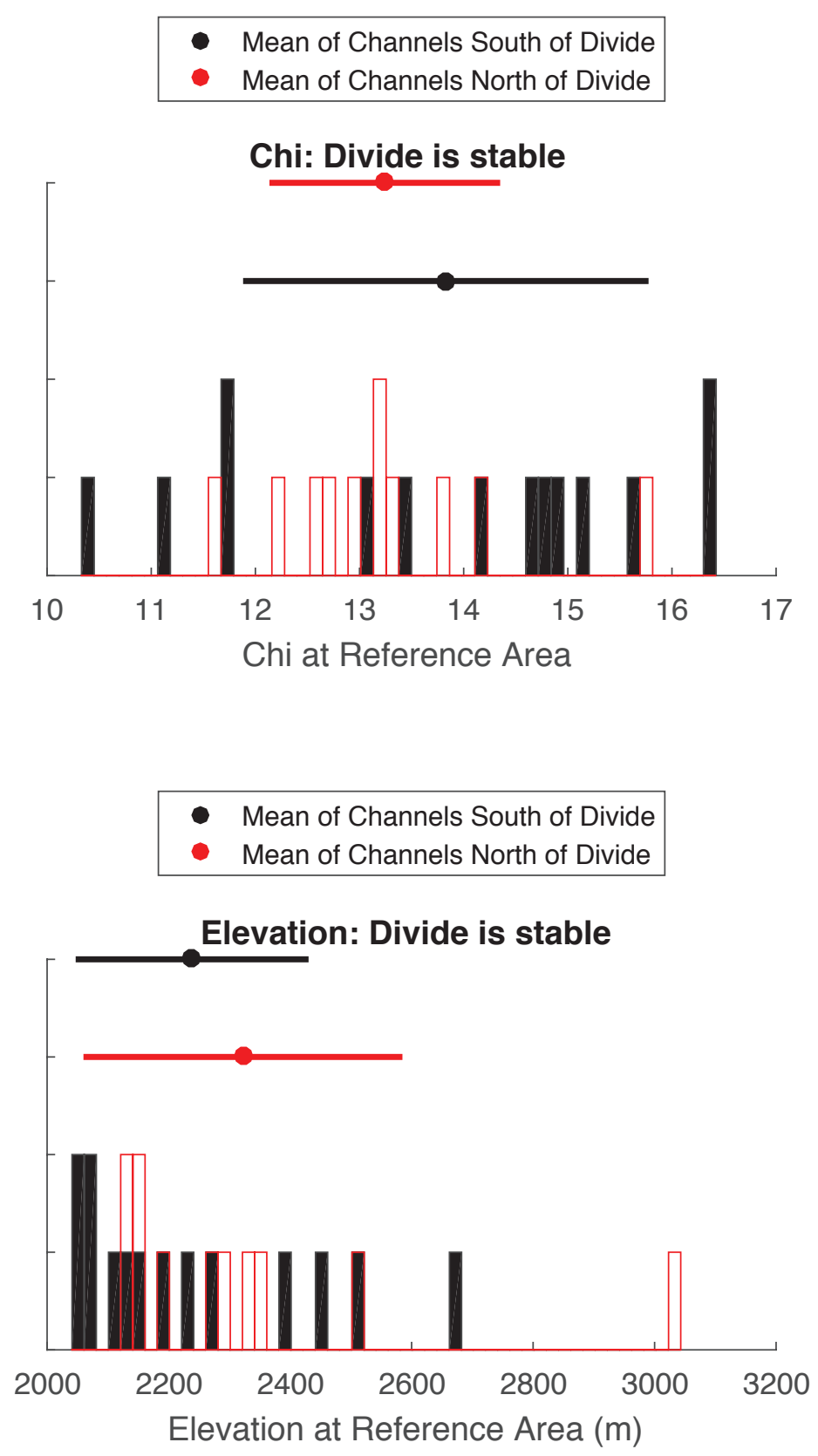

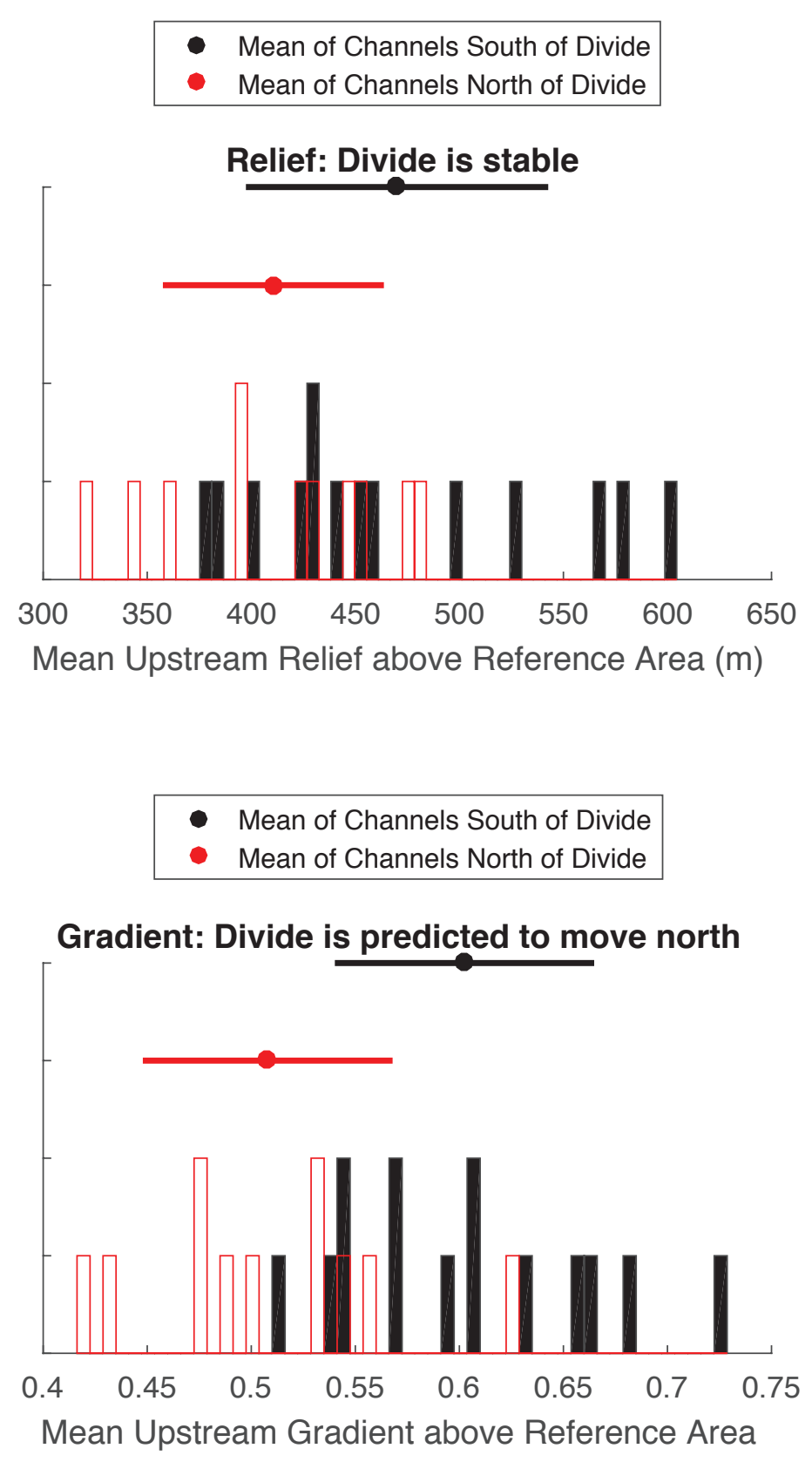

- Mean of Channels South of Divide

- Mean of Channels North of Divide

Relief: Divide is stable

- Mean of Channels South of Divide

- Mean of Channels North of Divide

\section{Supplemental Figure 13}




\section{Divide GC7}
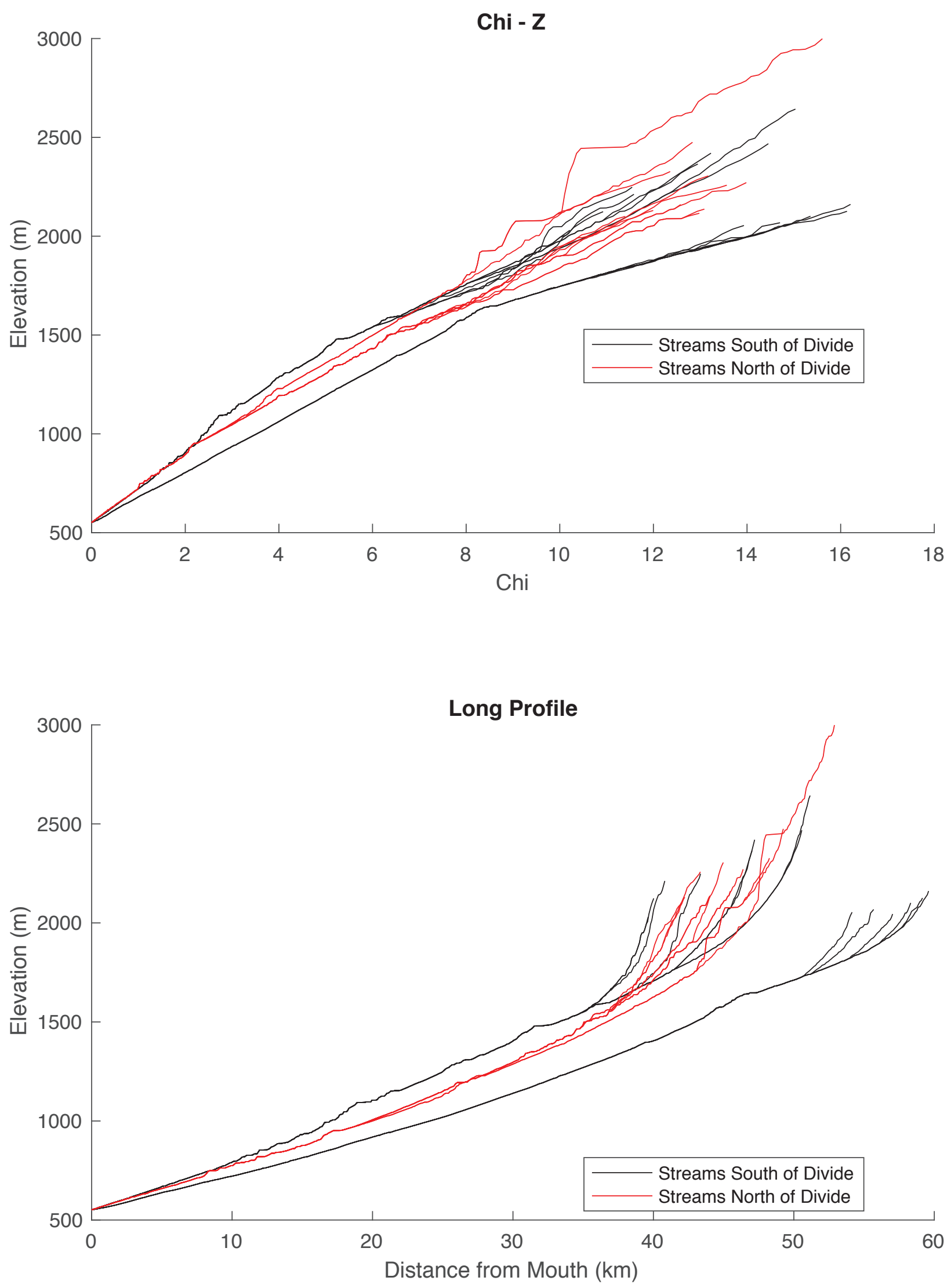

Supplemental Figure 14 


\section{Divide GC8}

- Mean of Channels South of Divide

- Mean of Channels North of Divide

Chi: Divide is predicted to move south

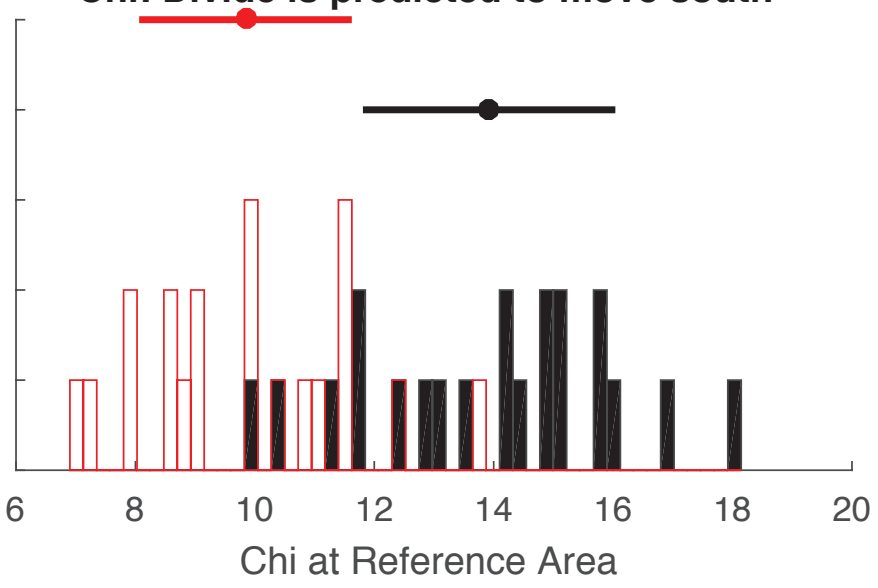

- Mean of Channels South of Divide

- Mean of Channels North of Divide

Elevation: Divide is stable

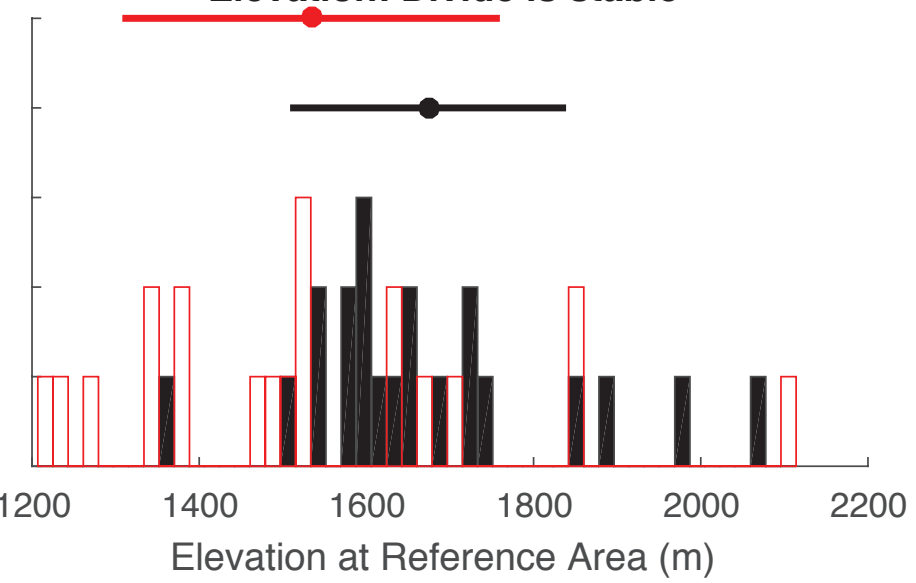

- Mean of Channels South of Divide

- Mean of Channels North of Divide

Relief: Divide is stable

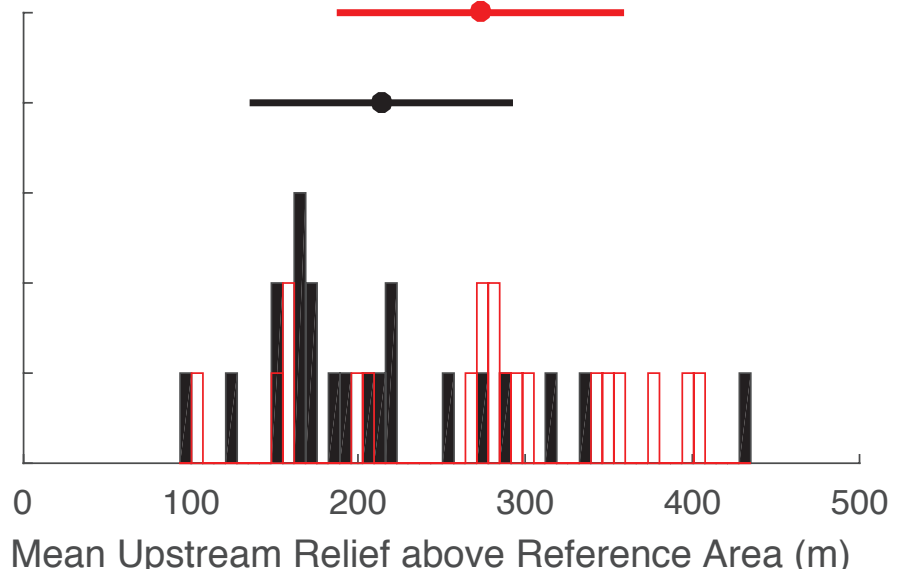

Mean Upstream Relief above Reference Area (m)

- Mean of Channels South of Divide

- Mean of Channels North of Divide

Gradient: Divide is stable

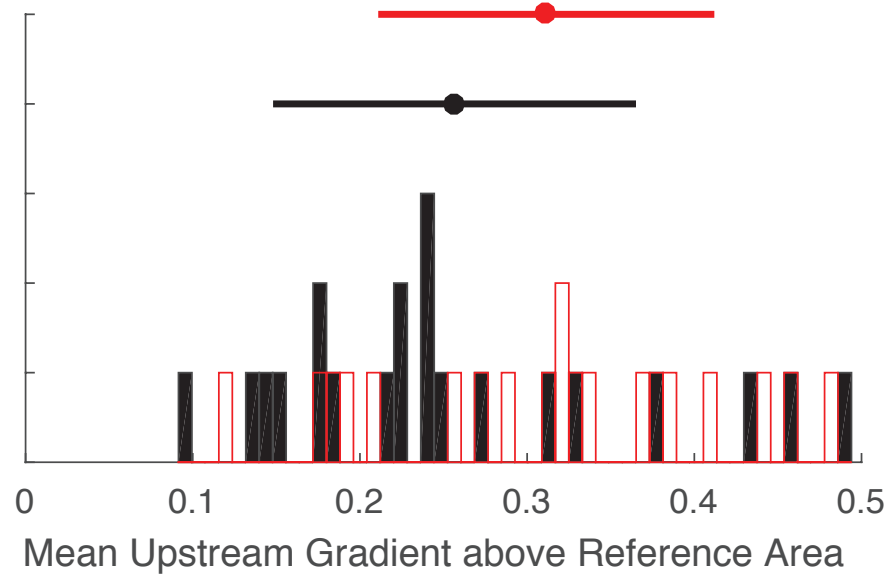

\section{Supplemental Figure 15}




\section{Divide GC8}
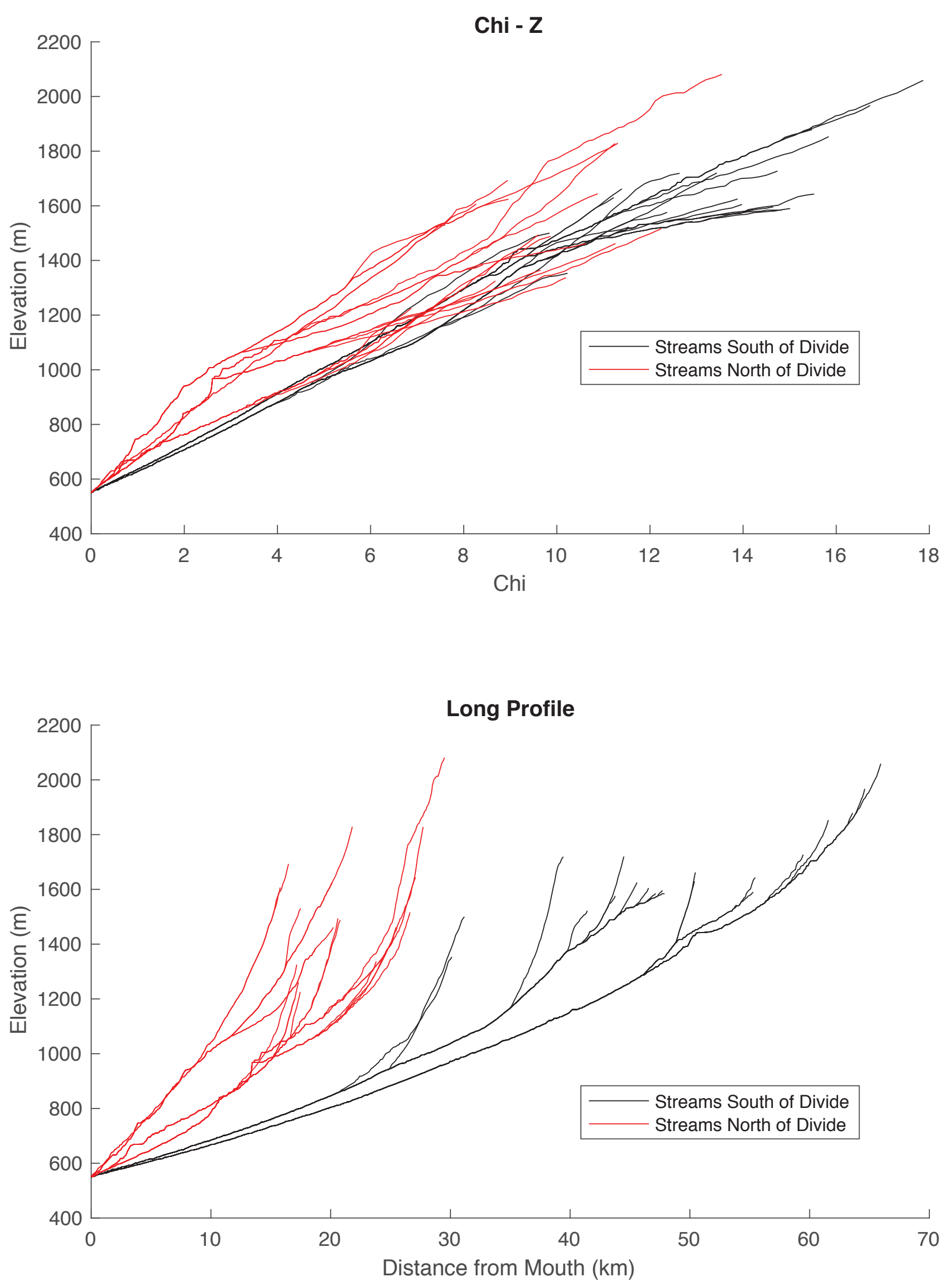


\section{Divide KV1}

- Mean of Channels Northwest of Divide

- Mean of Channels Southeast of Divide

Chi: Divide is predicted to move southeast

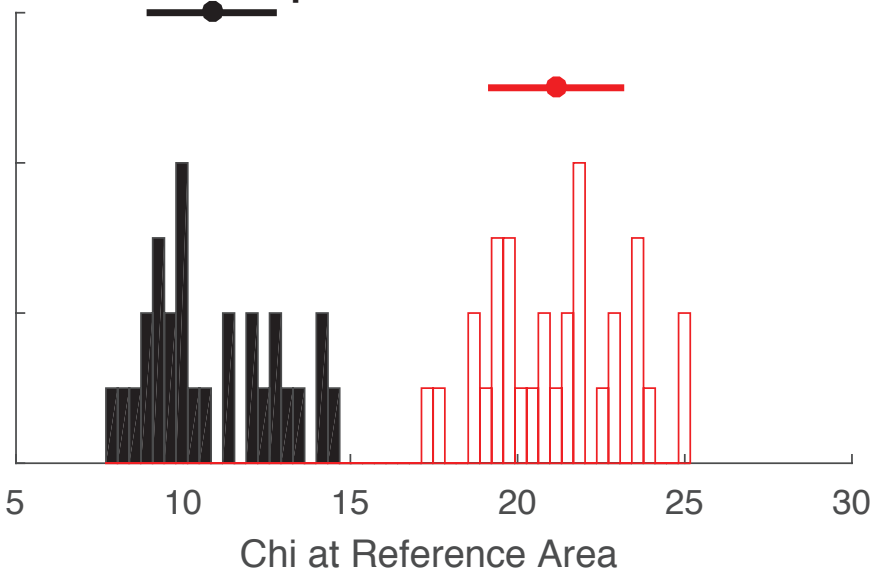

- Mean of Channels Northwest of Divide

- Mean of Channels Southeast of Divide

Elevation: Divide is stable

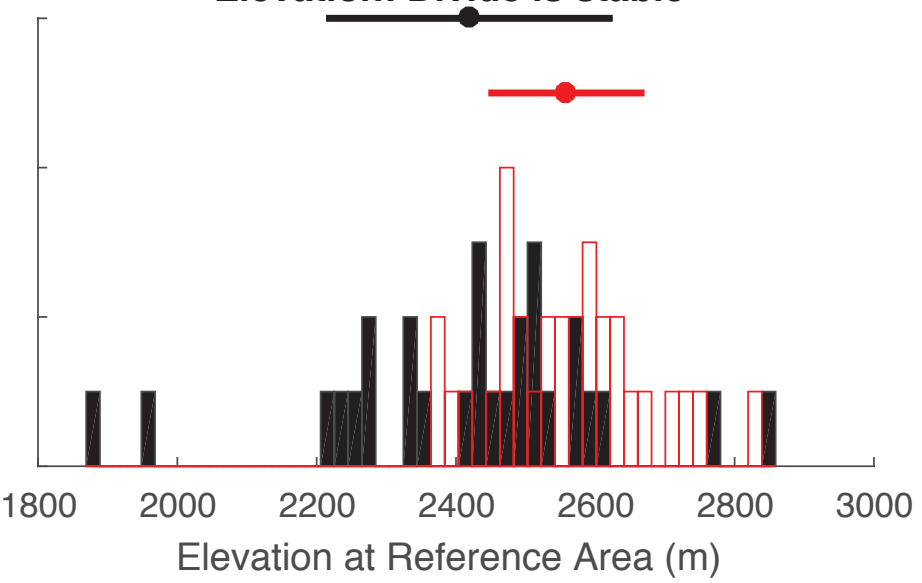

- Mean of Channels Northwest of Divide

- Mean of Channels Southeast of Divide

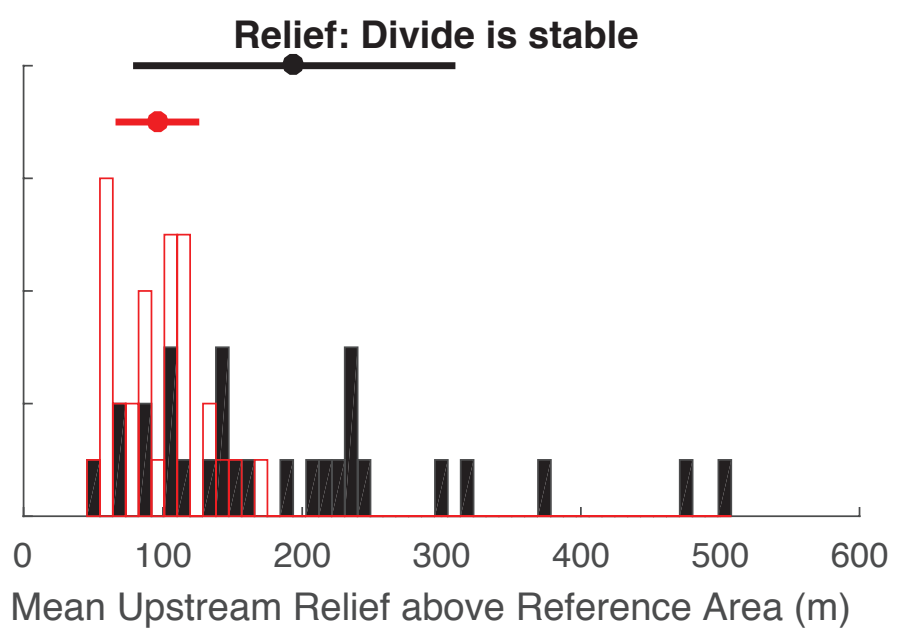

- Mean of Channels Southeast of Divide

\section{Gradient: Divide is stable}

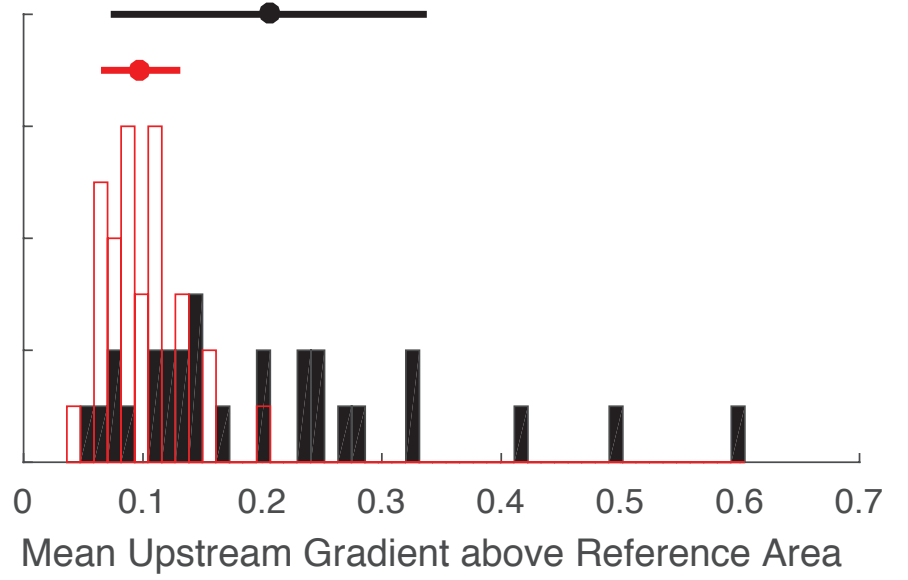

\section{Supplemental Figure 17}




\section{Divide KV1}
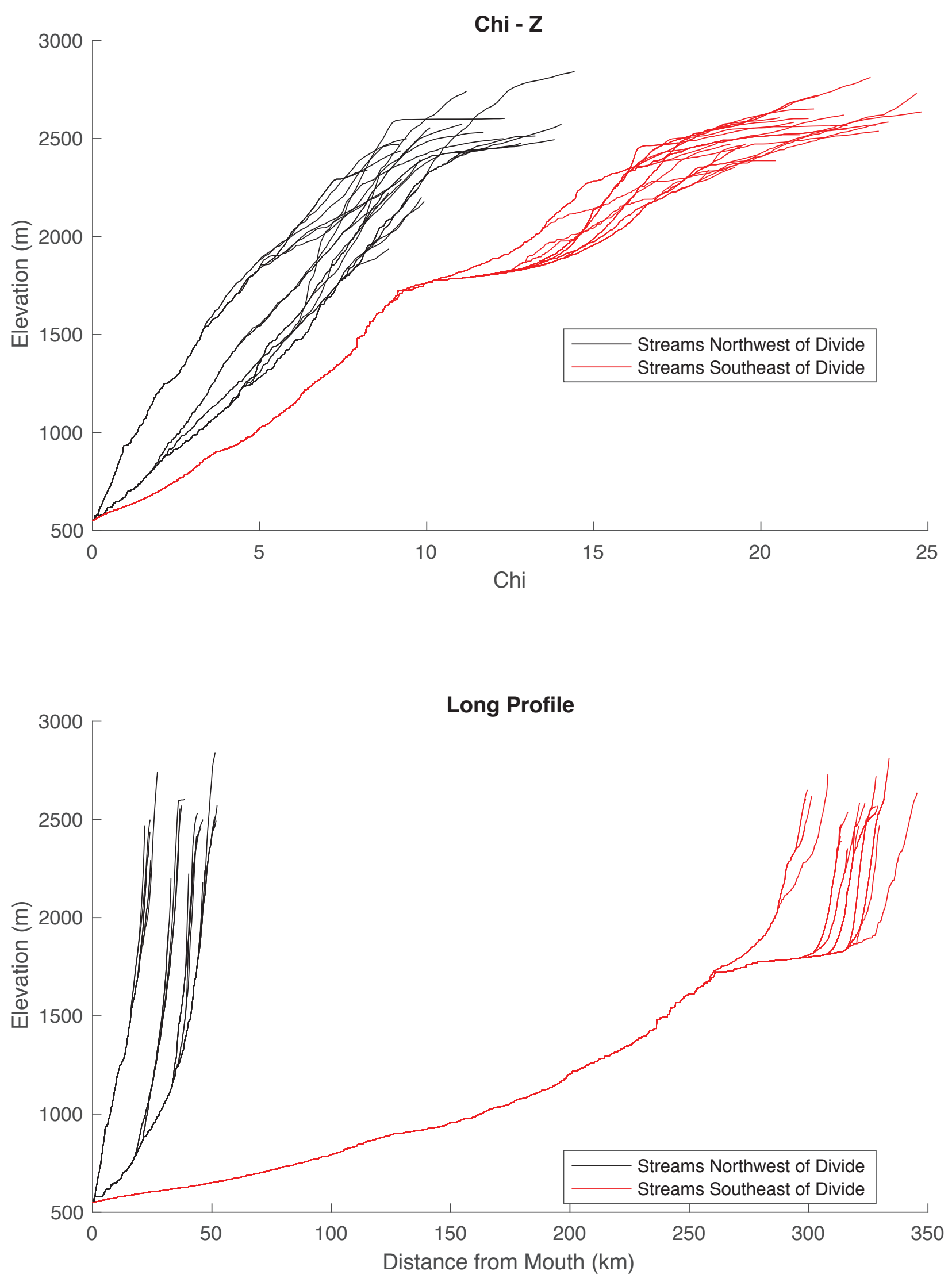


\section{Divide KV2}

- Mean of Channels Southwest of Divide

- Mean of Channels Northeast of Divide

Chi: Divide is predicted to move northeast

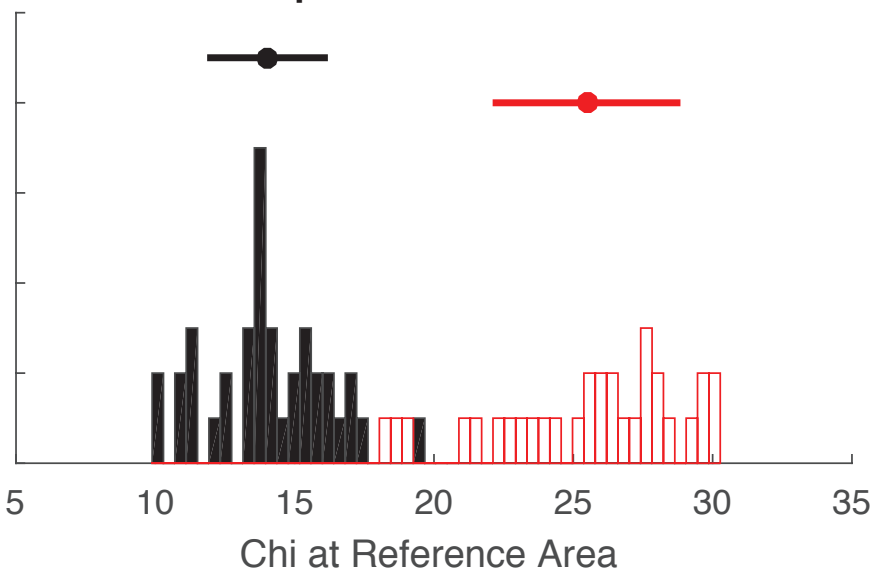

- Mean of Channels Southwest of Divide

- Mean of Channels Northeast of Divide

Elevation: Divide is stable

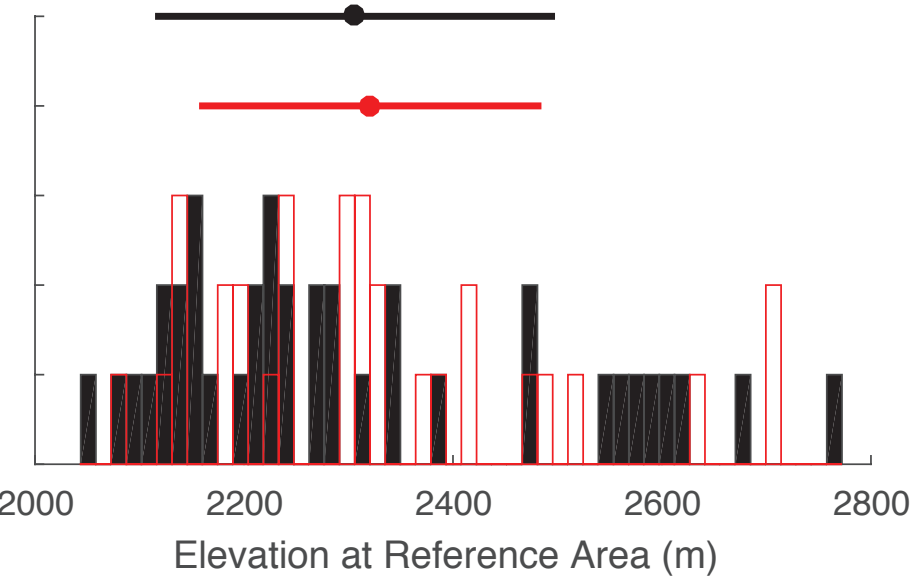

- Mean of Channels Southwest of Divide

- Mean of Channels Northeast of Divide

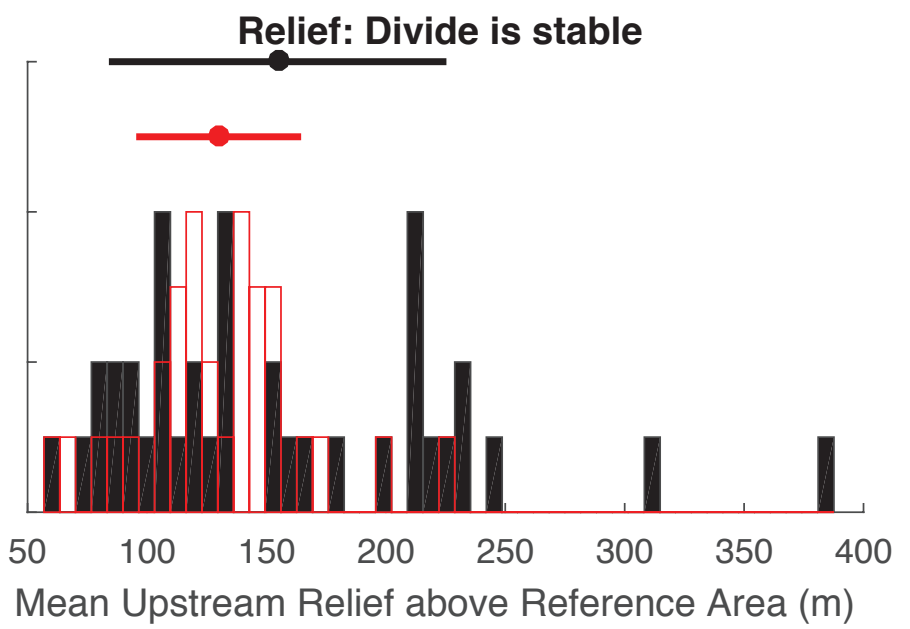

- Mean of Channels Southwest of Divide

- Mean of Channels Northeast of Divide

Gradient: Divide is stable

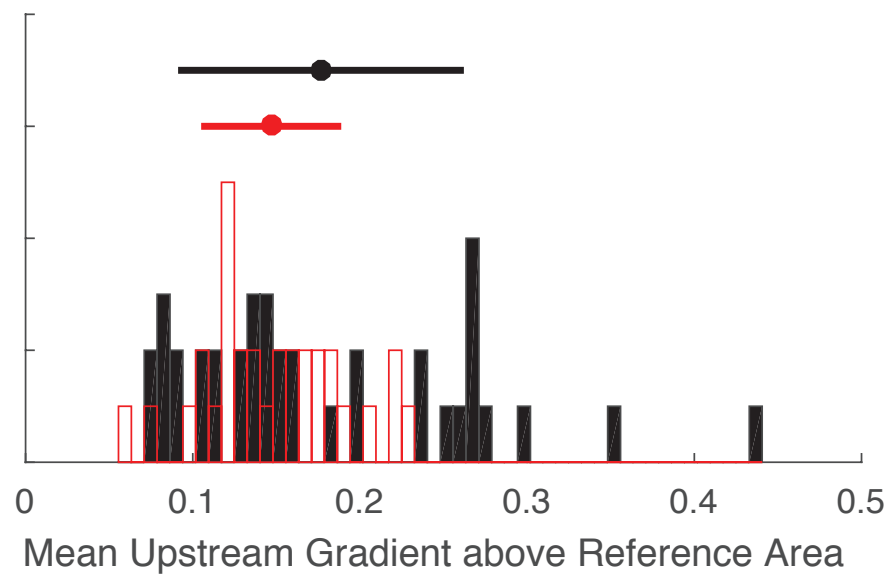

\section{Supplemental Figure 19}




\section{Divide KV2}
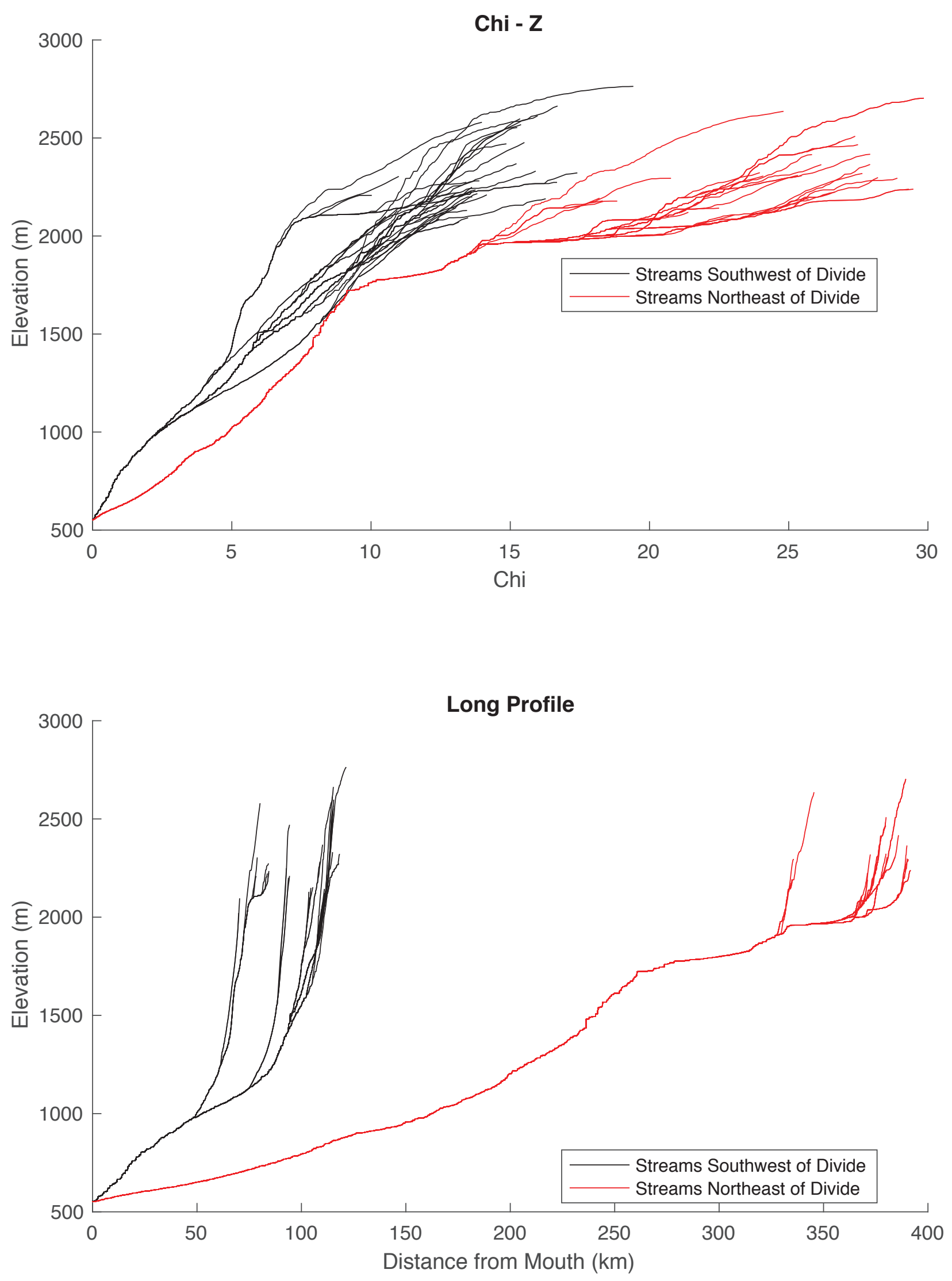

Supplemental Figure 20 


\section{Divide KV3}

- Mean of Channels Northwest of Divide

- Mean of Channels Southeast of Divide

Chi: Divide is predicted to move southeast

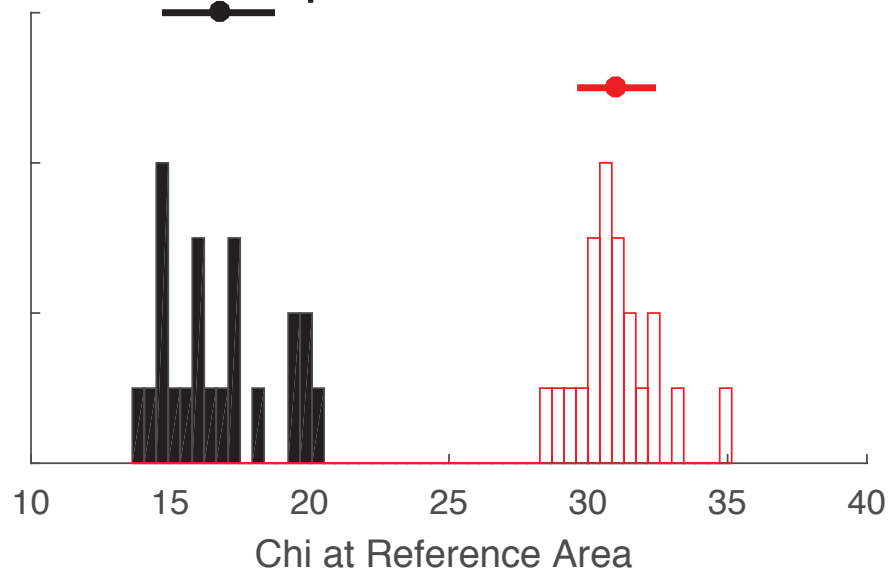

- Mean of Channels Northwest of Divide

- Mean of Channels Southeast of Divide

\section{Elevation: Divide is stable}

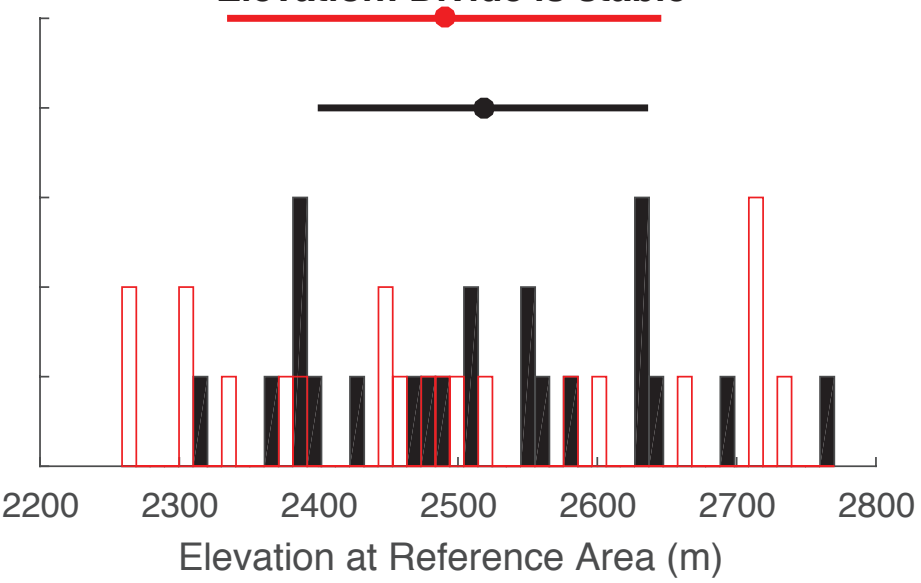

- Mean of Channels Northwest of Divide

- Mean of Channels Southeast of Divide

Relief: Divide is stable

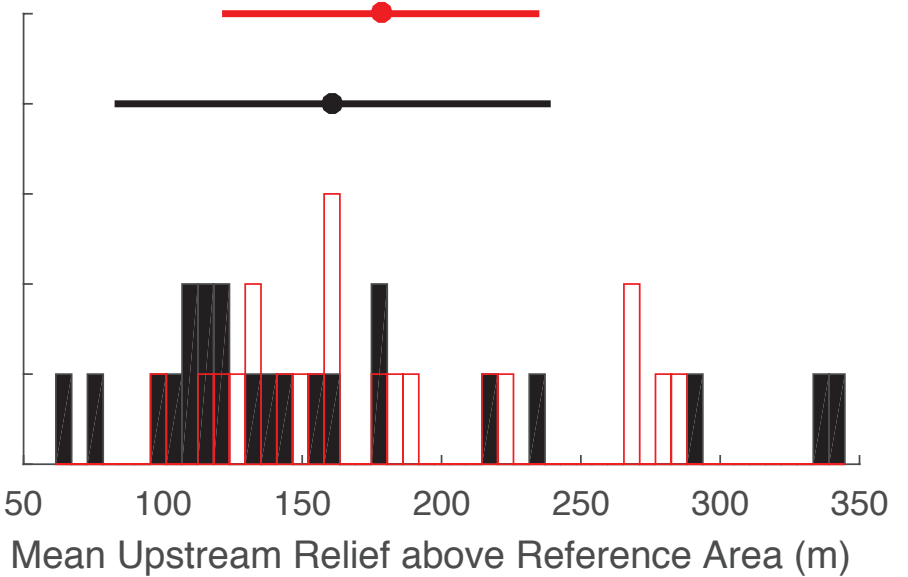

- Mean of Channels Northwest of Divide

- Mean of Channels Southeast of Divide

Gradient: Divide is stable

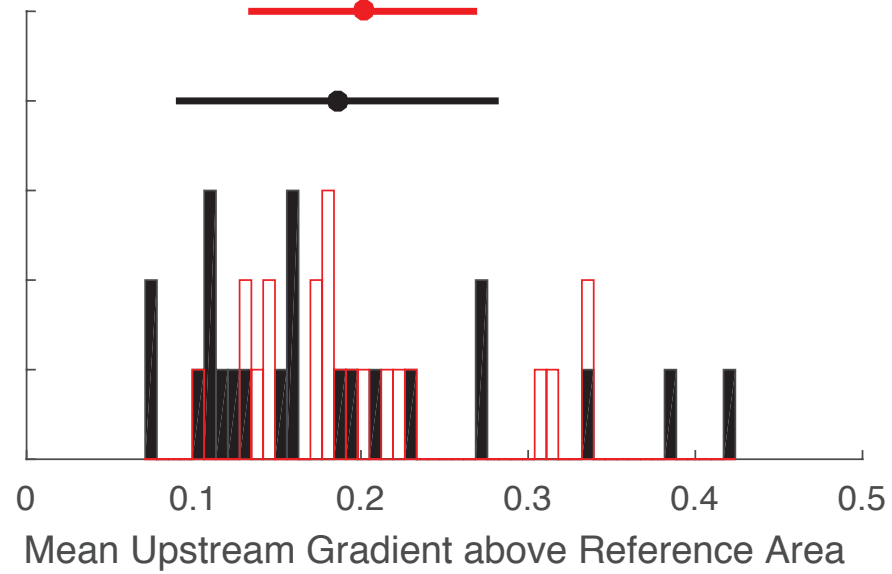

\section{Supplemental Figure 21}




\section{Divide KV3}
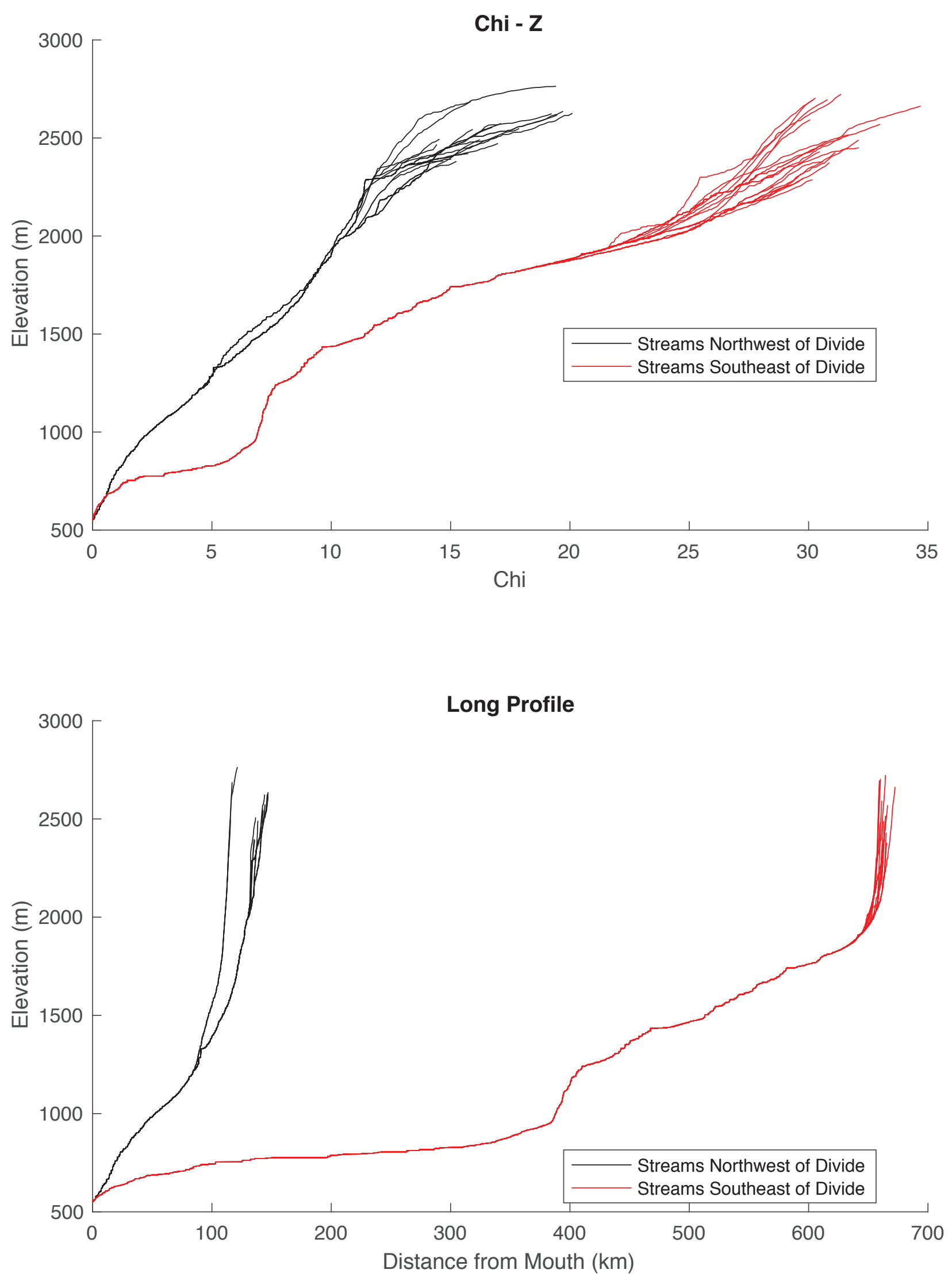

Supplemental Figure 22 


\section{Divide KV4}

- Mean of Channels South of Divide

- Mean of Channels North of Divide

Chi: Divide is predicted to move north

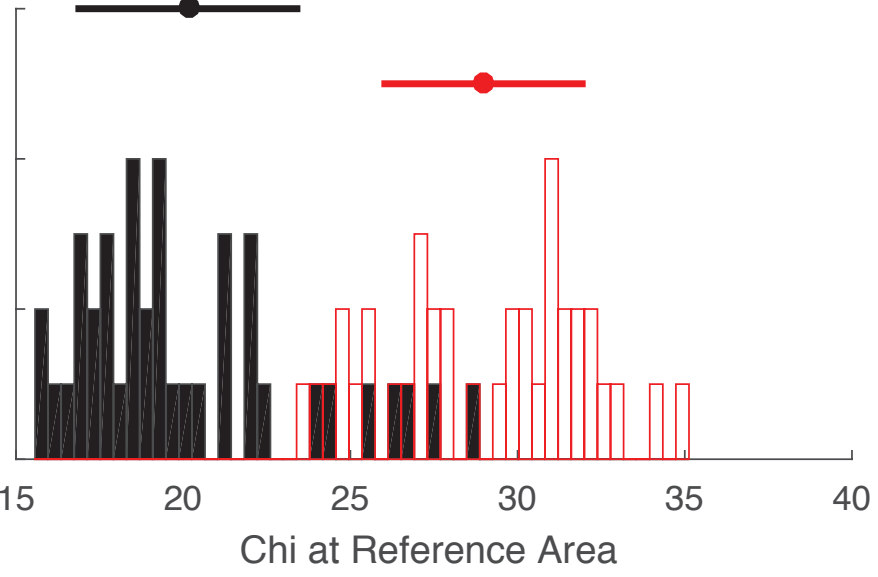

- Mean of Channels South of Divide

- Mean of Channels North of Divide

Elevation: Divide is stable

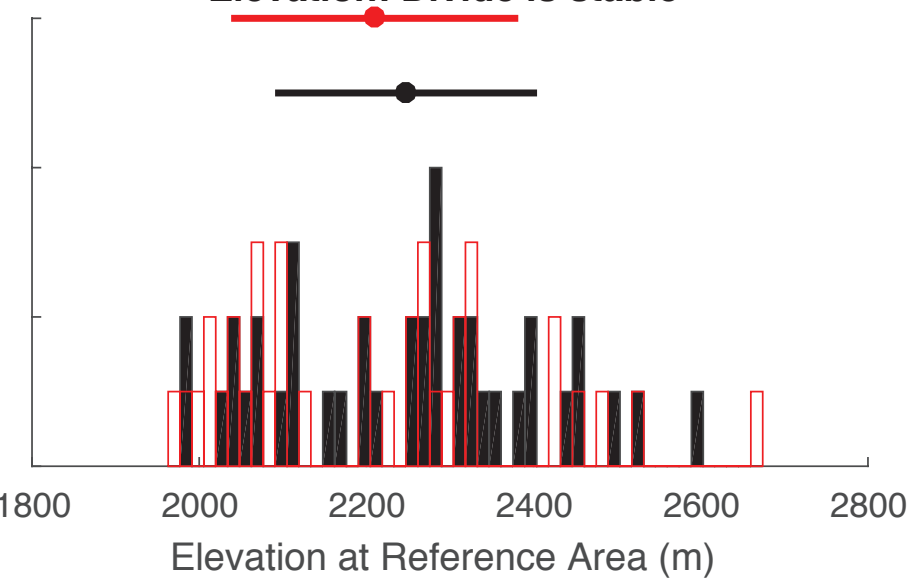

- Mean of Channels South of Divide

- Mean of Channels North of Divide

Relief: Divide is stable

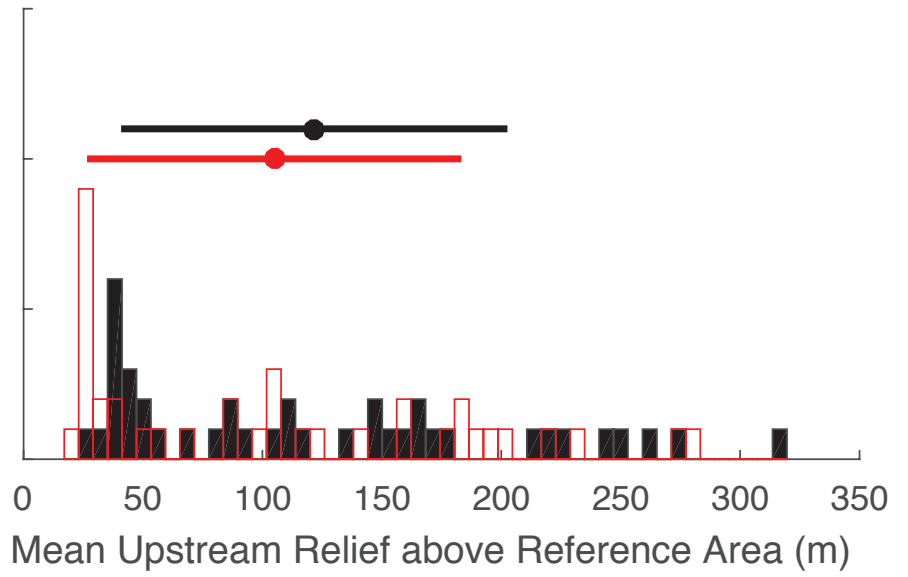

- Mean of Channels South of Divide

- Mean of Channels North of Divide

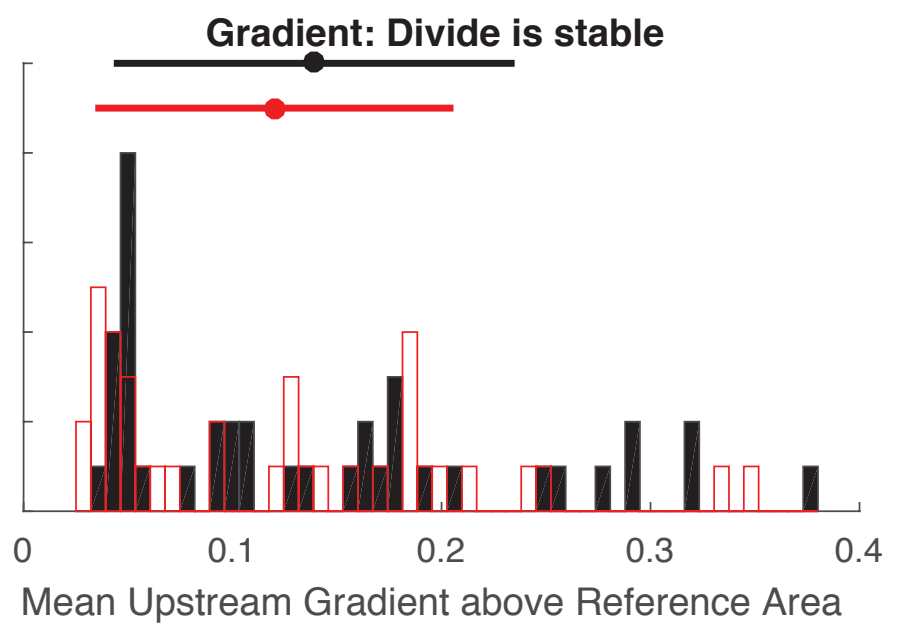

Supplemental Figure 23 


\section{Divide KV4}
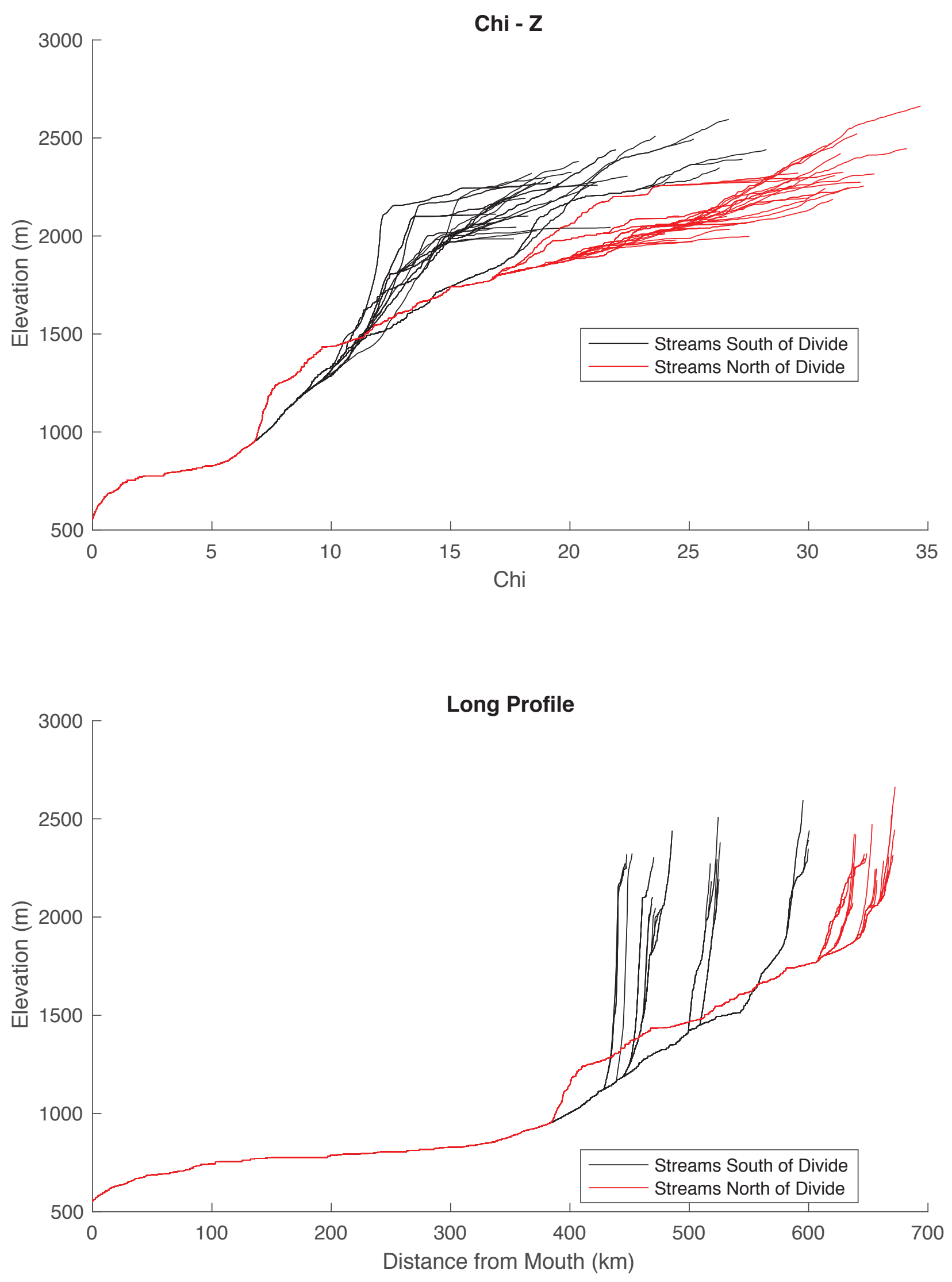

Supplemental Figure 24 


\section{Divide KV5}

- Mean of Channels Southwest of Divide

- Mean of Channels Northeast of Divide

Chi: Divide is predicted to move southwest

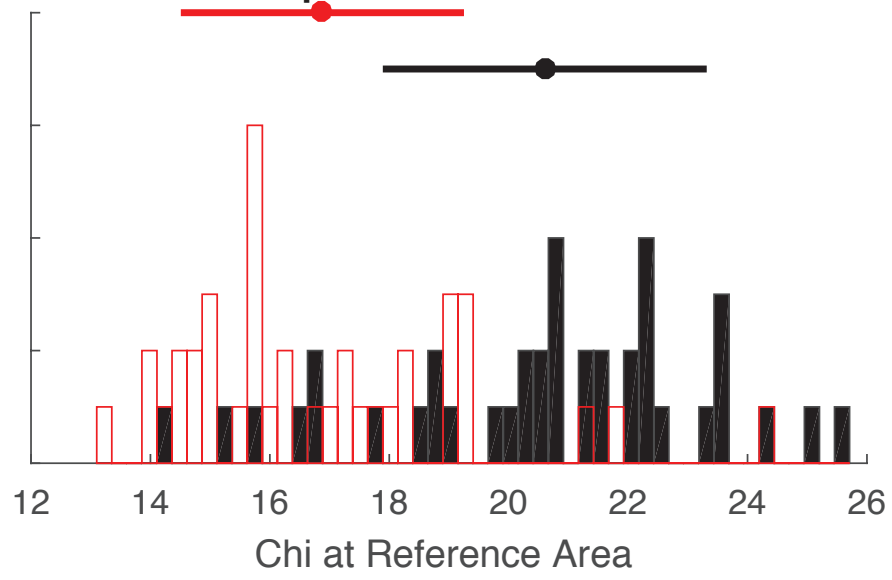

- Mean of Channels Southwest of Divide

- Mean of Channels Northeast of Divide

Elevation: Divide is stable

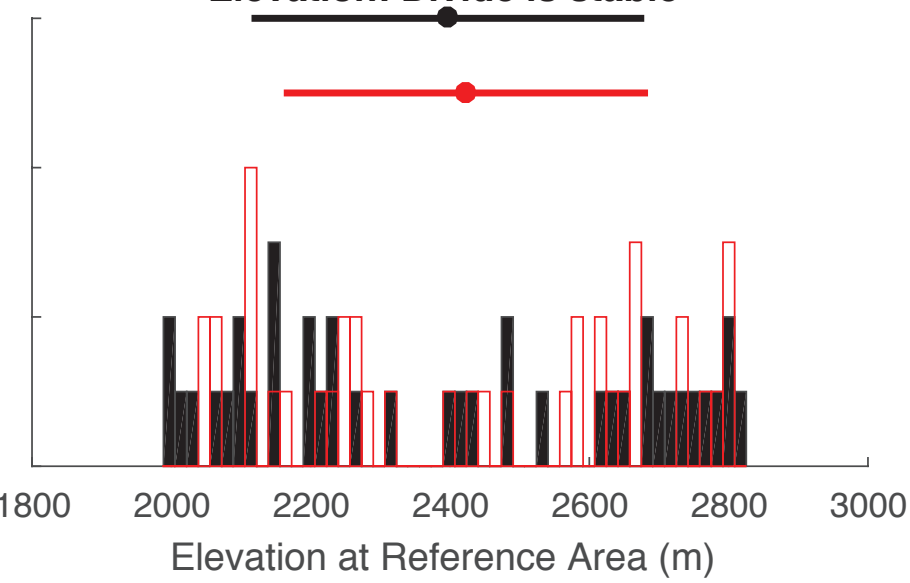

- Mean of Channels Southwest of Divide

- Mean of Channels Northeast of Divide

Relief: Divide is stable

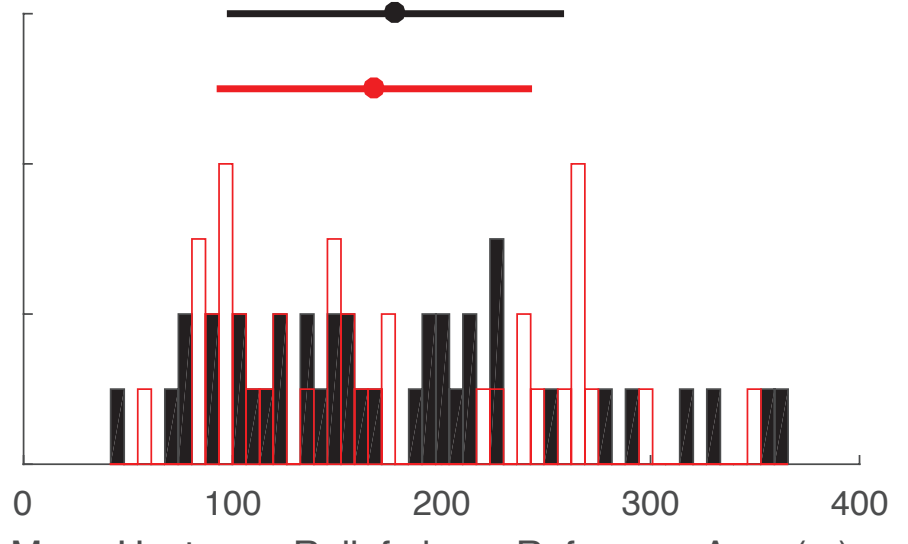

Mean Upstream Relief above Reference Area (m)

- Mean of Channels Northeast of Divide

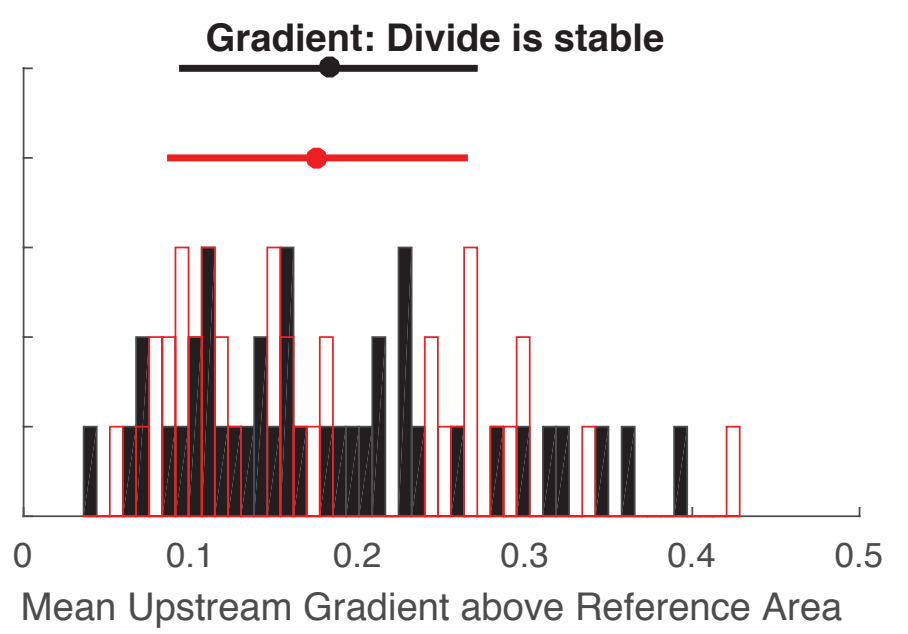

\section{Supplemental Figure 25}




\section{Divide KV5}
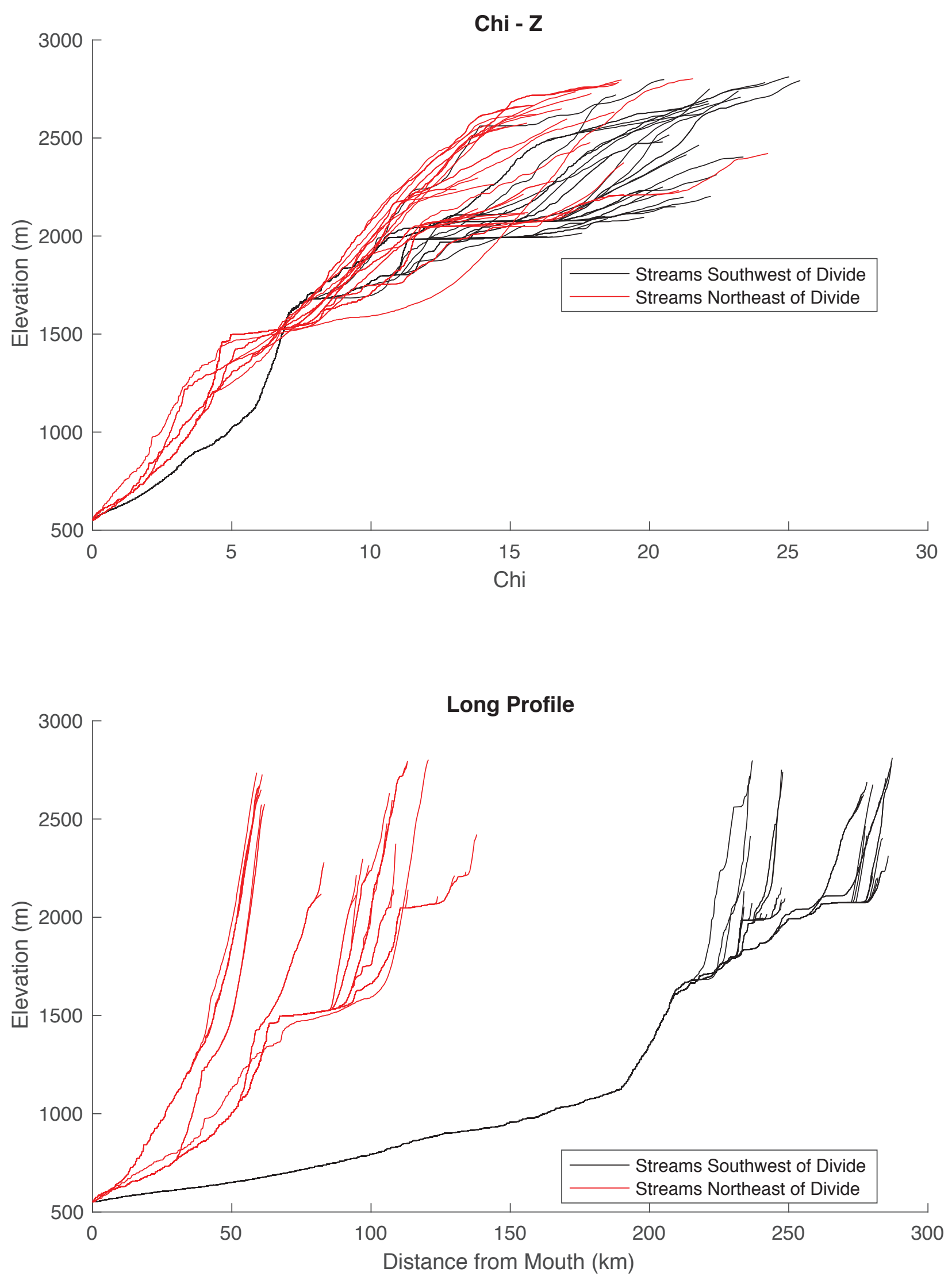

Supplemental Figure 26 


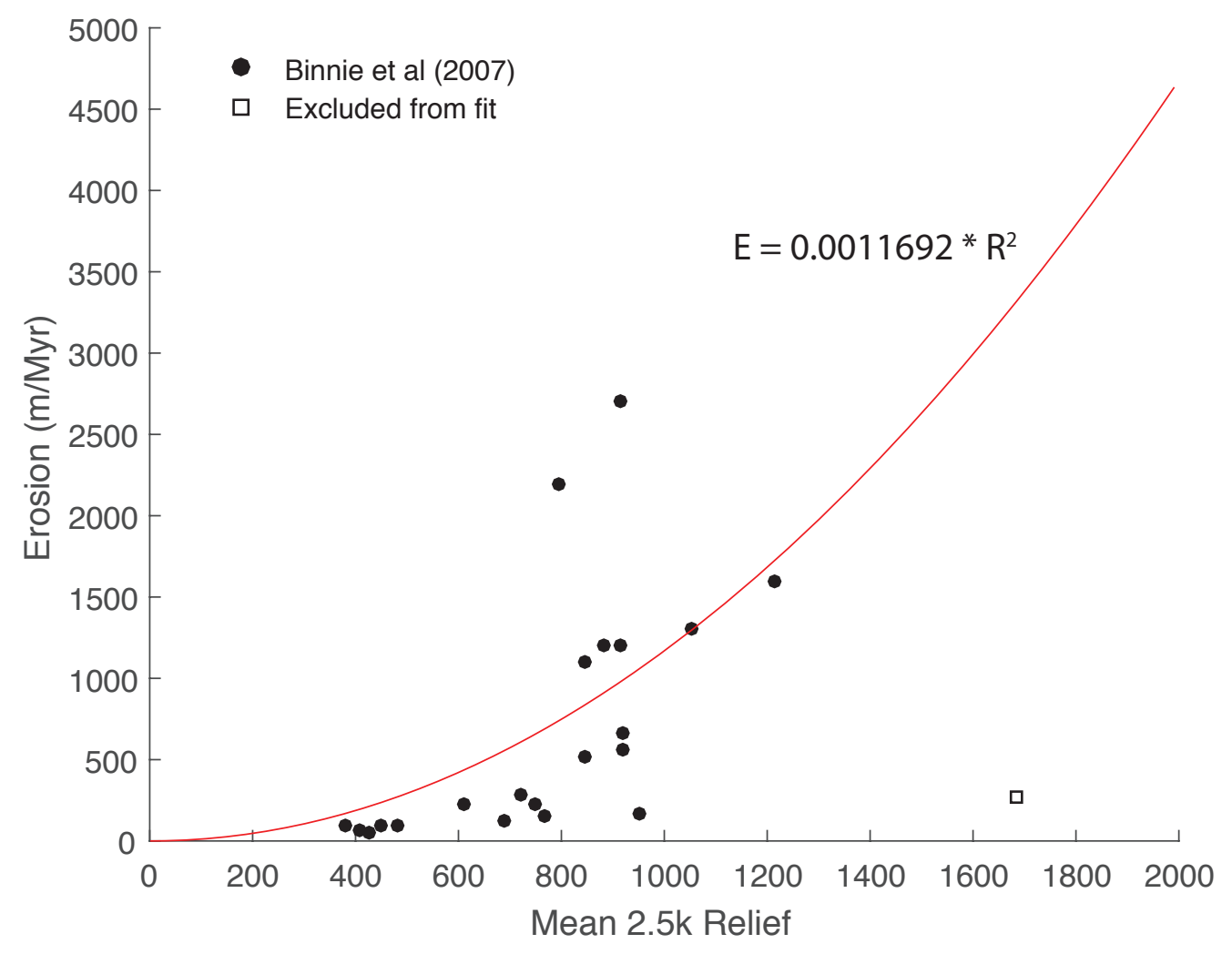

Supplemental Figure 27 


\section{Divide SB 1}

- Mean of Channels South of Divide

- Mean of Channels North of Divide

Chi: Divide is predicted to move north

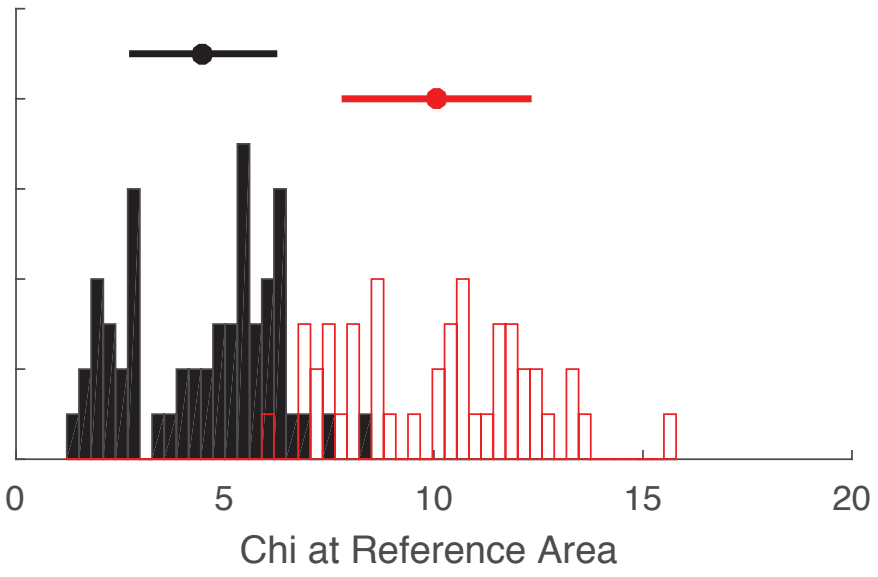

- Mean of Channels South of Divide

- Mean of Channels North of Divide

Elevation: Divide is stable

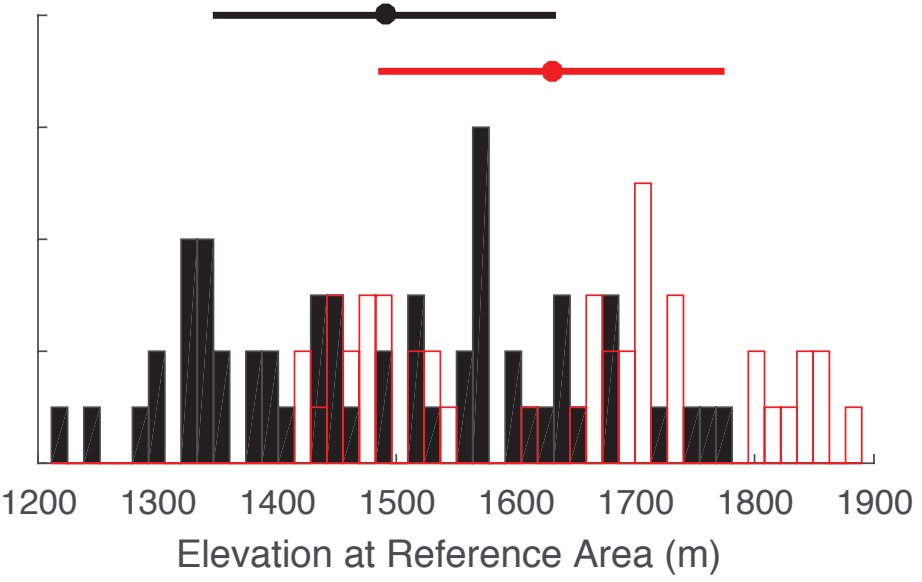

- Mean of Channels South of Divide

- Mean of Channels North of Divide

Relief: Divide is predicted to move north

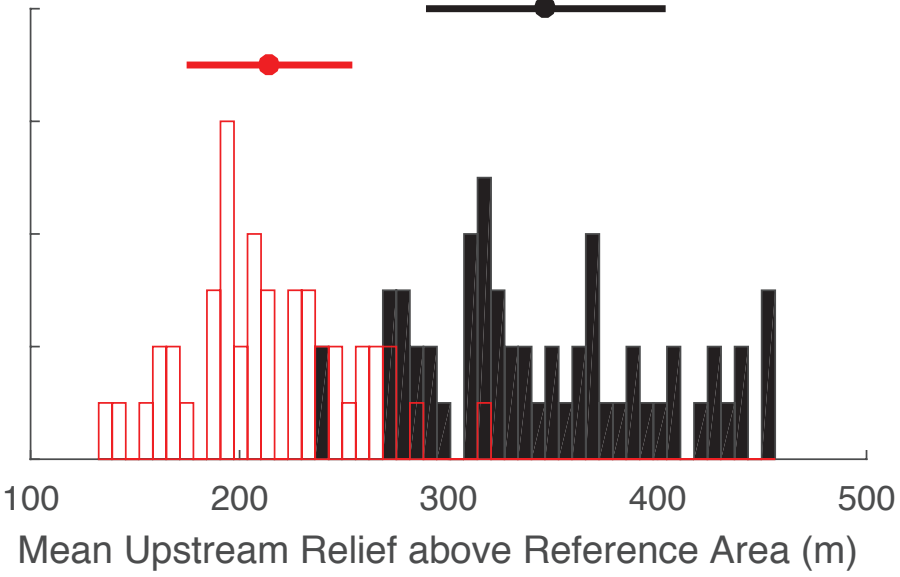

- Mean of Channels South of Divide

- Mean of Channels North of Divide

Gradient: Divide is predicted to move north

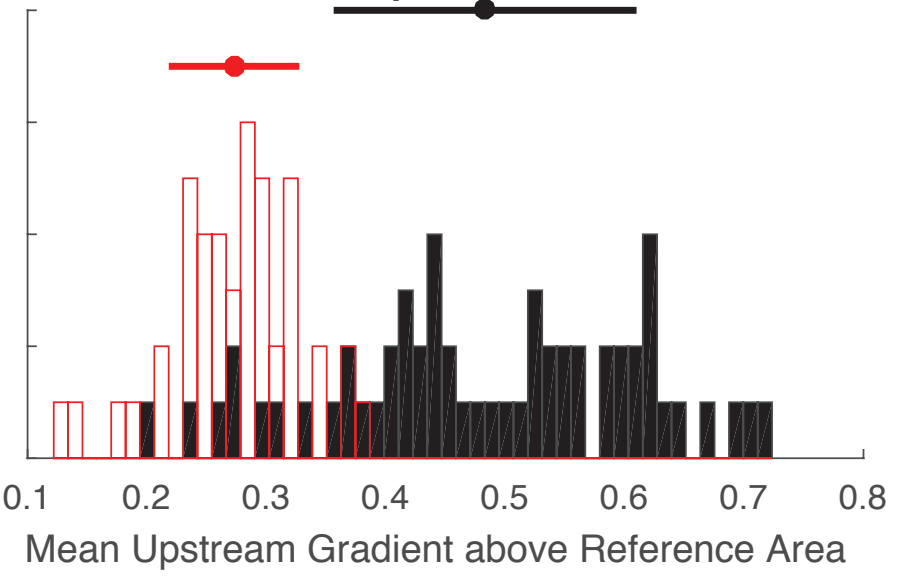

Supplemental Figure 28 
Divide SB 1
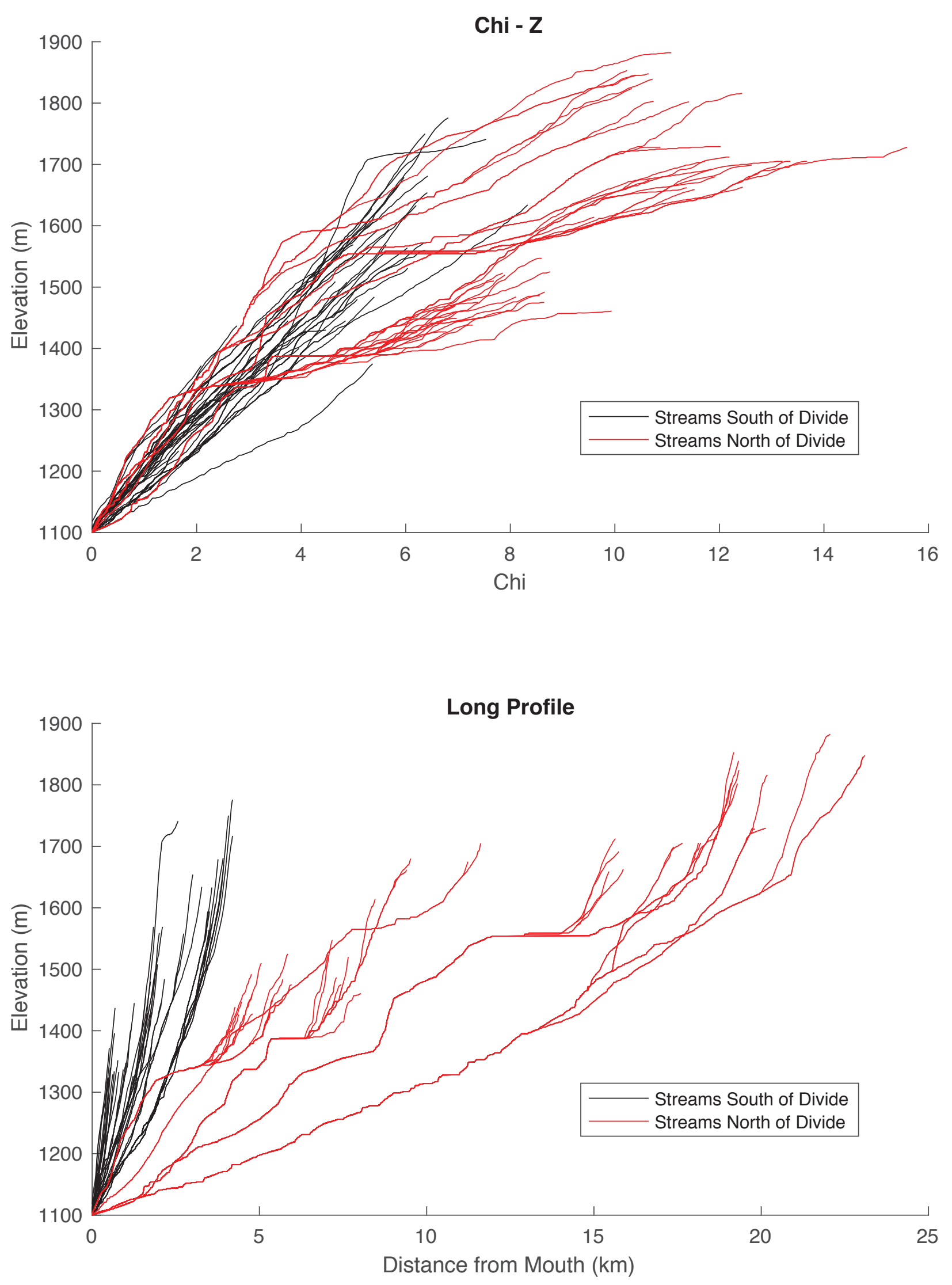


\section{Divide SB2}

- Mean of Channels Southwest of Divide

- Mean of Channels Northeast of Divide

Chi: Divide is predicted to move northeast

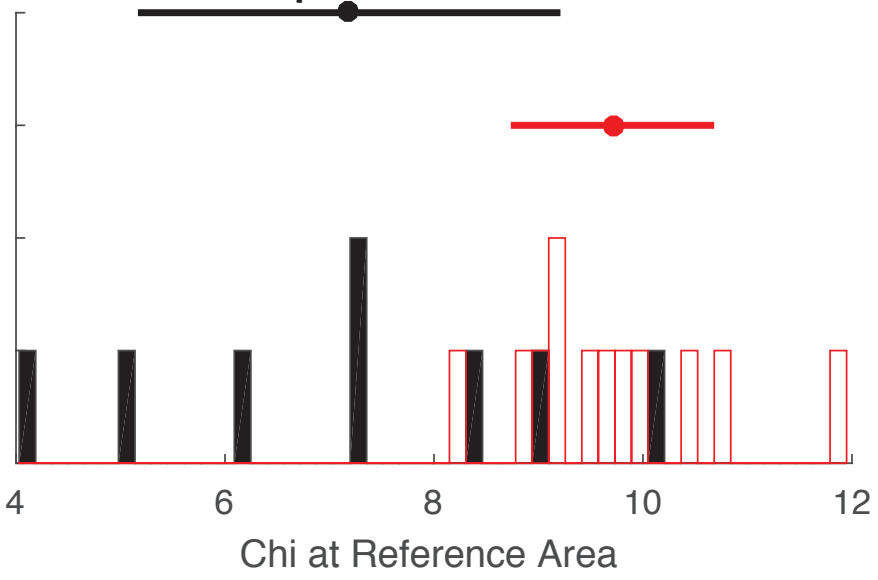

- Mean of Channels Northeast of Divide

\section{Elevation: Divide is stable}

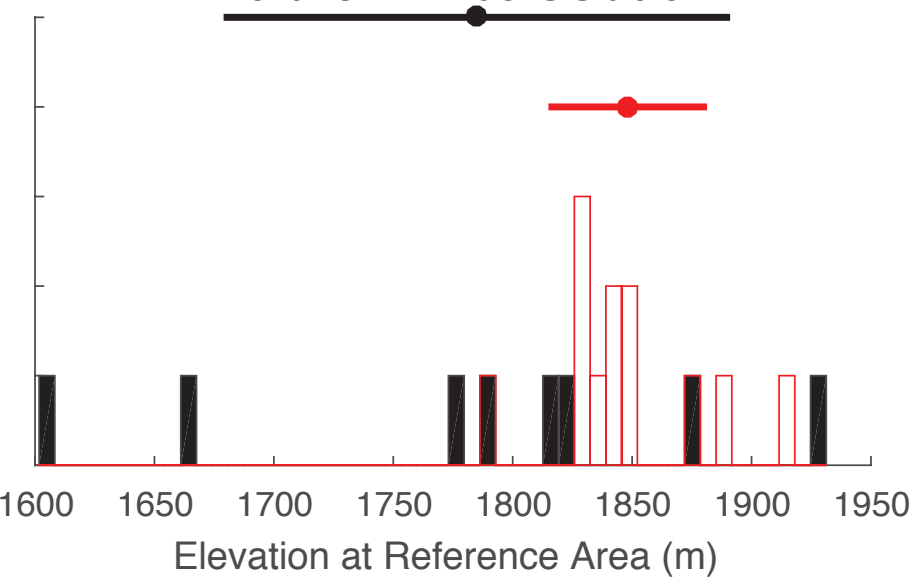

- Mean of Channels Southwest of Divide

- Mean of Channels Northeast of Divide

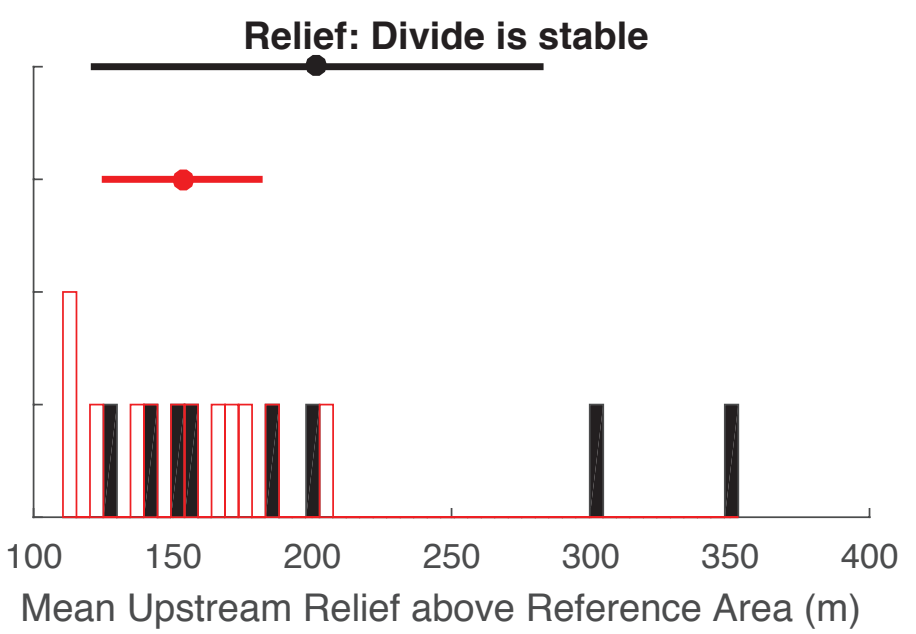

- Mean of Channels Southwest of Divide

- Mean of Channels Northeast of Divide

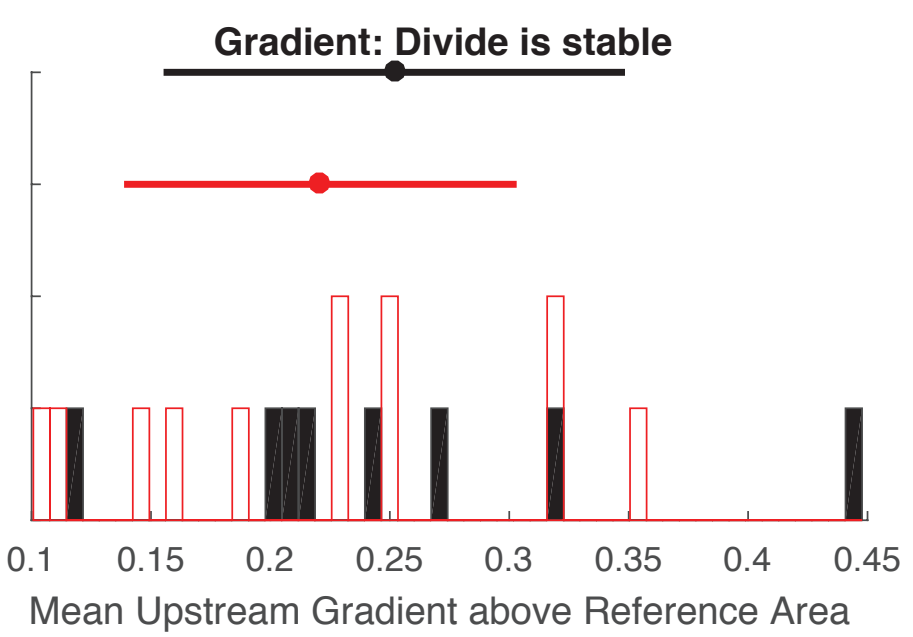

\section{Supplemental Figure 30}


Divide SB2
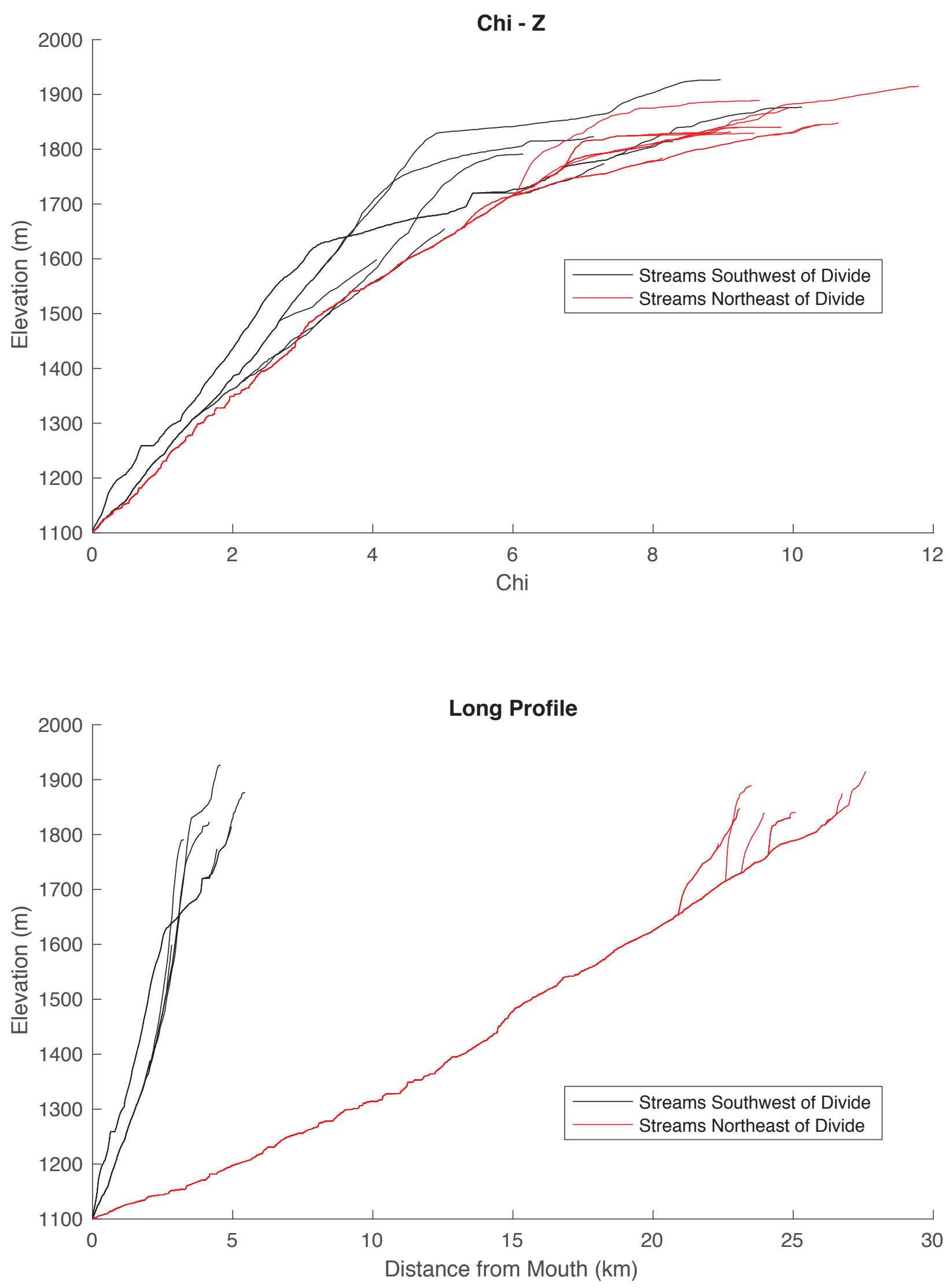

Supplemental Figure 31 


\section{Divide SB3}

- Mean of Channels Southeast of Divide

- Mean of Channels Northwest of Divide

Chi: Divide is predicted to move northwest

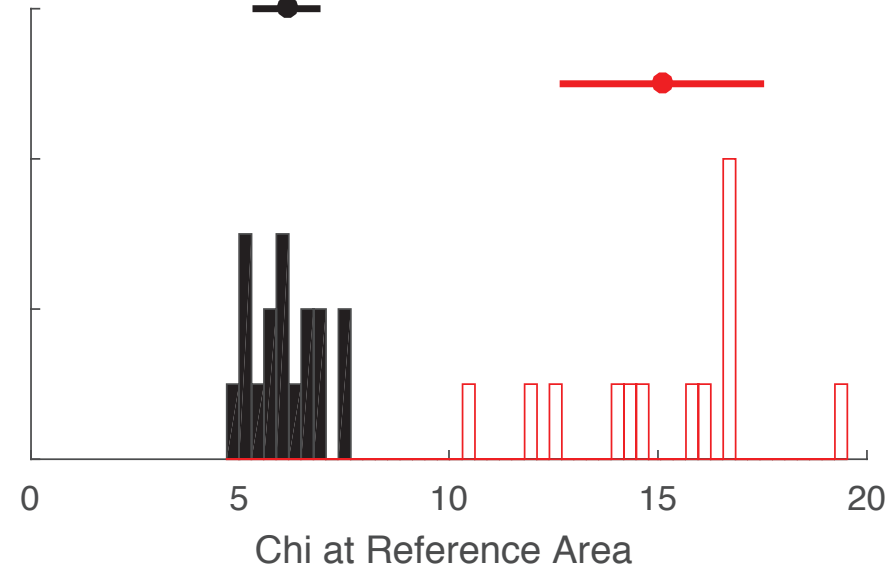

- Mean of Channels Southeast of Divide

- Mean of Channels Northwest of Divide

Elevation: Divide is predicted to move northwest

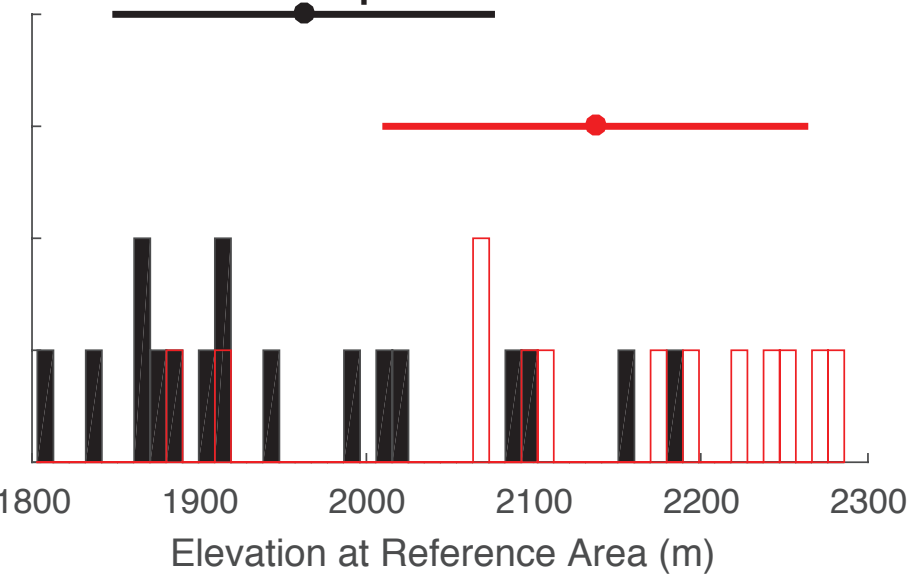

- Mean of Channels Southeast of Divide

- Mean of Channels Northwest of Divide

Relief: Divide is predicted to move northwest

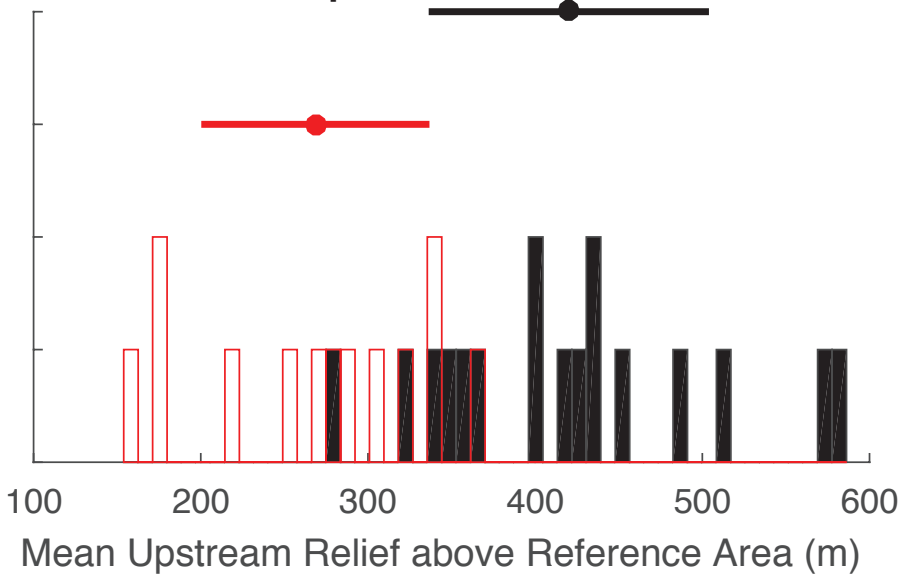

- Mean of Channels Southeast of Divide

- Mean of Channels Northwest of Divide

Gradient: Divide is predicted to move northwest

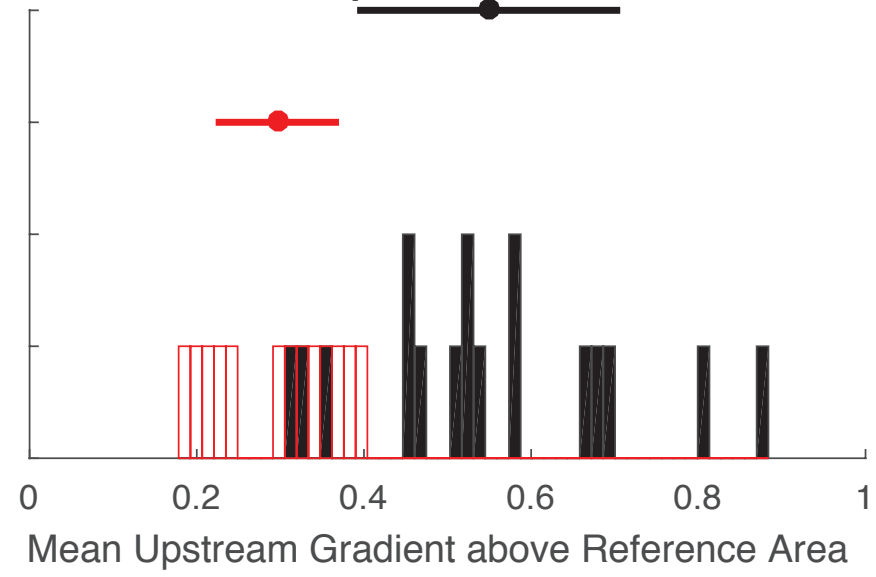

\section{Supplemental Figure 32}


Divide SB3
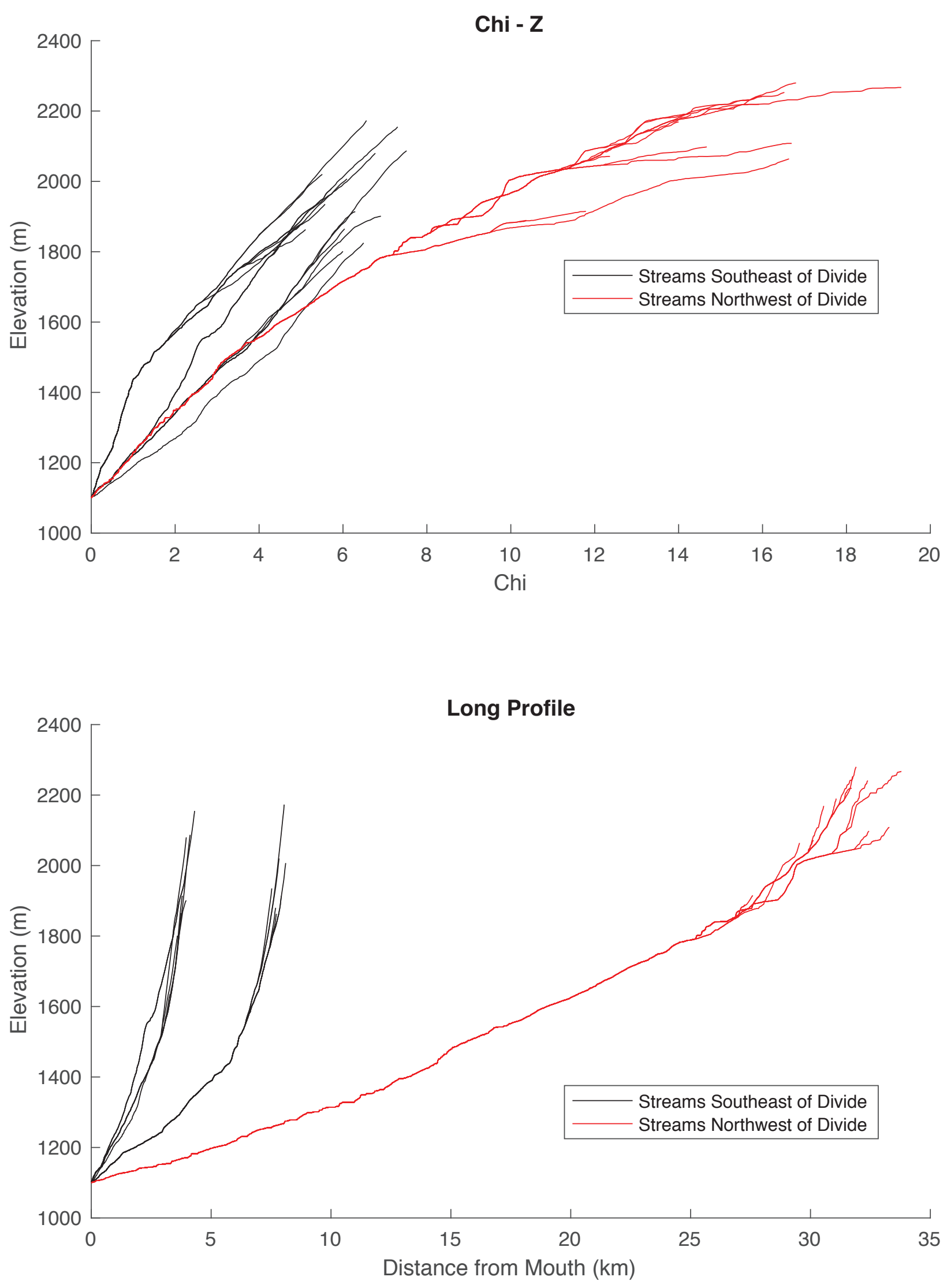

Supplemental Figure 33 


\section{Divide SB4}

- Mean of Channels South of Divide

- Mean of Channels North of Divide

Chi: Divide is predicted to move north

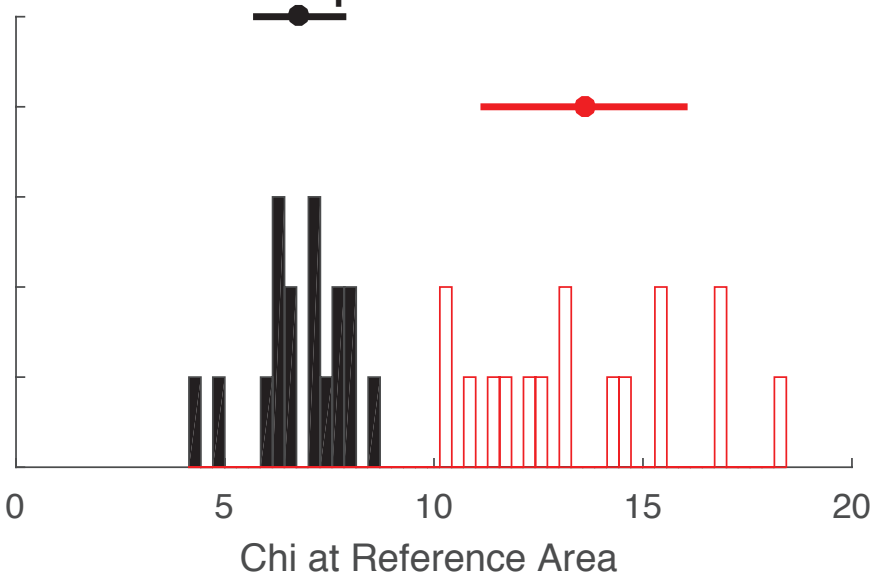

- Mean of Channels South of Divide

- Mean of Channels North of Divide

Elevation: Divide is predicted to move north

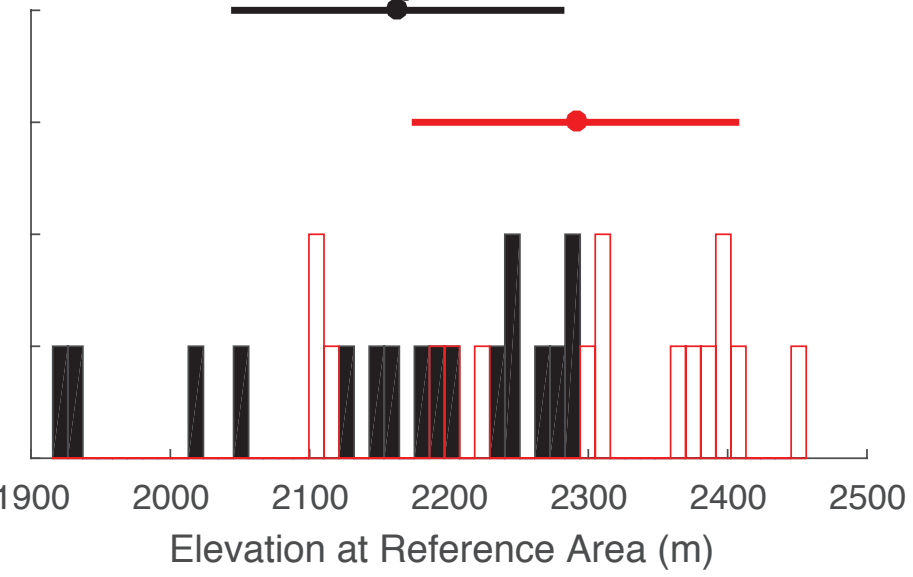

- Mean of Channels South of Divide

- Mean of Channels North of Divide

Relief: Divide is predicted to move north

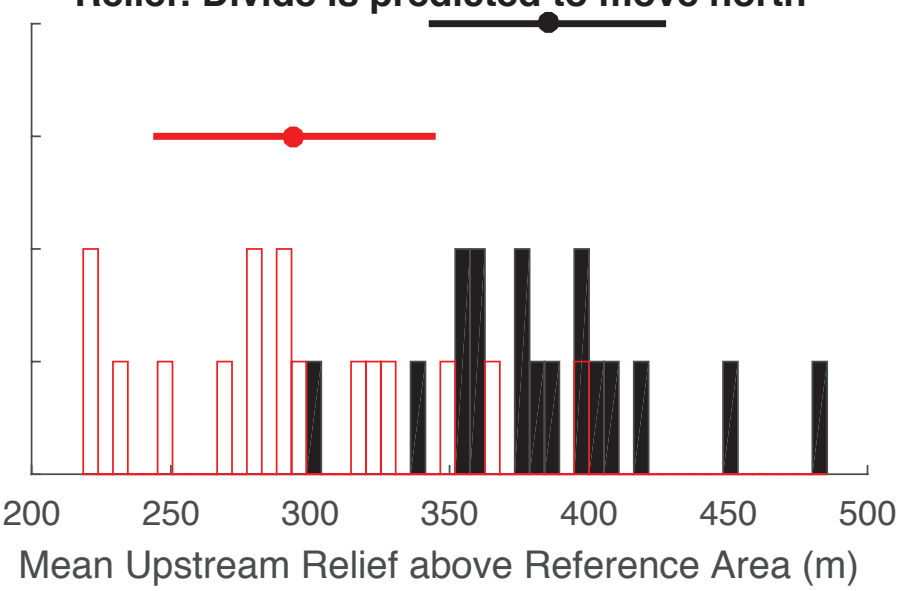

- Mean of Channels South of Divide

- Mean of Channels North of Divide

Gradient: Divide is predicted to move north

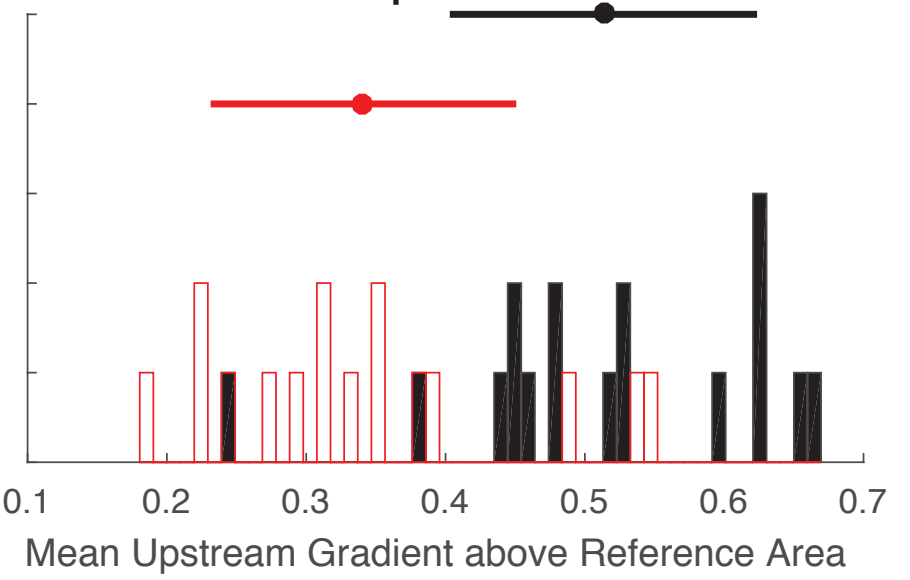

Supplemental Figure 34 


\section{Divide SB4}
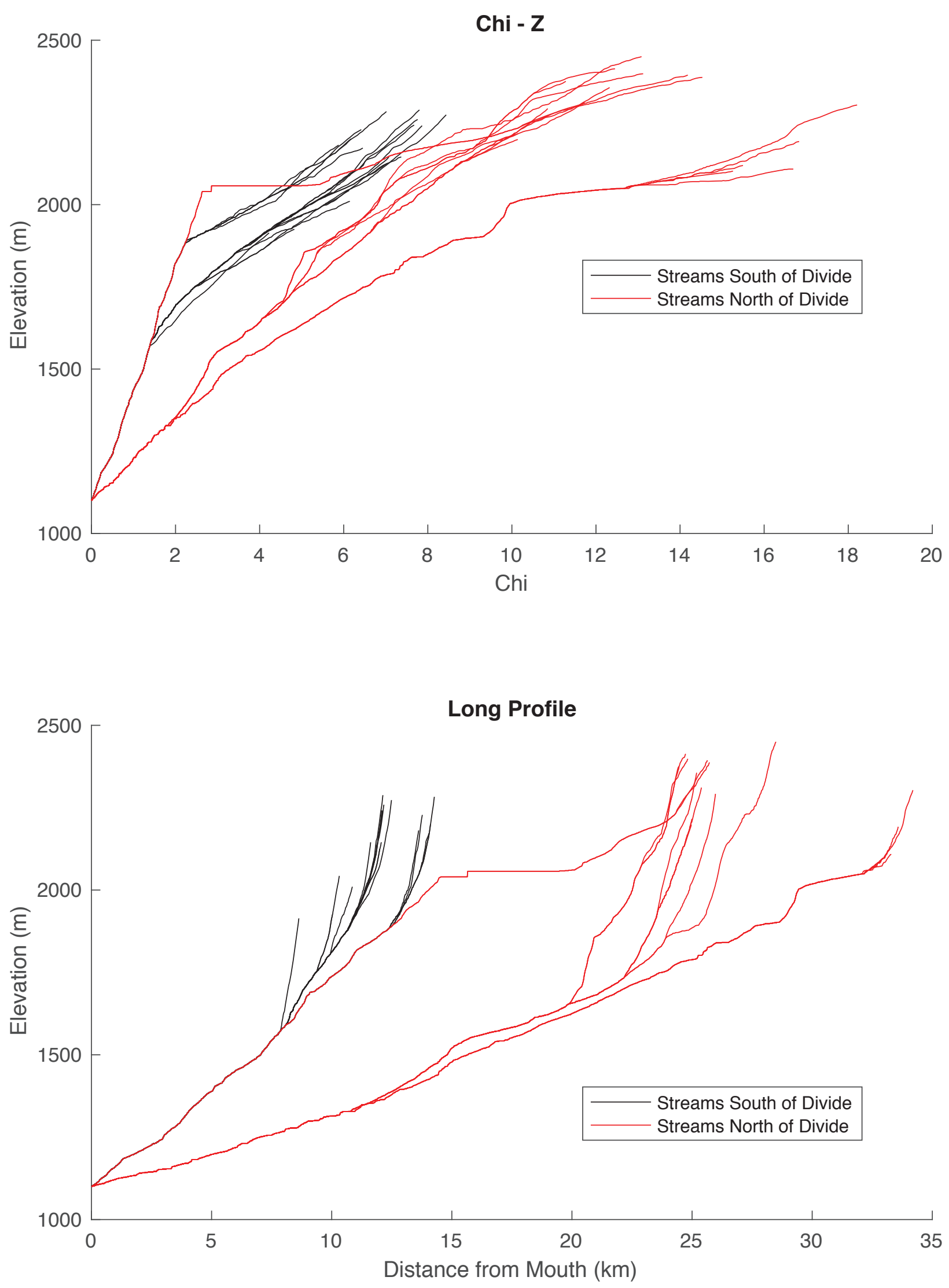

Supplemental Figure 35 


\section{Divide SB5}

- Mean of Channels South of Divide

- Mean of Channels North of Divide

Chi: Divide is stable

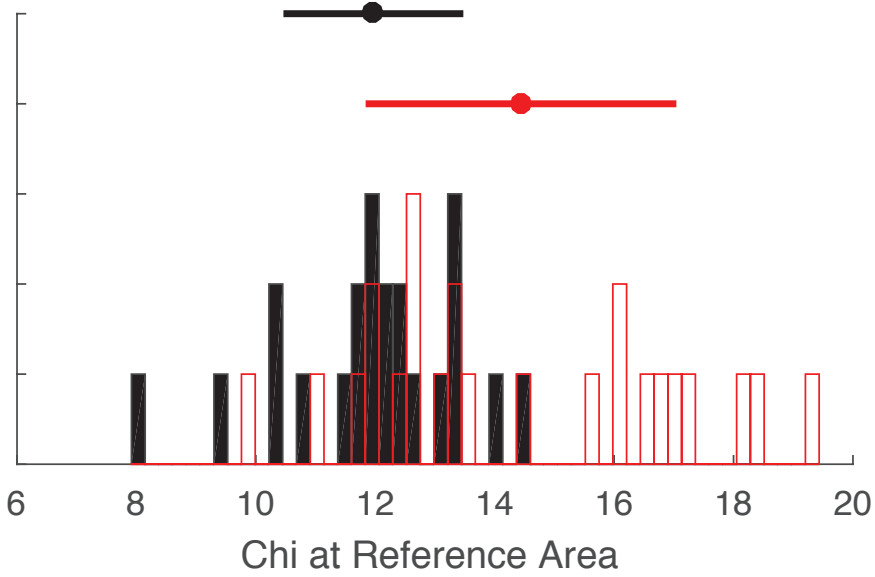

- Mean of Channels South of Divide

- Mean of Channels North of Divide

Elevation: Divide is stable

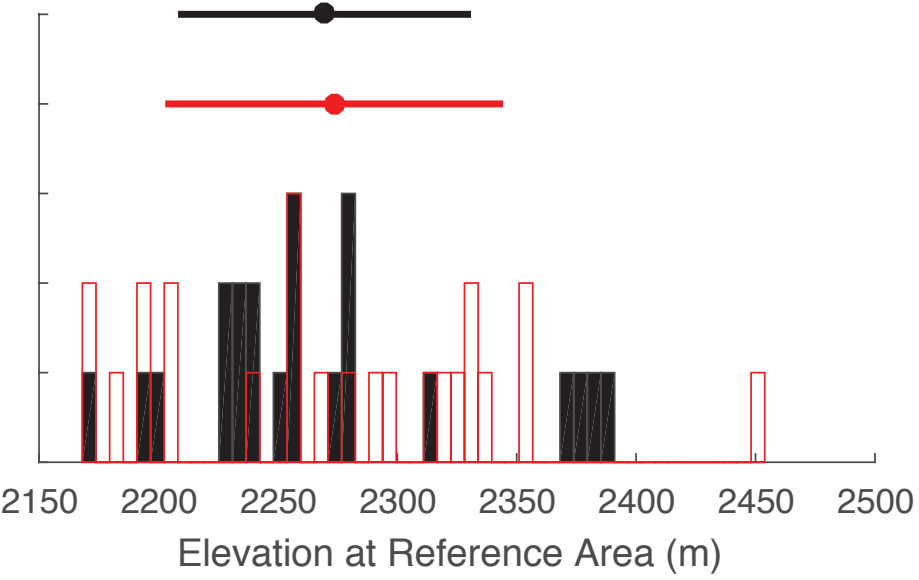

- Mean of Channels South of Divide

- Mean of Channels North of Divide

Relief: Divide is stable

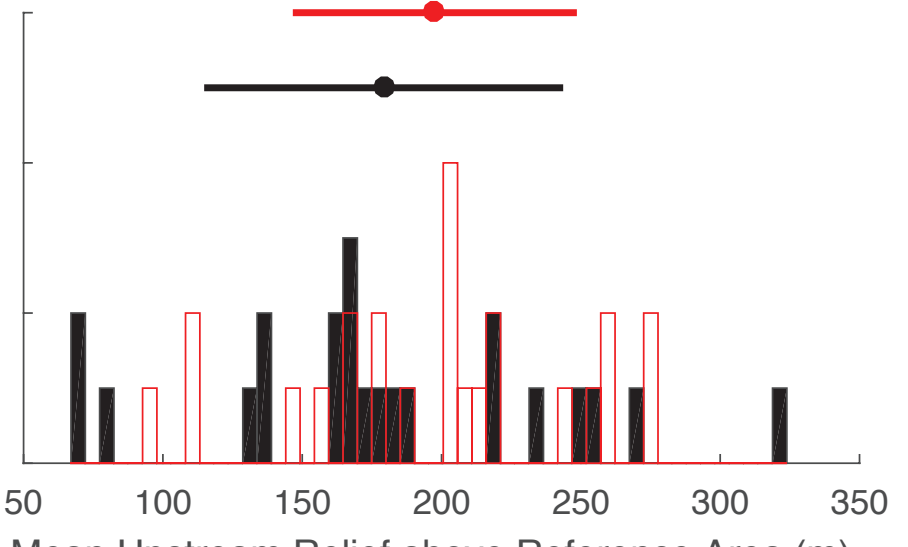

Mean Upstream Relief above Reference Area (m)

- Mean of Channels South of Divide

- Mean of Channels North of Divide

Gradient: Divide is stable

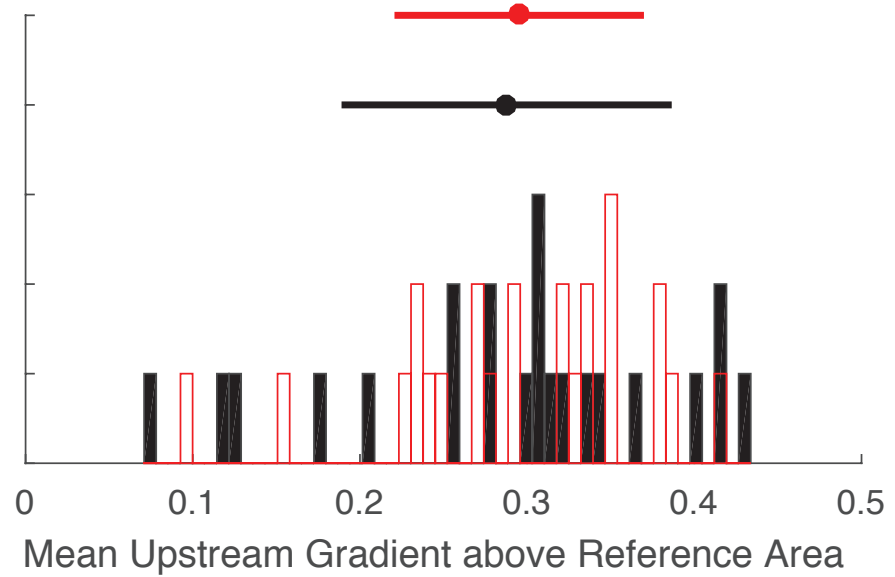

Supplemental Figure 36 


\section{Divide SB5}
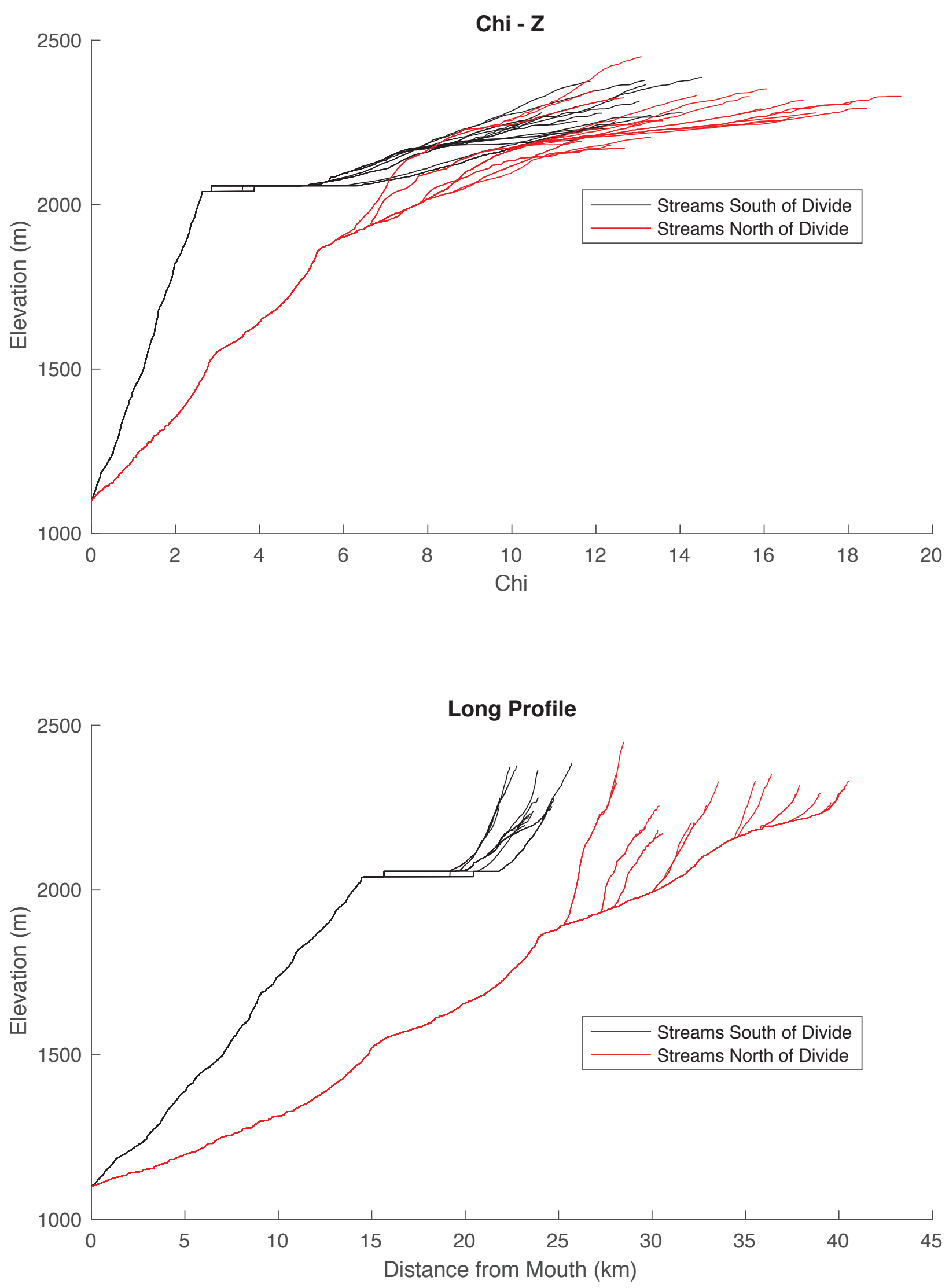


\section{Divide SB6}
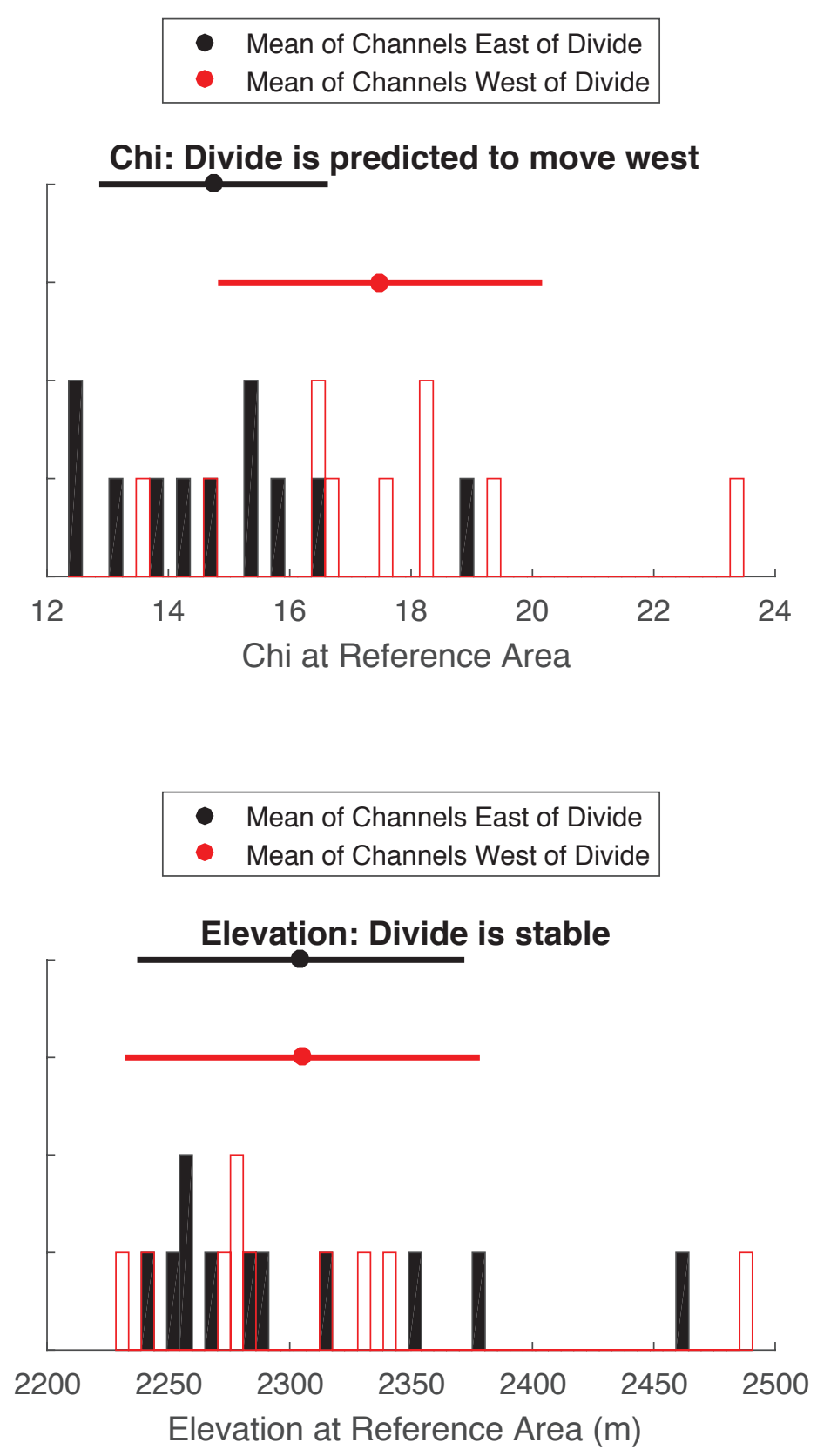

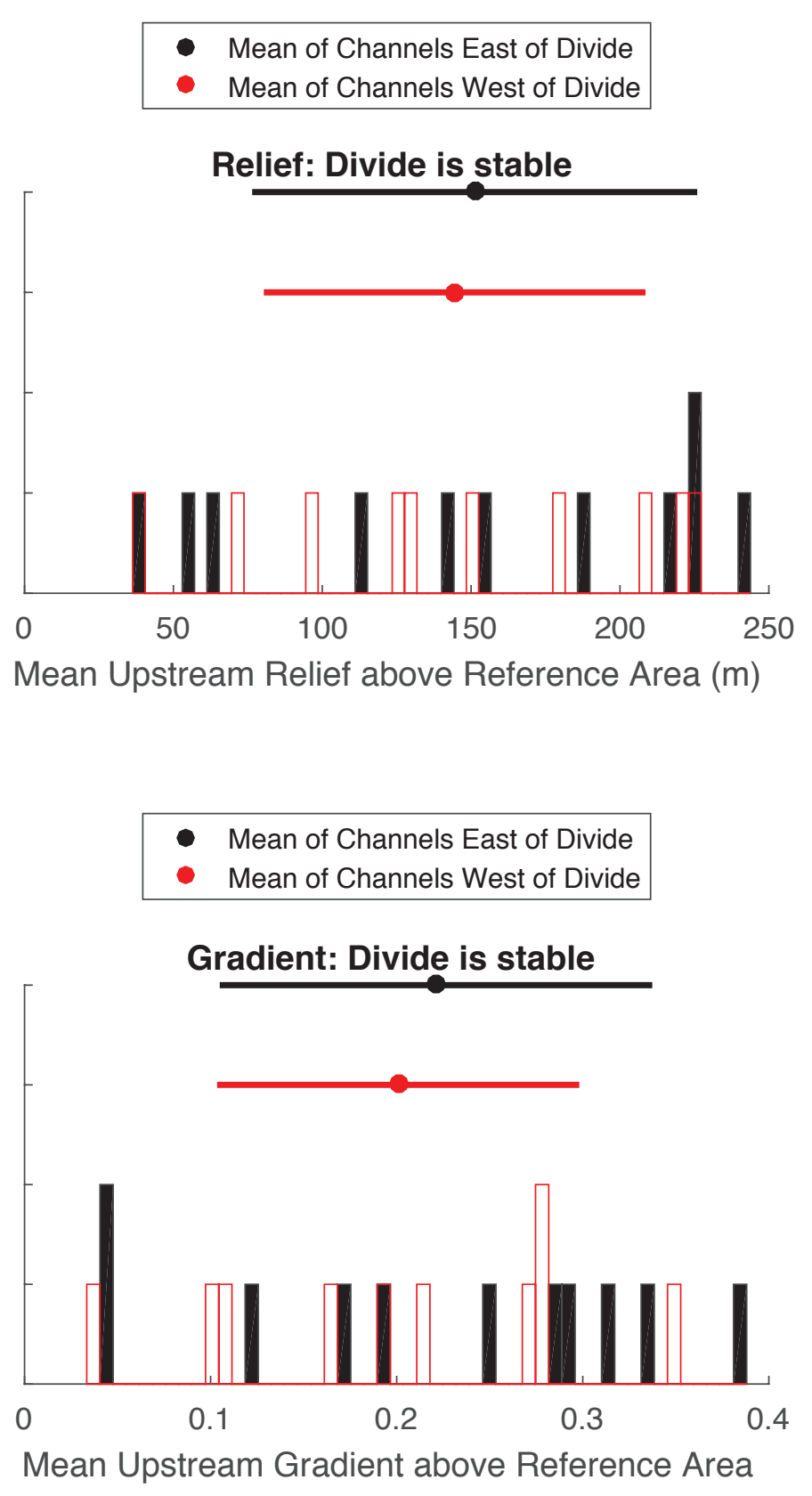

- Mean of Channels East of Divide

Relief: Divide is stable

- Mean of Channels East of Divide

- Mean of Channels West of Divide

Gradient: Divide is stable

\section{Supplemental Figure 38}


Divide SB6
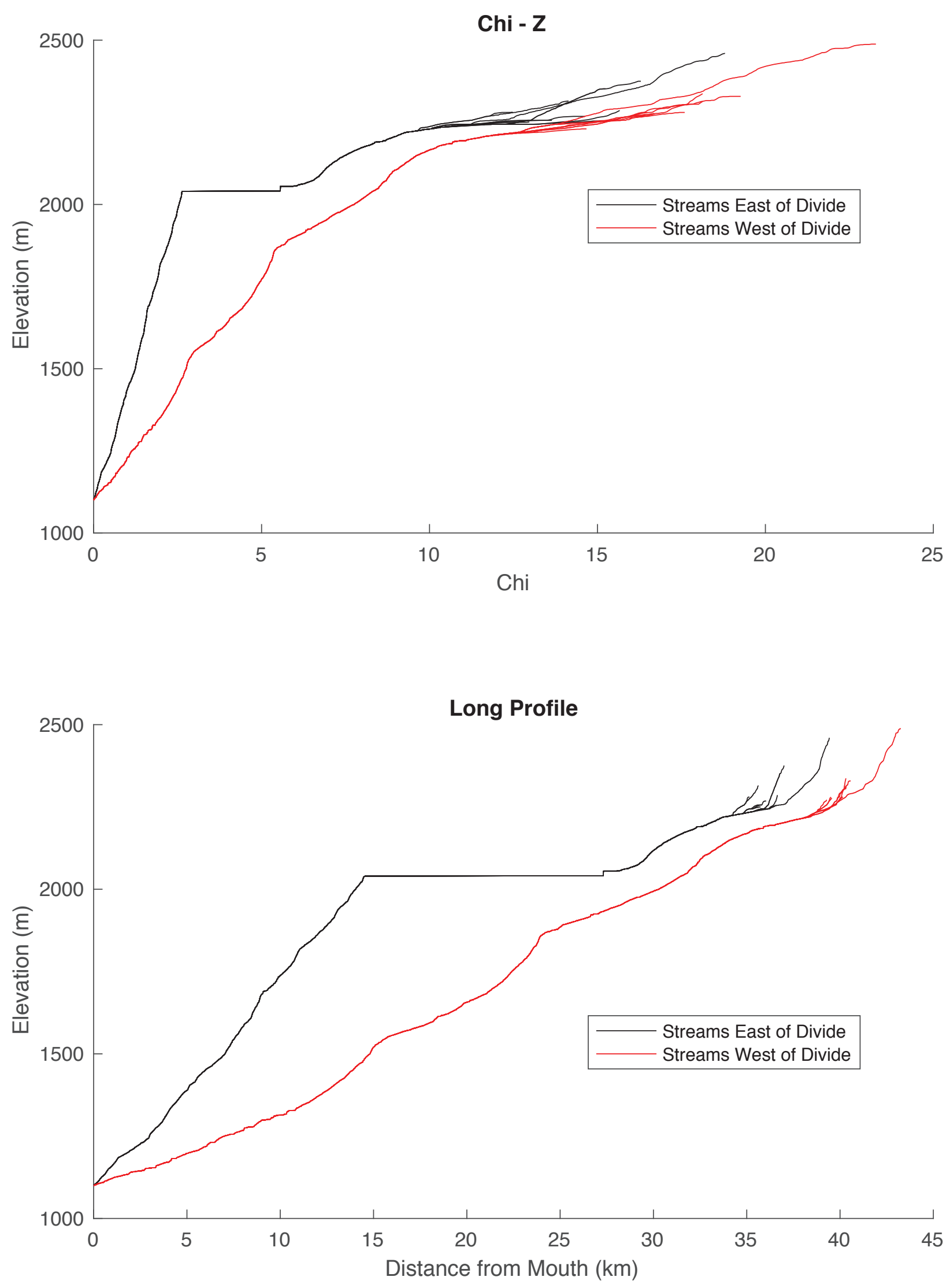

Supplemental Figure 39 


\section{Divide SB7}

- Mean of Channels Southwest of Divide

- Mean of Channels Northeast of Divide

Chi: Divide is predicted to move southwest

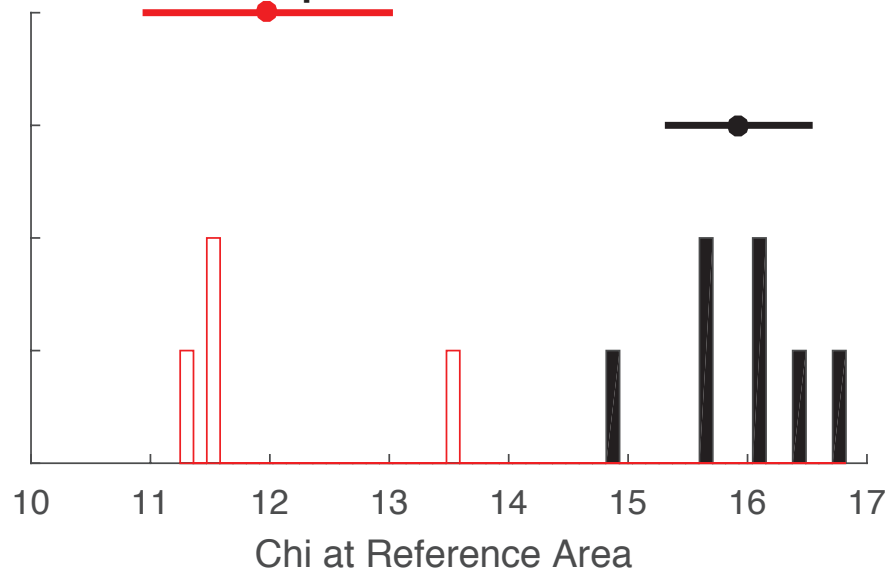

- Mean of Channels Southwest of Divide

- Mean of Channels Northeast of Divide

Elevation: Divide is stable

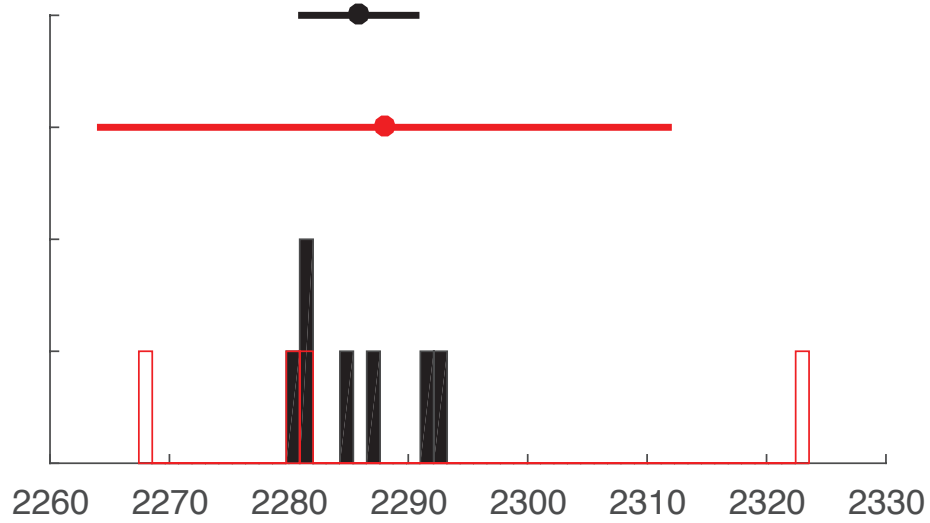

Elevation at Reference Area (m)
- Mean of Channels Southwest of Divide

- Mean of Channels Northeast of Divide

Relief: Divide is predicted to move southwest

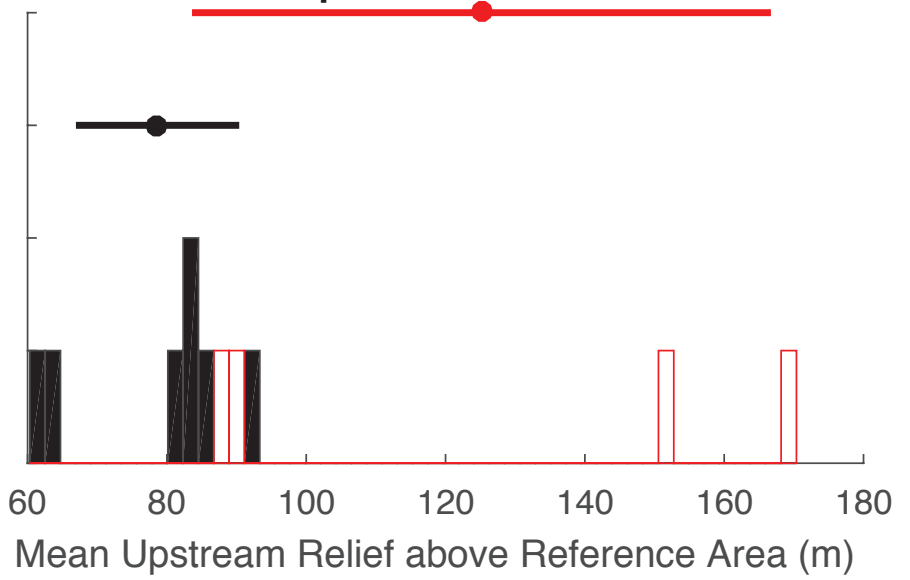

- Mean of Channels Southwest of Divide

- Mean of Channels Northeast of Divide

Gradient: Divide is predicted to move southwest

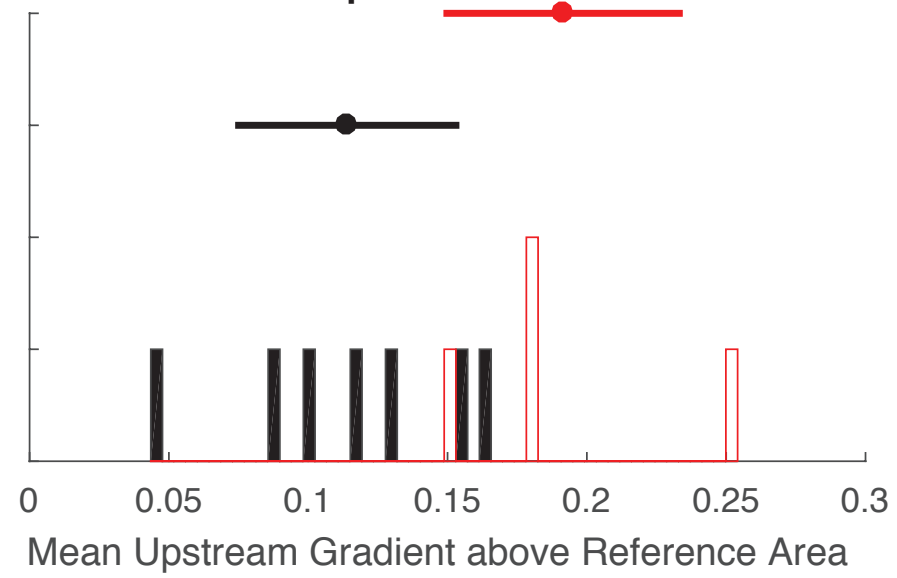

\section{Supplemental Figure $\mathbf{4 0}$}


Divide SB7
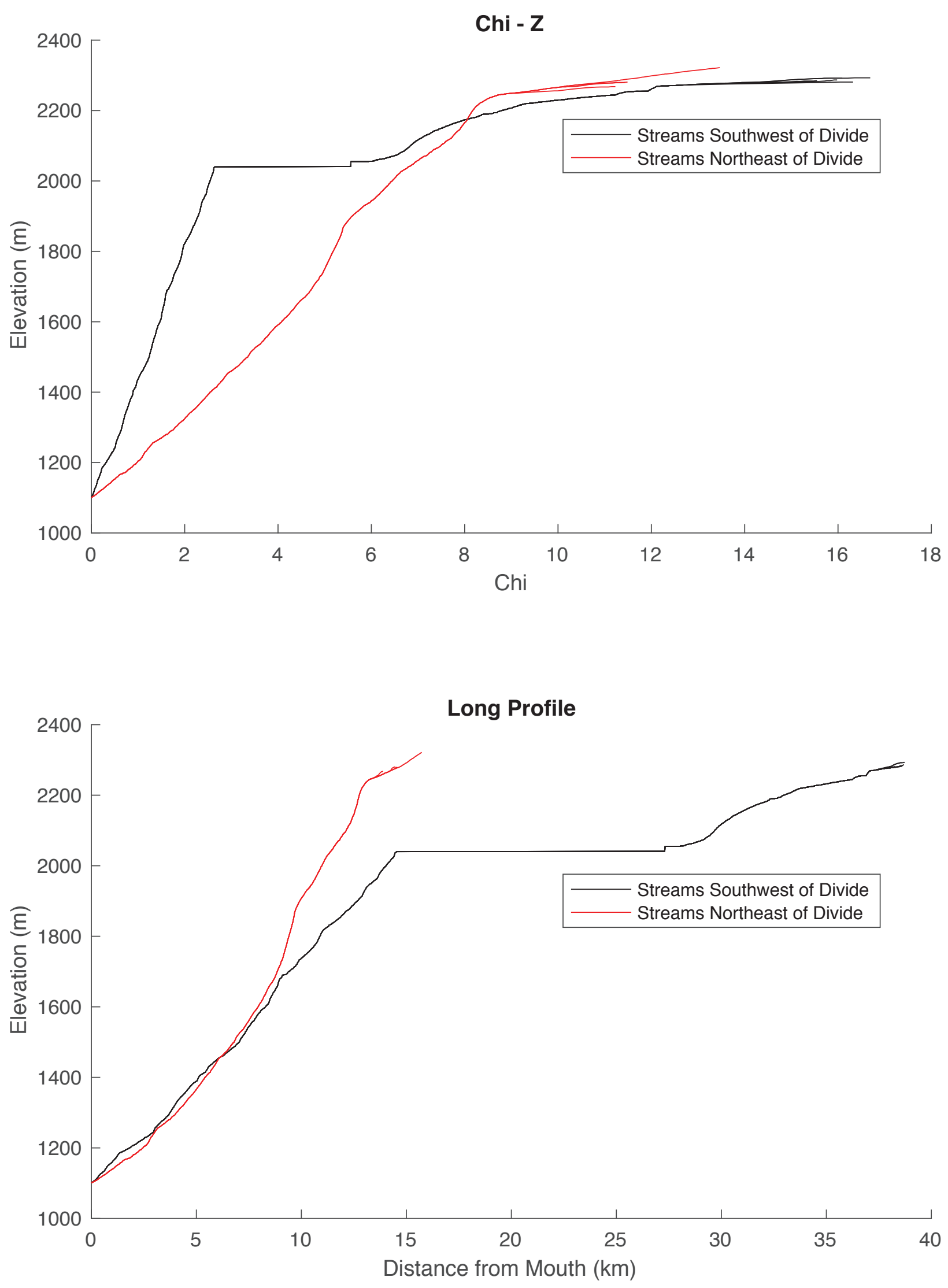

Supplemental Figure 41 


\section{Divide SB8}

- Mean of Channels South of Divide

- Mean of Channels North of Divide

Chi: Divide is predicted to move south

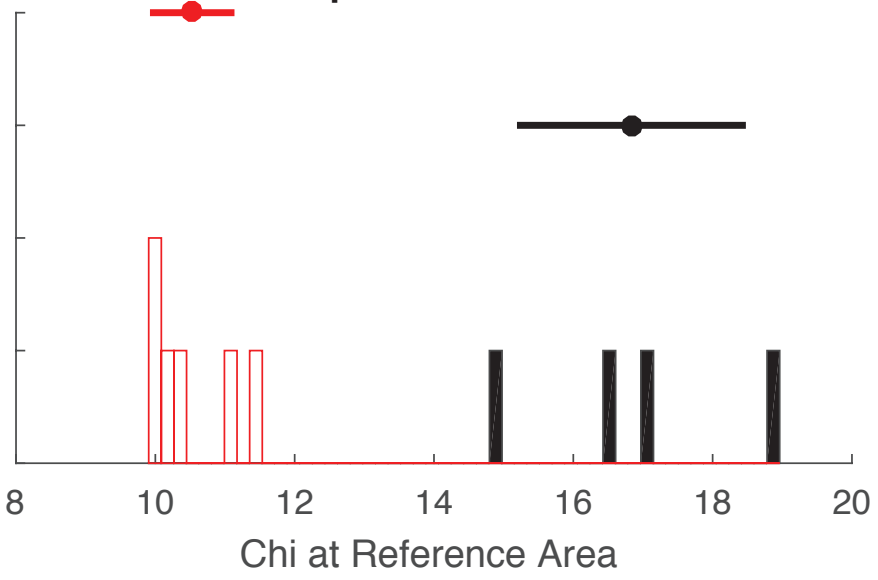

- Mean of Channels South of Divide

- Mean of Channels North of Divide

Elevation: Divide is stable

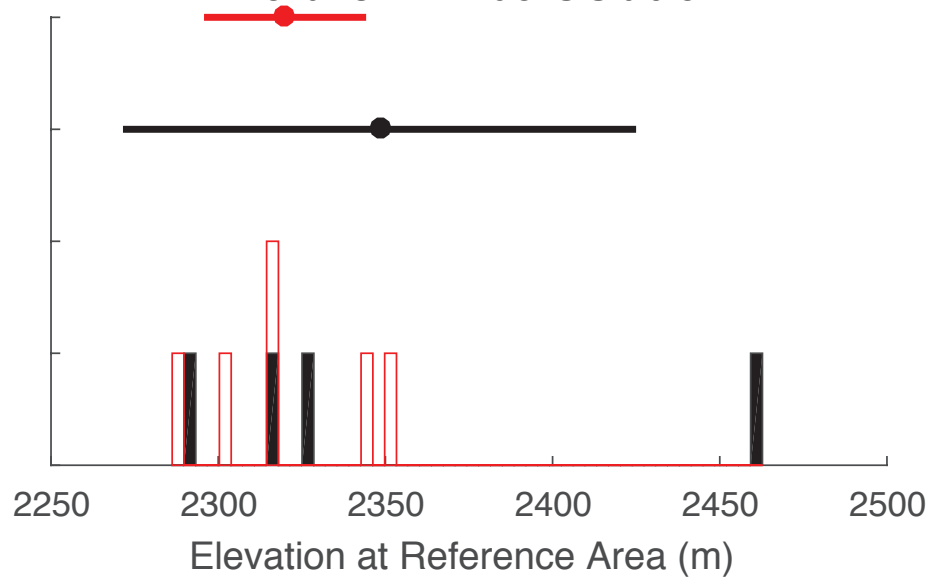

- Mean of Channels South of Divide

- Mean of Channels North of Divide

Relief: Divide is stable

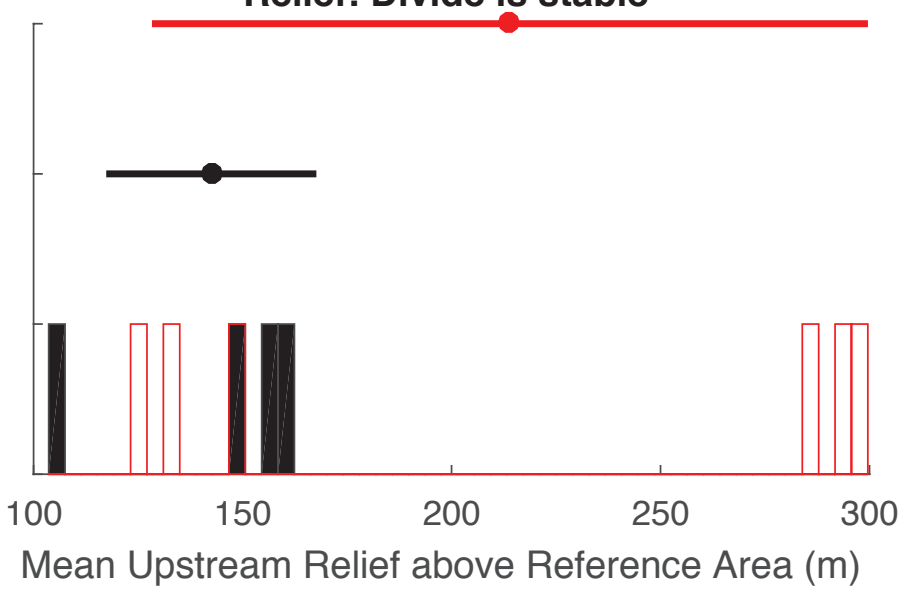

- Mean of Channels South of Divide

- Mean of Channels North of Divide

Gradient: Divide is stable

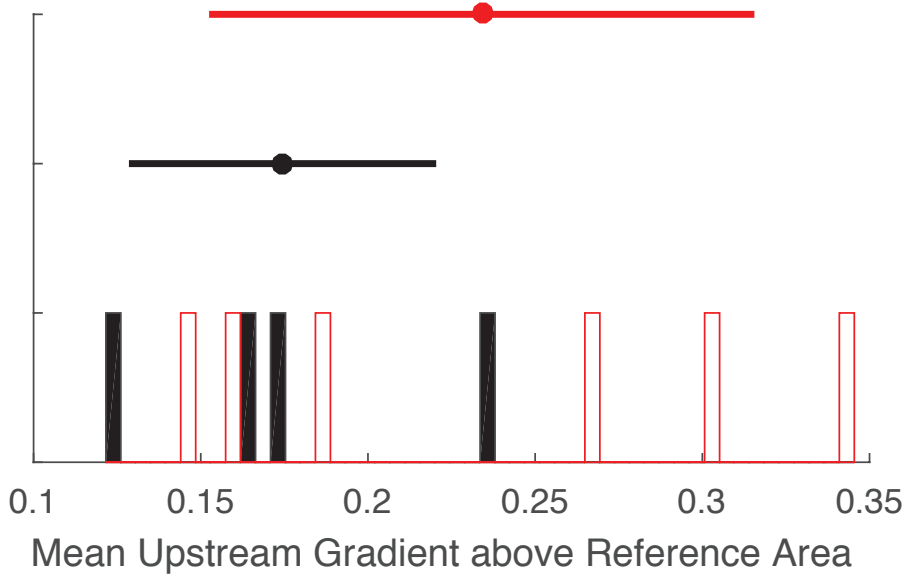

\section{Supplemental Figure 42}


Divide SB8
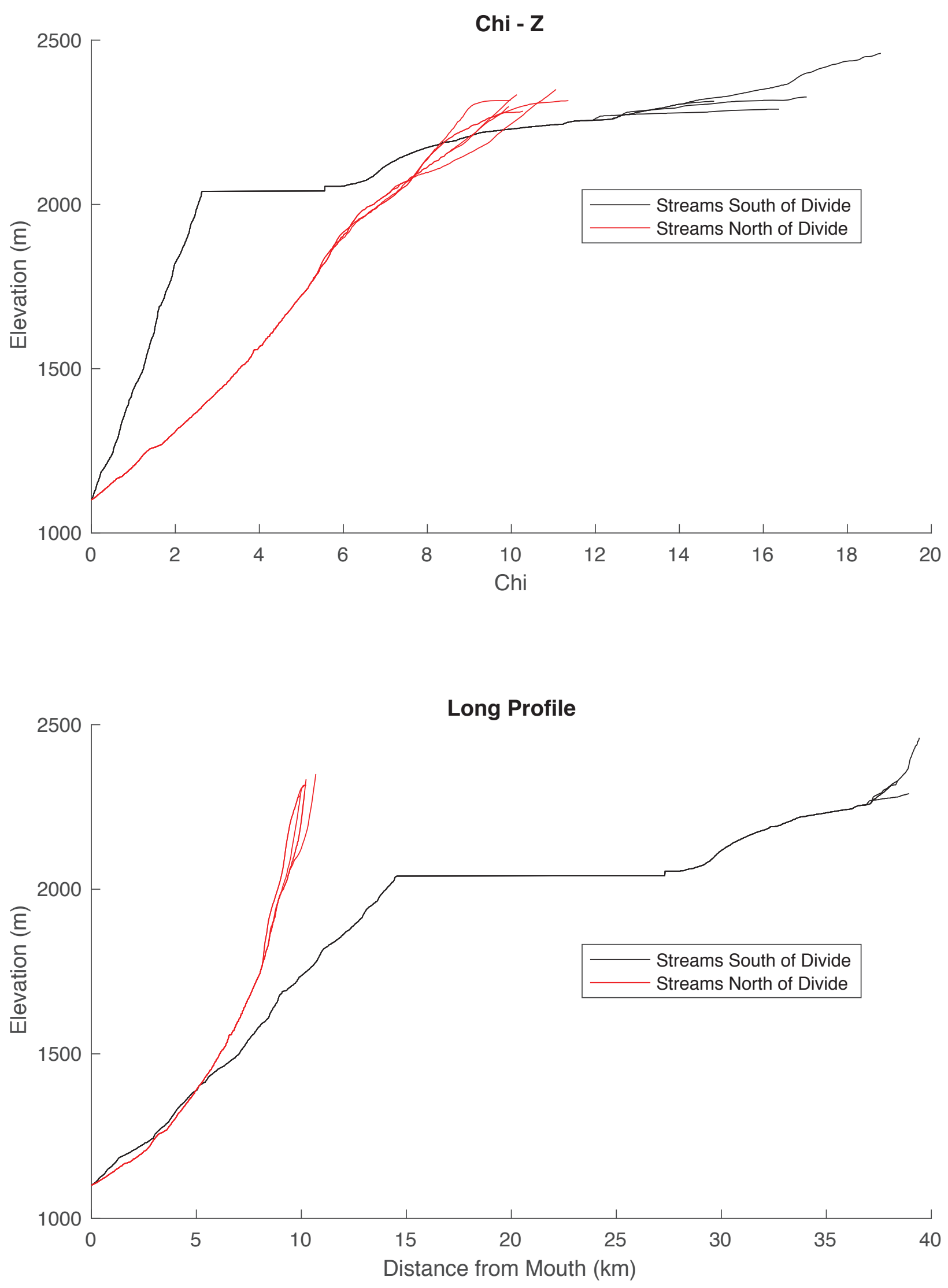

Supplemental Figure 43 


\section{Divide SB9}

- Mean of Channels South of Divide

- Mean of Channels North of Divide

Chi: Divide is predicted to move south

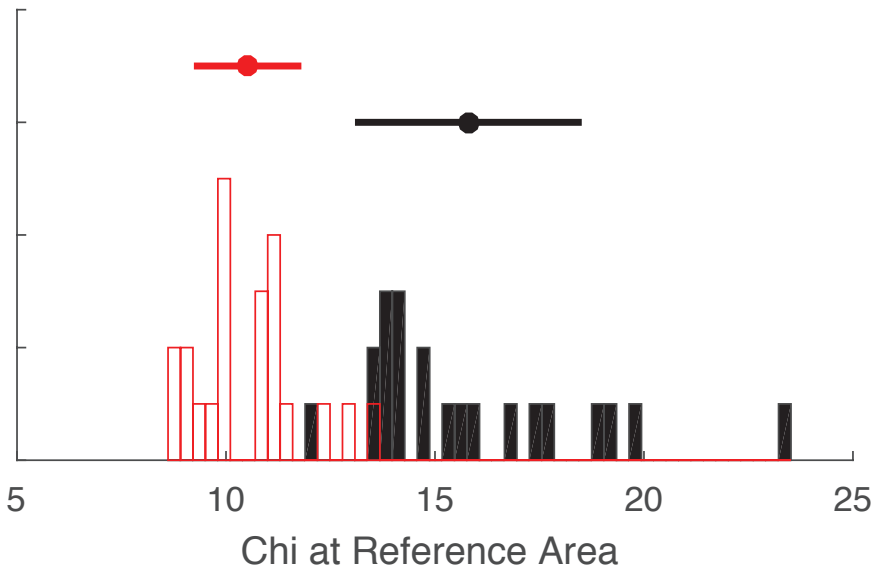

- Mean of Channels South of Divide

- Mean of Channels North of Divide

Elevation: Divide is stable

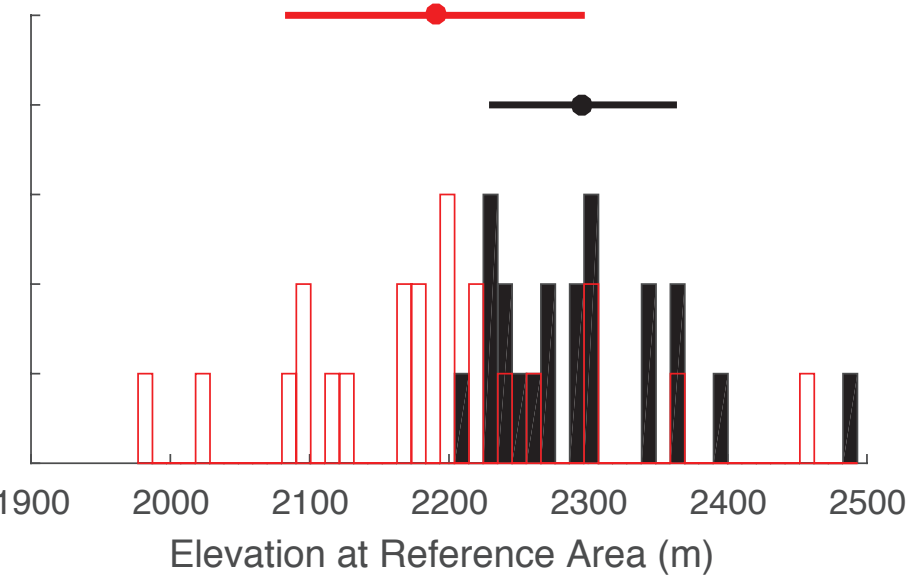

- Mean of Channels South of Divide

- Mean of Channels North of Divide

Relief: Divide is predicted to move south

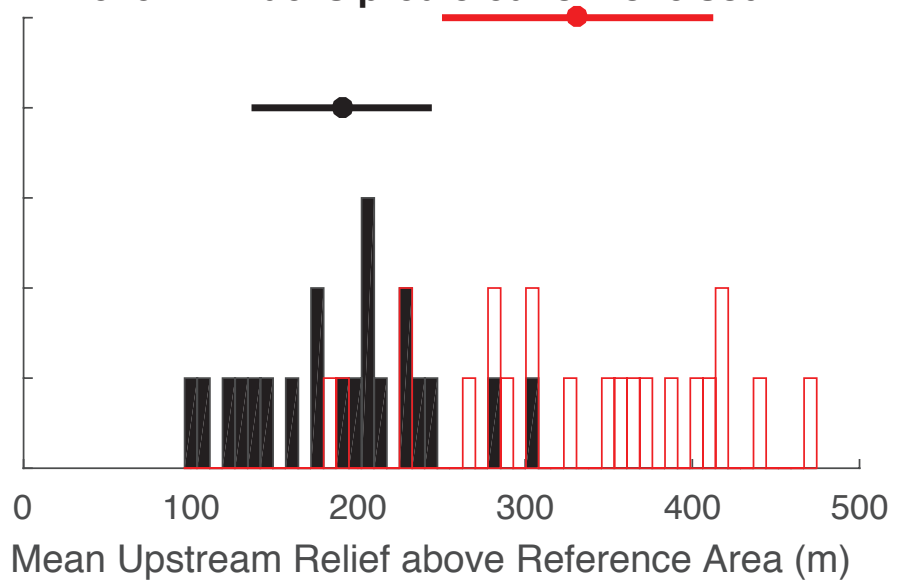

- Mean of Channels South of Divide

- Mean of Channels North of Divide

Gradient: Divide is predicted to move south

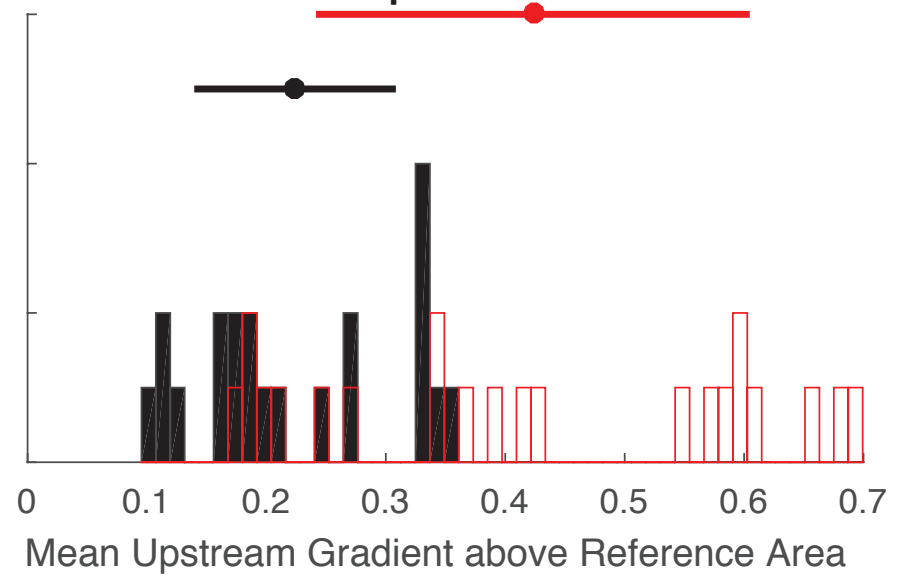

\section{Supplemental Figure 44}


Divide SB9
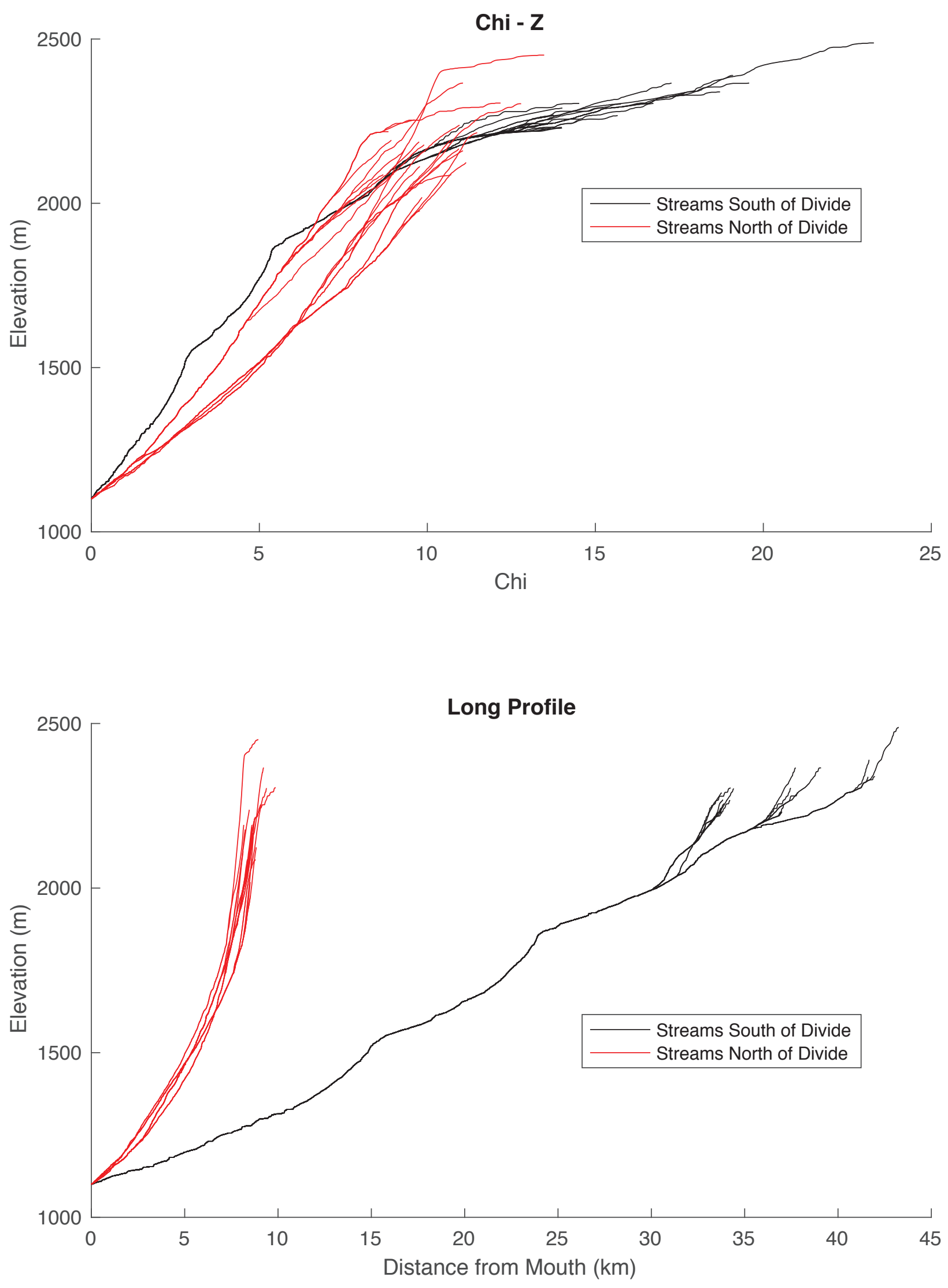

Supplemental Figure 45 


\section{Divide SB10}

- Mean of Channels Southwest of Divide

- Mean of Channels Northeast of Divide

Chi: Divide is predicted to move southwest

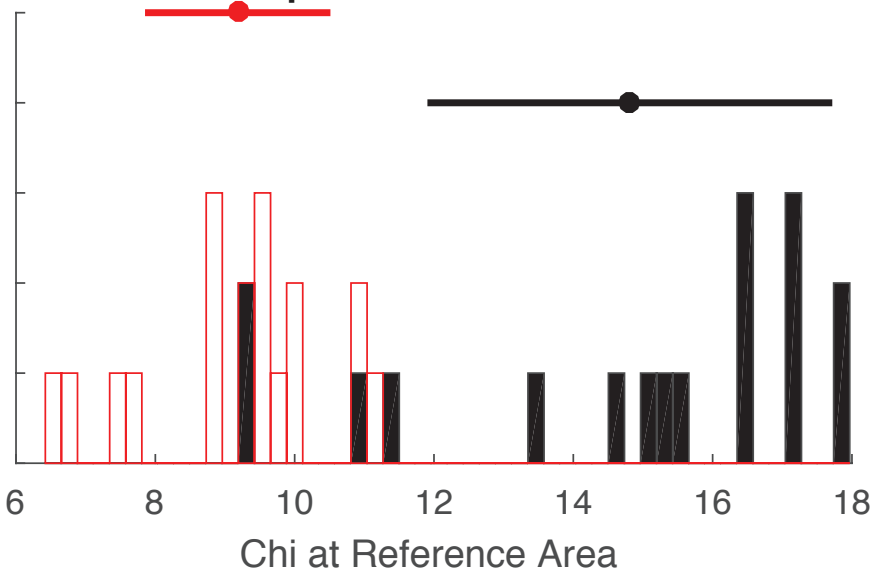

- Mean of Channels Northeast of Divide

Elevation: Divide is stable

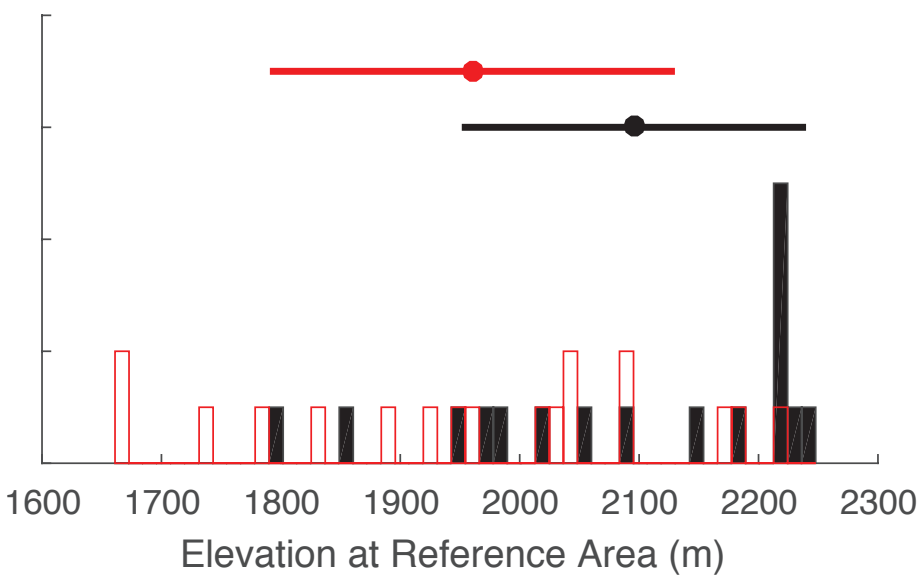

- Mean of Channels Southwest of Divide

- Mean of Channels Northeast of Divide

Relief: Divide is predicted to move southwest

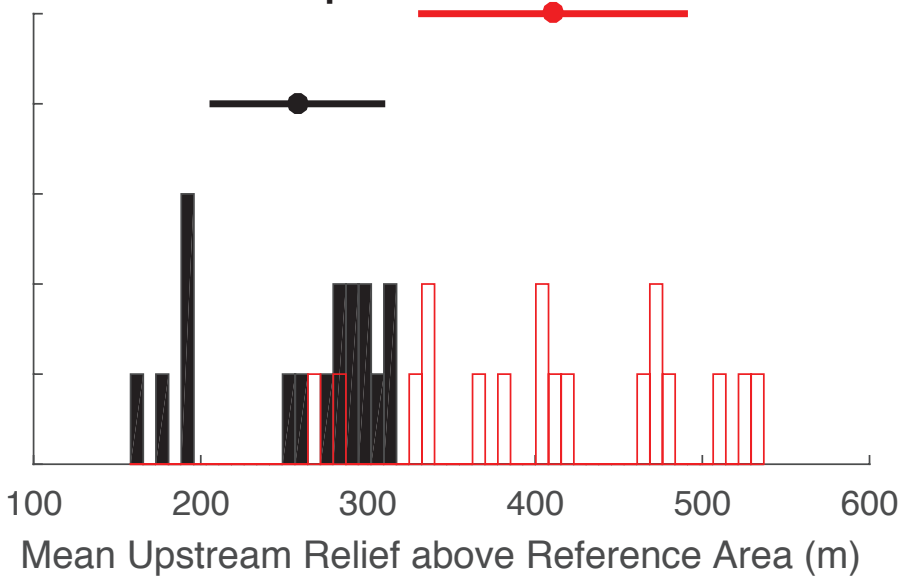

Mean Upstream Relief above Reference Area (m)

- Mean of Channels Southwest of Divide

- Mean of Channels Northeast of Divide

Gradient: Divide is predicted to move southwest

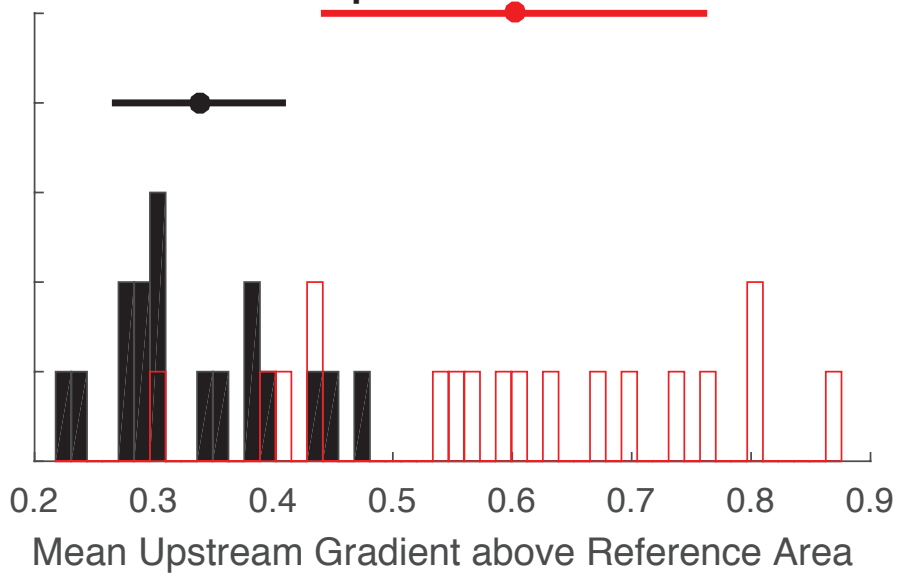

\section{Supplemental Figure 46}




\section{Divide SB10}
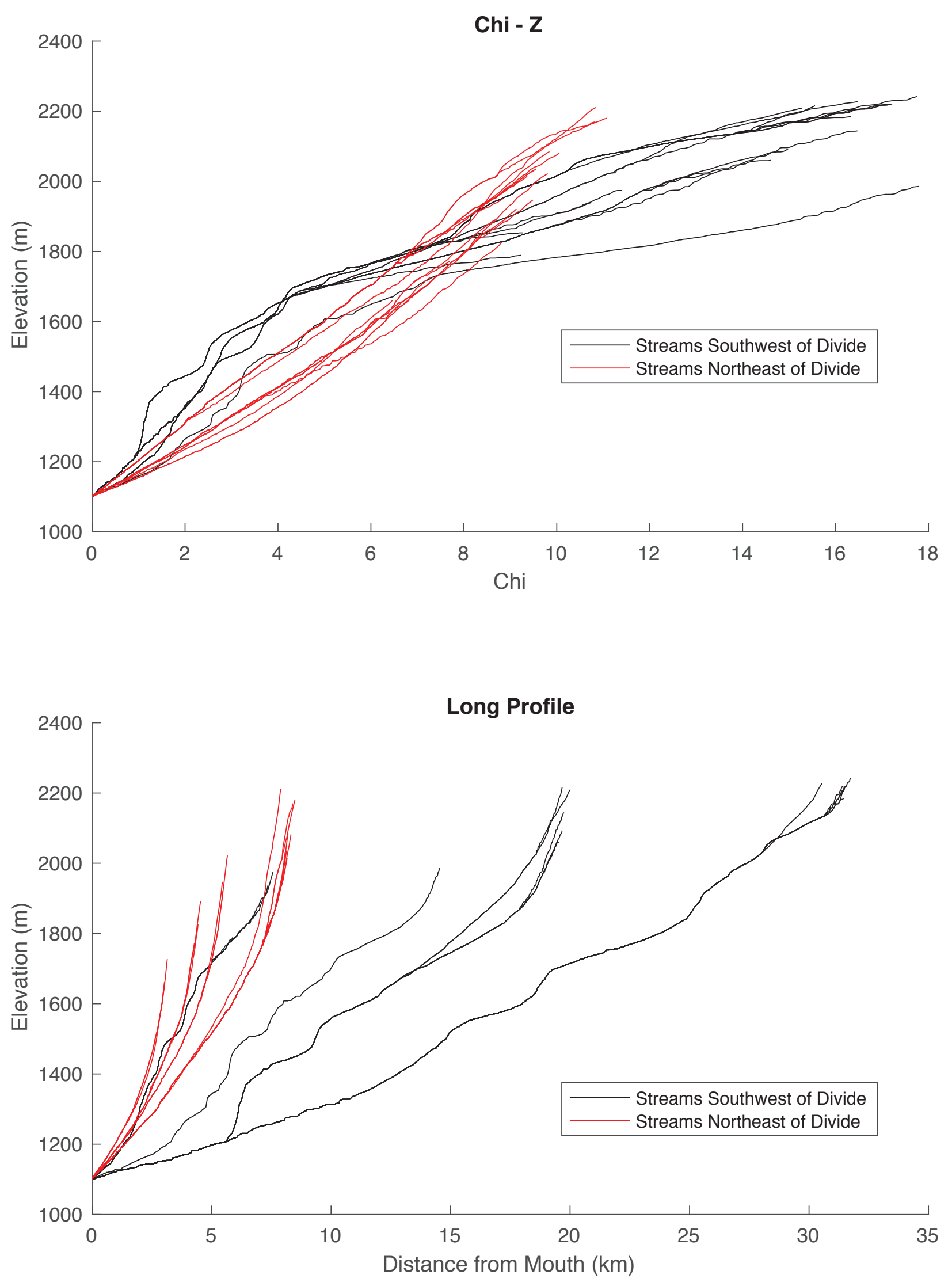